\title{
Clarifying the Structure and Nature of Left-wing Authoritarianism
}

\author{
Thomas H. Costello, Shauna M. Bowes \\ Emory University
}

\author{
Sean T. Stevens \\ New York University \\ Foundation for Individual Rights in Education
}

\author{
Scott O. Lilienfeld \\ Emory University \\ University of Melbourne
}

\begin{abstract}
Authoritarianism has been the subject of scientific inquiry for nearly a century, yet the vast majority of authoritarianism research has focused on right-wing authoritarianism. In the present studies, we investigate the nature, structure, and nomological network of left-wing authoritarianism (LWA), a construct famously known as "the Loch Ness Monster" of political psychology. We iteratively construct a measure and data-driven conceptualization of LWA across six samples $(\mathrm{N}=7,258)$ and conduct quantitative tests of LWA's relations with over 60 authoritarianism-related variables. We find that LWA, rightwing authoritarianism, and social dominance orientation reflect a shared constellation of personality traits, cognitive features, beliefs, and motivational values that might be considered the "heart" of authoritarianism. Still, relative to right-wing authoritarians, left-wing authoritarians were lower in dogmatism and cognitive rigidity, higher in negative emotionality, and expressed stronger support for a political system with substantial centralized state control. Our results also indicate that LWA powerfully predicts behavioral aggression and is strongly correlated with participation in political violence. We conclude that a movement away from exclusively right-wing conceptualizations of authoritarianism may be required to illuminate authoritarianism's central features, conceptual breadth, and psychological appeal.
\end{abstract}

Author Note: Data, research materials, analytic code, a preregistration document, and all supplementary materials referenced in this manuscript are available at the following link: https://osf.io/4e2jf/.

Keywords: left-wing authoritarianism; right-wing authoritarianism; social dominance orientation; political violence; political extremism.

In January 1975, an explosion rocked the U.S. State Department Headquarters in Washington, D.C. A group known as the Weather Underground claimed responsibility. Originally termed the Weathermen-a reference to a line in Bob Dylan's Subterranean Homesick Blues - the famed faction of self-described "communist-minded people, independent organizers, and anti-imperialists" (Berger, 2006, p. 200) embraced

Scott O. Lilienfeld, PhD, was the Samuel Candler Dobbs Professor of Psychology at Emory University. Dr. Lilienfeld died of pancreatic cancer on September 30th, 2020, at the age of 59. We consider ourselves astonishingly lucky to have known him.

*Corresponding author: Thomas H. Costello, 36 Eagle Row, Department of Psychology, Emory University, Atlanta, GA, 30322. E-mail: thcostello1@gmail.com violence as a means of bringing about rapid societal change. Paradigmatically authoritarian, the Weathermen discouraged individualism, were centrally controlled by charismatic leaders, punitively enforced in-group obedience and conformity, aggressed against different others, clung dogmatically to their beliefs, and reacted harshly to threat (Eckstein, 2016; Lerner, 2002). The group ultimately carried out dozens of bombings, including attacks on the U.S. Capitol, the Pentagon, and a New York City police station, in service of forcefully overthrowing the U.S. government.

Around the same time that the Weathermen were wreaking havoc throughout the U.S., Altemeyer was beginning his work on right-wing authoritarianism (RWA; e.g., Altemeyer, 1988), a construct that is now one of the most significant in all of social psychology, 
having been referenced in thousands of papers and studied in relation to hundreds of psychosocial variables (Sibley \& Duckitt, 2008). RWA, which is characterized by (a) obedience and deference to established authorities, (b) adherence to socially conservative norms, and (c) strong approval of punitive and coercive social control, arguably remains the "gold standard" for conceptualizing authoritarianism (Altemeyer, 1996).

In contrast to RWA's prominence in the literature, there is scant systematic evidence for the existence of left-wing authoritarianism (LWA), a putatively allied construct that describes authoritarianism in service of left-wing outcomes (e.g., as in the case of the Weathermen). For instance, a Google Scholar search for the phrase "right-wing authoritarianism" returns 12,700 results while a search for "left-wing authoritarianism" returns only 635 results - the first of which is a paper titled The Myth of Left-wing Authoritarianism (Stone, 1980). Remarking on this asymmetry, Altemeyer (1996) captured many psychologists' skepticism concerning LWA's existence: "I think that I have not found any authoritarians on the left because, if there ever were any, most of them have dried up and blown away...You don't have to be much of a weatherman to know which way the wind has been blowing for the past twenty-five years" (p. 229).

Yet the Weathermen were hardly alone. From Maoist China to the Khmer Rouge (and perhaps even the French Reign of Terror) history abounds with examples of LWA at the broader societal level, rendering psychology's inability to identify left-wing authoritarians puzzling. This mystery has long captured the attention of social scientists. Since the 1950s, LWA has been the subject of numerous controversies pitting those who consider authoritarianism largely orthogonal to leftright ideology (e.g., Conway et al., 2018; Eysenck, 1954; Fromm, 1950; LeVasseur, 1997; Popper, 1945; Ray, 1983; Rokeach, 1960) against those who view LWA as "the Loch Ness Monster" of political psychology (Altemeyer, 1996, p. 216; see Adorno et al., 1950; Jost et al., 2003; Nilsson \& Jost, 2020; Reich, 1933). Many decades later, a core question remains unresolved: are some individuals on the left disposed to authoritarianism? Here, we address this longstanding problem.

Across six samples, we generated and tested a datadriven conceptualization of LWA (as well as a self-report instrument tied to said conceptualization) using exploratory test construction (Tellegen \& Waller, 2008) and construct validational bootstrapping (Westen \& Rosenthal, 2003). We employed best practices for scale development to facilitate sound measurement, latent variable modeling techniques to evaluate structural validity, and formal tests of LWA's relations with a host of authoritarianism-related variables (including behavioral aggression and participation in political violence) to evaluate construct validity. This iterative approach allowed us to account for the possibility that previous conceptualizations of authoritarianism, such as RWA, overlook key aspects of the construct. Indeed, the purpose of the present studies was not merely to establish that LWA exists, or to construct a useful measure of the construct, but to elucidate the nature and structure of LWA itself and, in so doing, better understand authoritarianism writ large.

\section{A Brief History of Authoritarianism Research}

Authoritarianism scholarship can be traced to 1930s Germany, when and where a cohort of psychoanalysts and social scientists strove to understand the psychological processes underlying Hitler's virulent appeal (e.g., Fromm, 1941; Reich, 1933). It was not until Adorno and colleagues' (1950) The Authoritarian Personality was published in the wake of World War II, however, that authoritarianism emerged as a central construct in political psychology. The Authoritarian Personality, which numbers among the most influential social scientific works of the $20^{\text {th }}$ century (Jenemann, 2020), popularized the notion that susceptibility to totalitarianism is rooted in personality. Adorno and colleagues posited that authoritarianism's principal attributes are submissiveness to authority figures and dominance towards subordinates, a superficially paradoxical pair of traits amounting to strict adherence to hierarchy. Further, they charged that authoritarianism is found preferentially or even exclusively among political conservatives, prompting a flurry of research both critical and supportive of this notion (e.g., Eysenck, 1954; Fromm, 1950; Rokeach, 1960; Shils, 1954).

Despite The Authoritarian Personality's many merits and enduring relevance, it has seen extensive criticism in the literature (e.g., Roiser \& Willig, 2002), with one author even calling it "the most deeply flawed work of prominence in political psychology" (Martin, 2001, p. 1). Perhaps consequently, authoritarianism research petered out by the 1970s, leaving the question of authoritarianism's specificity to conservatives unresolved. Altemeyer's (1981) reconceptualization of authoritarianism as RWA - the covariation of authoritarian submission (i.e., obsequiousness to established authority), authoritarian aggression (i.e., aggression towards outgroup members), and conventionalism (i.e., 
strict adherence to socially conservative norms) - reinvigorated the literature while circumventing questions of political specificity by explicitly integrating political conservatism, rendering RWA the dominant psychological account of authoritarianism (e.g., Altemeyer, 2007; Duckitt, 2009). Altemeyer (1998) later posited that Social Dominance Orientation (SDO; Pratto, Sidanius, Stallworth, \& Malle, 1994), which describes support for inequality and approval of power groups dominating weaker groups, reflects the "dominance" dimension of authoritarianism, whereas RWA reflects the "submission" dimension - a theory that has also been widely adopted by political psychologists (see Sibley \& Duckitt, 2013).

Nevertheless, scholars have proffered numerous competing accounts of authoritarianism over the last several decades (e.g., Billig, 1985; Christie, 1991; Conway et al., 2018; Duckitt, 2001; Eysenck, 1954; Fromm, 1950; Jost et al., 2003; LeVasseur, 1997; Ray \& Bozek, 1981; Rokeach, 1960; Shils, 1954; Sidanius $\&$ Pratto, 2001; Stone, 1980; Stenner, 2005). For instance, Rokeach (1960) conceptualized the authoritarian personality as an identifiable species of general cognitive rigidity that lists towards absolutism in the face of ideological threat, which he termed dogmatism. More recently, Stenner (2009) argued that authoritarianism reflects an intolerance of difference diathesis that manifests in response to disruptions of societal norms ${ }^{1}$, asserting broadly that: "Authoritarianism (and not conservatism, lack of education, or religion) is the principal determinant of intolerance of difference across time and space and domain, that is, across any stretch of history, all cultures and every aspect (including racial, political and moral intolerance)" (p. 142).

Thus, despite researcher agreement on several core aspects of the construct, longstanding questions concerning the appropriate scope and content of authoritarianism remain unresolved, including (a) how to delineate its key features and their structure and interrelations; (b) whether these features manifest differently across the left and right; (c) how and why these features are organized and/or interrelated; and (d) how best to identify desiderata for the psychometric assessment of authoritarian traits.

\footnotetext{
${ }^{1}$ Stenner's (2005) model holds explanatory power for scholars' longstanding difficulties concerning LWA; as norms differ across groups and over time, normative threats and any concomitant authoritarian behaviors may be idiosyncratic or even historically hydraulic in their manifestations across the left and right.
}

\section{Left-wing Authoritarianism: The Revolutionary Personality?}

Variations of authoritarianism have flourished in virtually every political context, including liberal democracies such as France and the U.K., Christian countries in Central and South America, Buddhist Myanmar, pro-Hindu India, and communist and post-communist nations (e.g., Economist Intelligence Unit, 2019). Growing research accords with the possibility that several core markers of authoritarianism, including dogmatism, cognitive rigidity, prejudice, and lethal partisanship are reasonably symmetrical across the left and right (e.g., Crawford \& Brandt, 2020; Ditto et al., 2019; Kalmoe \& Mason, 2018; Rollwage et al., 2018; Zmigrod et al., 2020; cf., Baron \& Jost, 2019; Jost, 2017; Jost \& Kende, 2020). Nevertheless, the prevailing psychological account of authoritarianism (i.e., RWA) is largely interchangeable with social conservatism. Consistent with this impression, little systematic evidence of LWA as an individual difference variable is present in the literature (but see Conway et al., 2020) and many contemporary scholars continue to deny or minimize the importance of LWA (e.g., Nilsson \& Jost, 2020).

This discord may partially stem from the outsized influence of Adorno et al.'s flawed original conceptualization of authoritarianism. By most standard definitions, political conservatism involves upholding the status-quo and protecting the present hierarchy (Jost et al., 2013). Accordingly, individuals who are disposed to (a) favor absolutist forms of government and (b) weaponize the presently dominant hierarchy to facilitate said absolutism (i.e., individuals who, per Adorno et al., are authoritarians; Altemeyer, 1988; Duckitt et al., 2010; Nilsson \& Jost, 2020), are necessarily also political conservatives. In contrast, individuals who are disposed to favor absolutist forms of government, but who believe that the presently dominant hierarchy should be overthrown (i.e., what might be considered left-wing authoritarians), are excluded from authoritarianism. Indeed, authoritarian communist governments have historically arisen via revolutionary movements, whereby the established hierarchy is overthrown (consider the many authoritarian states that seek to suppress "counter-revolutionaries" and/or include "revolutionary" in their party name) ${ }^{2}$.

\footnotetext{
${ }^{2}$ In early drafts of TAP, revolutionary Marxism was situated in diametric opposition to authoritarianism, such that the set of personality traits termed "the democratic personality" had originally been said to describe "the revolutionary personality" (Jay, 1973).
} 
The possibility that authoritarianism research has a blind spot for LWA is perhaps unsurprising given that The Authoritarian Personality was an effort to describe the psychological appeal of fascism, a far-right ideology. But just as psychologists have recently acknowledged the prospect that a systemic overreliance on Western, Educated, Industrialized, Rich, and Democratic (WEIRD) samples has distorted our ability to make generalized claims about human behavior (Gurven, 2018; Henrich et al., 2010), the psychological processes underlying authoritarianism may be challenging to understand when only rightist authoritarians have been studied. As a point of comparison, consider the consequences of using exclusively male samples to develop the diagnostic criteria for a mental disorder. Presumably, this approach would overrepresent symptoms more often found in men and underrepresent those more often found in women. In turn, this bias might lead researchers to conclude that sex differences exist in said disorder (e.g., Yagoda, 2013). A similar process has plausibly occurred in political psychology-understanding authoritarianism's manifestations in left- and right-wing populations may be a critical step in clarifying the nature of authoritarianism writ large.

\section{Past Efforts to Define and Measure Left-wing Authoritarianism}

Given the degree to which the RWA Scale's conceptualization of authoritarianism is tied to and imbued with social conservatism, parsing RWA's authoritarian "wheat" from its conservatism "chaff" may be nigh-impossible without first developing an independent measure of LWA with which to contrast RWA. To be clear, we are neither the first to attempt to define and measure LWA nor the first to argue that LWA may not precisely parallel RWA. Altemeyer (1996) conceptualized LWA as authoritarianism (i.e., aggression, submission, conventionalism) in individuals who oppose established hierarchies of moral and practical authority, noting that

\footnotetext{
${ }^{3}$ In so doing, Altemeyer sought to move beyond the simple unidimensional contrast between ideological liberals/leftists and ideological conservatives/rightists, a longstanding dilemma in the authoritarianism literature. For instance, despite their manifest ideological differences on the left-right political spectrum, Stalinists in the former U.S.S.R. and right-wing authoritarians in the United States both sought to uphold the established system. In contrast, ideologically left-wing extremist groups in the U.S., such as the Weathermen, attempted to overthrow the existing power hierarchy. Were Stalinists more psychologically similar to the RWAs or the revolutionary authoritarians? Which, if any, of these groups can be appropriately labeled LWA? Categorizing authoritarians based solely on their political ideology obviates a great deal of nuance in how the political and psychological characteristics of authoritarians
}

left-wing authoritarians are "revolutionaries who (1) submit to movement leaders who must be obeyed, (2) have enemies who must be ruined, and (3) have rules and 'party discipline' that must be followed" (pp. 219220). In so doing, Altemeyer put forth a psychological, rather than ideological ${ }^{3}$, definition of "left-wing" and "right-wing" that denotes submission to the perceived established authorities in one's life. Namely, "psychological right-wingers (by definition) support the perceived established authorities in society, and psychological left-wingers oppose them" (Altemeyer, 1996, p. 218). The underlying dispositional core of LWA and RWA is authoritarianism, while the "winged-ness" varies according to one's orientation towards the present hierarchy. We adopt this definition of "left-wing" and "right-wing" in relation to authoritarianism in the present work.

Following this conceptual framework, Altemeyer created the first published measure of LWA. Problematically, however, this first LWA Scale used only direct parallels of the three RWA dimensions. As we have argued, there is little reason to believe that RWA provides a sufficient account of authoritarianism writ large and, therefore, that LWA manifests solely along variations of RWA's three dimensions. Altemeyer concluded that LWA is virtually non-existent after finding that subjects rarely scored above his scale's mid-point ${ }^{4}$.

Several others have attempted to construct a self-report measure of LWA (e.g., Conway et al., 2018; De Regt et al., 2011; LeVasseur, 1997; Van Hiel et al., 2006). Despite their promise, these efforts have not seen widespread adoption in the political psychology literature ${ }^{5}$. Most recently, Conway et al. (2018) constructed a measure of LWA by rewriting RWA Scale items to confound submission to established authority and liberal political views. This measure found extensive support from a large, multi-faceted construct validational investigation, providing strong evidence that elements of authoritarianism are present in ideologically left-wing U.S. samples (Conway et al., 2020).

can be understood, which is why Altemeyer's psychological definitions of "left" and "right" may be especially useful in mapping the similarities and differences across LWA and RWA.

${ }^{4}$ Absent established population norms, there is little reason to consider the scale's mid-point meaningful: Individuals who are high on a latent LWA construct would score well below the midpoint on a scale marked by levels of extreme item difficulty.

${ }^{5}$ LaVasseur's (1997) dissertation work yielded the second measure of LWA. The definitional core of LeVasseur's LWA Scale is "a sacrifice of freedom in exchange for equality" (p. 27), but the measure also reflects seven conceptual clusters found in the original $\mathrm{F}$ scale, adapted to apply to the political left. LeVasseur's scale manifested large positive relations with dogmatism, mental rigidity, and intolerance of ambiguity, suggesting promising external validity. 
Nevertheless, as Conway and colleagues' LWA Scale directly parallels Altemeyer's RWA Scale, this line of scholarship excludes the possibility that the tripartite conceptualization of authoritarianism (i.e., aggression, submission, conventionalism) is not an accurate conceptualization of LWA. To understand and measure LWA, a ground-up reconceptualization is merited, one that begins with an expansive view of the construct and draws upon systematic empirical exploration rather than solely deductive methods to clarify LWA's constituent domains.

\section{The Present Investigation: Clarifying and Measuring Left-wing Authoritarianism}

Given the literature reviewed thus far, it is clear that authoritarianism is a useful construct, but that RWA is not a definitive account of authoritarianism writ large. We suspect that previous conceptualizations of author-itarianism are unnecessarily narrow, having been guided by armchair speculation and ideological inertia rather than sound empirical exploration. Certainly, a construct capturing, for example, the psychological appeal of violently installing a left-wing dictatorshipwhether or not one refers to such a construct as LWAmay provide a useful approximation of reality. From there, whether there is substantive overlap between such a construct and RWA is an empirical question, one that holds the potential to shed considerable light on the possibility of LWA and authoritarianism more generally.

We therefore approached the construction of a measure of LWA as a "bootstrapping operation" (Westen \& Rosenthal, 2003, p. 609), whereby (1) a broad preliminary conceptualization is leveraged to construct an initial measure with good content validity for said conceptualization, (2) the new measure's relations with relevant criterion variables are then evaluated to determine whether and to what extent changes to the measure, conceptualization, or (more likely) both are needed, and (3) this self-refining process is repeated as both the measure and conceptualization improve (Loevinger, 1957). This methodological approach, which is sometimes described as "exploratory test construction" (Tellegen \& Waller, 2008), is bidirectional, iteratively using induction and deduction to move from ideas to data and back again. Overall, then, the complementary purposes of the present set of studies were to construct a measure of LWA and, in so doing, to clarify the nature and structure of LWA.
An auxiliary aim of the present investigation was to examine relations between LWA and authoritarian behaviors. Few behavioral measures of authoritarianism are present in the scientific literature, with one notable exception being from Stenner (2005), who found that highly authoritarian participants exposed to normative threats (e.g., news articles disparaging their preferred political candidate) demonstrated increased intolerance relative to other participants. We used a conceptually similar behavioral paradigm as a means of further validating the LWA Index. Moreover, in a large nationally representative sample, we examine the correlations between LWA and past participation in violent political extremism, including violence during the (predominantly peaceful) protests for racial justice in the summer of 2020.

\section{Overview and Hypotheses}

Given the complex and multi-pronged nature of construct validational bootstrapping, our initial construction and validation of the LWA Index spanned three versions of the measure and six samples. Each sample was administered a pool of candidate LWA items alongside a battery of variables theorized to lie within LWA's and/or RWA's nomological network. We assessed over 60 criterion-related variables across the six samples (see Table 2). Due to the relative paucity of research exploring LWA, and left-wing political extremism more generally (but see Kruglanski et al., 2020), little is known about the traits, attitudes, and behaviors that reflect LWA. We considered RWA's nomological network to afford a general framework for establishing the LWA Index's convergent and discriminant validity, but also anticipated that LWA and RWA's nomological networks would differ in important ways, as we describe below. Thus, in the spirit of revisiting the possibility of heterogeneity in authoritarianism, we did not rely solely on RWA's nomological network when constructing and quantifying validity.

We present our results in six "phases" (see Table 1). Phase 1 describes our process of initial item generation and exploratory assessment of the LWA Index's structural properties using Sample 1. Phase 2 describes updates to the item pool according to the results of Phase 1 , exploratory assessment of the LWA Index's structural properties using Sample 2, and confirmatory tests of candidate factor structures using Sample 3. Phase 3 follows the procedures of Phase 2 for the third and final version of the LWA Index using Samples 4 and 5, yielding a quasi-final version of the LWA Index. 
Table 1. Overview of Aims and Basic Demographics for Each Sample

\begin{tabular}{|c|c|c|c|c|c|c|}
\hline & Sample 1 & Sample 2 & Sample 3 & Sample 4 & Sample 5 & Sample 6 \\
\hline Source & MTurk & MTurk & $\begin{array}{l}\text { YourMor- } \\
\text { als.org }\end{array}$ & MTurk & MTurk & Prolific \\
\hline Aims & $\begin{array}{l}\text { Conceptualization, } \\
\text { item writing, EFA, } \\
\text { external validity. }\end{array}$ & $\begin{array}{l}\text { Conceptualiza- } \\
\text { tion, item reduc- } \\
\text { tion, item writing, } \\
\text { EFA, external va- } \\
\text { lidity. }\end{array}$ & $\begin{array}{l}\text { Tests of dimen- } \\
\text { sionality (CFA } \\
\text { and ESEM), ex- } \\
\text { ternal validity. }\end{array}$ & $\begin{array}{l}\text { Conceptualization, } \\
\text { item reduction, } \\
\text { EFA, external va- } \\
\text { lidity. }\end{array}$ & $\begin{array}{l}\text { Tests of dimen- } \\
\text { sionality, item re- } \\
\text { duction, external } \\
\text { validity, behav- } \\
\text { ioral measure. }\end{array}$ & $\begin{array}{l}\text { Pre-registered } \\
\text { tests of external } \\
\text { validity and di- } \\
\text { mensionality. }\end{array}$ \\
\hline $\begin{array}{l}\text { Version of LWA } \\
\text { Index }\end{array}$ & 1 & 2 & 2 & 3 & 3 & 3 \\
\hline Sample size & 479 & 498 & 4,165 & 490 & 508 & 834 \\
\hline $\begin{array}{l}\text { Women in Sam- } \\
\text { ple }(\%)\end{array}$ & 53.2 & 55.8 & 32.4 & 47.9 & 49.8 & 50.1 \\
\hline Mean Age (SD) & $41.1(12.6)$ & $39.6(12.4)$ & $34.3(14.4)$ & $38.2(12.1)$ & $37.7(11.5)$ & $45.8(15.9)$ \\
\hline $\begin{array}{l}\% \text { Democratic } \\
\text { Party }\end{array}$ & 42.7 & 43.3 & 32.3 & 47.8 & 52.4 & 49.0 \\
\hline $\begin{array}{l}\text { LWA Index Vers } \\
\text { lowing data clean } \\
\text { sented in online s } \\
\text { exploratory facto } \\
\text { standard deviatio } \\
\text { samnles }\end{array}$ & $\begin{array}{l}\text { Is indicate the d } \\
\text { on the basis o } \\
\text { plemental mate } \\
\text { halysis; CFA = } \\
\text { Prior uses of Sa } \\
\text { en described in }\end{array}$ & $\begin{array}{l}\text { rent sets of iter } \\
\text { rant or inconsis } \\
\text { s. Detailed dem } \\
\text { firmatory facto }\end{array}$ & $\begin{array}{l}\text { administered } \\
\text { tt responding } \\
\text { raphic inforn } \\
\text { inalysis; ESE } \\
\text { lished resear }\end{array}$ & $\begin{array}{l}\text { participants as } \\
\text { lore detailed de } \\
\text { ion for Sample } \\
=\text { exploratory s } \\
\text { are described at }\end{array}$ & $\begin{array}{l}\text { study unfolde } \\
\text { iptions of each } \\
\text { presented in } 1 \\
\text { ctural equation } \\
\text { ps://osf.io/4e } 2 j\end{array}$ & $\begin{array}{l}\text { Ns are fol- } \\
\text { mple are pre- } \\
\text { le } 9 . \mathrm{EFA}= \\
\text { deling; SD = } \\
\text { All other }\end{array}$ \\
\hline
\end{tabular}

Phase 4 quantitatively assesses the convergent and discriminant validity of the LWA Index by examining its relations with external criteria across these five samples. Although each scale version's relations with external criteria informed our construction of later versions, we present our construct validity analyses together in Phase 4 for purposes of readability. Phase 5 assesses LWA's and RWA's ability to predict behavioral aggression towards political opponents and helping towards political allies using a novel behavioral paradigm. Finally, Phase 6 (a) examines the replicability of core findings from previous phases and (b) conducts preregistered tests of LWA's ability to predict self-reported extremist and/or authoritarian behaviors, including involvement in political violence, using data matched to the demographic characteristics of the U.S. population.

External validity hypotheses. We used Stenner's (2009) descriptive account of authoritarianism as a general framework for identifying appropriate criterion-related variables. Within this framework, authoritarianism fosters attitudes and behaviors that serve to enhance sameness and minimize diversity of people, ideology, and behavior in one's social environment. Fur- ther, because enhancing social uniformity requires control over others' beliefs and behaviors, authoritarianism entails both coercion of different others and approval of the use of group authority (e.g., coercion by the state), which may entail legal discrimination, limits on free speech and association, and state regulation of moral behavior.

We hypothesized that left- and right-wing authoritarianism are not mirror images but that they share a yet-unknown constellation of traits that might be considered the psychological "core" of authoritarianism. Evidence for such a shared core would manifest as a similar pattern of relations with relevant external criteria across LWA and RWA.

We predicted that individuals high in LWA are generally dogmatic, hostile towards the present hierarchy, prejudiced and punitive towards perceived enemies, disposed towards moral absolutism, and tolerant of political violence. Given that our many external criteria can be broadly classified as personality traits, cognitive 
styles, partisanship/political intolerance, and beliefs/worldviews, we expected that, in descending order of similarity, LWA and rightist forms of authoritarianism (which were operationalized using the RWA Scale and the $\mathrm{SDO}_{7}$ ) would manifest similar patterns of relations with partisanship/political intolerance, personality, cognitive style, and beliefs/worldviews. Our specific hypotheses regarding the directionality and magnitude of LWA's relations with criterion-related variables measures in Samples 1 to 5 are presented in Table
3. Our hypotheses regarding LWA's relations for criterion-related variables in Sample 6 were preregistered (https://osf.io/cseyx/) and are detailed in Phase 6.

Table 2. Overview of External Criteria for All Samples

\begin{tabular}{|c|c|c|c|c|c|c|}
\hline Variables & Sample 1 & Sample 2 & Sample 3 & Sample 4 & Sample 5 & Sample 6 \\
\hline Political Ideology (Symbolic) & $\checkmark$ & $\checkmark$ & $\checkmark$ & $\checkmark$ & $\checkmark$ & $\checkmark$ \\
\hline Political Ideology (Social) & $\checkmark$ & - & $\checkmark$ & $\checkmark$ & $\checkmark$ & $\checkmark$ \\
\hline Political Ideology (Economic) & $\checkmark$ & - & $\checkmark$ & $\checkmark$ & $\checkmark$ & $\checkmark$ \\
\hline Right-wing Authoritarianism & $\checkmark$ & $\checkmark$ & - & - & $\checkmark$ & $\checkmark$ \\
\hline Social Dominance Orientation & $\checkmark$ & - & - & - & $\checkmark$ & - \\
\hline Dogmatism & $\checkmark$ & $\checkmark$ & - & $\checkmark$ & $\checkmark$ & $\checkmark$ \\
\hline General Personality & $\checkmark$ & $\checkmark$ & $\checkmark$ & $\checkmark$ & - & - \\
\hline Personality Disorder Traits & $\checkmark$ & - & - & - & - & - \\
\hline Need for Cognitive Closure & $\checkmark$ & - & - & $\checkmark$ & - & - \\
\hline Political Intolerance & $\checkmark$ & - & - & - & - & - \\
\hline Determinism Beliefs & $\checkmark$ & - & - & - & - & - \\
\hline Psychopathic Personality & $\checkmark$ & - & - & - & - & - \\
\hline Affective Polarization & - & $\checkmark$ & - & - & - & - \\
\hline Cognitive Reflection & - & $\checkmark$ & - & - & - & - \\
\hline Confirmatory Thinking & - & $\checkmark$ & - & - & - & - \\
\hline Belief in Conspiracy Theories & $\checkmark$ & $\checkmark$ & - & - & - & - \\
\hline Intellectual Humility & - & $\checkmark$ & - & - & $\checkmark$ & $\checkmark$ \\
\hline Cognitive Ability & - & $\checkmark$ & - & - & - & - \\
\hline Preference for State Control & - & - & - & $\checkmark$ & $\checkmark$ & - \\
\hline Epistemic Certainty & - & - & - & $\checkmark$ & - & - \\
\hline Social Vigilantism & - & - & - & $\checkmark$ & - & - \\
\hline Objectivism & - & - & - & $\checkmark$ & - & - \\
\hline Moral Foundations & - & - & $\checkmark$ & - & - & - \\
\hline Disgust Sensitivity & - & - & $\checkmark$ & - & - & - \\
\hline Moral Disengagement & - & - & - & - & $\checkmark$ & $\checkmark$ \\
\hline Partisan Violence & - & - & - & - & $\checkmark$ & $\checkmark$ \\
\hline Free Speech Suppression & - & - & - & - & $\checkmark$ & - \\
\hline Partisan Schadenfreude & - & - & - & - & $\checkmark$ & $\checkmark$ \\
\hline Belief in a Dangerous World & - & - & - & - & $\checkmark$ & - \\
\hline Autocratic Orientation & - & - & - & - & - & $\checkmark$ \\
\hline Political Social Media Use & - & - & - & - & - & $\checkmark$ \\
\hline Political Violence - Actual & - & - & - & - & - & $\checkmark$ \\
\hline Political Violence - Desired & - & - & - & - & - & $\checkmark$ \\
\hline Authoritarianism Petitions & - & - & - & - & - & $\checkmark$ \\
\hline Involvement in Violent Protests & - & - & - & - & - & $\checkmark$ \\
\hline Support for Violent Protests & - & - & - & - & - & $\checkmark$ \\
\hline
\end{tabular}

Note. Different measures of general personality and dogmatism are present across samples. 
Table 3. Hypothesized Relations between LWA and External Criteria (Samples 1 - 5)

Construct

Predicted correlation with LWA

Personality

Cognitive Styles

$\begin{array}{lc}\text { Agreeableness } & -.20 \\ \text { Conscientiousness } & -.20 \\ \text { Emotionality } & .15 \\ \text { Extraversion } & .00 \\ \text { Honesty-humility } & -.25 \\ \text { Openness } & .00 \\ \text { Antagonism } & .25 \\ \text { Detachment } & .15 \\ \text { Disinhibition } & .25 \\ \text { Negative affect } & .25 \\ \text { Psychoticism } & .30 \\ \text { Coldheartedness } & .20 \\ \text { Fearless dominance } & .00 \\ \text { Self-centered impulsivity } & .25 \\ & \\ \text { Confirmatory thinking } & .20 \\ \text { Cognitive reflectivity } & -.15 \\ \text { Dogmatism } & .35 \\ \text { Epistemic certainty } & .20 \\ \text { Intellectual humility } & -.25 \\ \text { Need for closure } & .25 \\ \text { Objectivism } & -.20\end{array}$

Political Behavior

Affective polarization $\quad .35$

Free speech suppression $\quad .35$

Moral disengagement $\quad .35$

Partisan schadenfreude $\quad .35$

Political intolerance $\quad .35$

Partisan violence $\quad .35$

Social vigilantism $\quad .35$

Beliefs/worldviews

Conspiracist ideation $\quad .20$

Belief in a dangerous world $\quad .35$

Belief in science $\quad .15$

Belief in determinism $\quad .25$

State control $\quad .35$

Conformity $\quad .20$

Power $\quad .25$

Self-direction $\quad-.25$

Other

IQ

$-.15$

Note. We used Gignac and Szodorai's (2016) effect size guidelines for individual difference researchers to identify plausible magnitudes for these predicted relations. Theoretical rationales for these hypotheses are provided in Phase 4. 


\section{Methodological and Analytic Approach ${ }^{6}$}

\section{Item Development}

We initially articulated a broad, provisional conceptual model of LWA from which to begin our bootstrapping operation. In selecting focal constructs to target during test construction, we were informed by scholarly efforts to conceptualize LWA, RWA, and general authoritarianism (e.g., Adorno et al., 1950; Altemeyer, 1996; Altemeyer, 1998; Conway et al., 2018; DiRenzo, 1967; Duckitt \& Sibley, 2010; Duckitt, 1989; Eysenck, 1954; Feldman \& Stenner, 1997; Fromm, 1941; LeVasseur, 1997; Ludeke, 2016; Ray, 1983; Rokeach, 1960; Shils, 1954; Stenner, 2005; Stone, 1980; Van Hiel et al., 2006). We also consulted with experts from the fields of psychology, political science, and philosophy. These scholars provided guidance regarding LWA's conceptualization, suggested items for the LWA Index, and outlined potential obstacles to measure construction. Table 4 presents the focal constructs.

We used both deductive and inductive approaches to item generation. Following our delineation of focal constructs, the first and last authors wrote items reflecting each focal construct, and items solicited from our panel of experts were typically refined (e.g., rewritten for clarity) and then added to this item pool. Additional items were constructed by writing left-wing versions of RWA Scale items (e.g., Conway et al., 2018). In Phases 1 and 2, items were answered using a Likert-type scale with four response options. This format was amended

\footnotetext{
${ }^{6}$ Data and research materials from Samples 1, 2, 4, 5, and 6 are available at https://osf.io/4e2jf/. Data from Sample 3 will not be made publicly available (as we do not own the data). Materials from Sample 3 are available at yourmorals.org. Code for Phases 4, 5 , and 6 is available at https://osf.io/4e2if/. Code used for Phases 1-3 is not presently accessible due to COVID-19.

${ }^{7}$ Our rationale for including left-wing content in our initial item pool is as follows. First, authoritarianism typically exists in service of a specific political ideology, rather than in a "Platonic" form, and therefore may be quite difficult to measure in an ideologically neutral manner. Consider the following item: "Our government should have the power to prosecute fraudulent reporters." This statement does not necessarily reflect authoritarianism; after all, libel is illegal in the United States. In contrast, an item such as "Our government should have the power to prosecute members of the Fake News Media" may be more likely to capture authoritarianism, as would the item "Fox News and similar media outlets should be prohibited from broadcasting their views". Hence, even if ideology and authoritarianism are quite distinct constructs, as we suspect, measures of authoritarianism may need to be imbued with ideology to assess authoritarianism. We expand on this point in the Discussion. Second, the structure of non-rightist forms of authoritarianism remains unknown. In exploratory test construction (Tellegen \& Waller, 2008), convergent correlations between diverse candidate items are necessary to (a) infer the presence of the construct of interest (i.e., LWA)
}

to a 7-point scale in Phase 3, following contemporary best practices (Simms et al., 2019).

Several general guidelines were considered during item writing (Fowler, 1995). First, items exclusively assessing left-wing ideology were avoided. Nevertheless, many items described authoritarian attitudes and behaviors in reference to upholding, enhancing, or coercively imposing left-wing ideology and, as such, were imbued with left-wing ideological content ${ }^{7}$. Second, we made efforts to include both positive and negative candidate items to minimize acquiescence and counteracquiescence response biases, but we did not require the item pool to comprise an equal number of both. Instead, we viewed the critical attributes by which items should be evaluated for inclusion to be their construct validity. Third, items were written to assess both authoritarian attitudes and behaviors, given the ongoing theoretical debate concerning the degree to which authoritarianism is a stable personality trait (e.g., Ludeke $\&$ Krueger, 2013). Fourth, items were written to target a wide range of item difficulties so as to allow for sufficient discrimination at all levels of LWA. As our objective was to arrive at a scale of roughly 40 items, our initial item pool was nearly three times as long (Schinka, 2012), at 108 items. Before data collection, the items were administered to 10 research assistants familiar with the LWA construct and amended for clarity based on their comments.

and (b) identify its superficially heterogeneous manifestations. Similarly, discriminant correlations among diverse candidate items are necessary to define and draw the construct's boundaries (see also Loevinger, 1957). In other words, we will require LWA items, quasi-LWA items, and non-LWA items. Critically, we cannot know before beginning the scale construction process which items reflect LWA and which do not - this will be determined based on the structural, psychometric, and nomological properties of the items themselves, rather than their face validity. Hence, to distinguish between LWA and left-wing political ideology, items involving varying degrees of political content must be included in the initial item pool To ensure satisfactory discrimination between the LWA Index and political ideology, LWA items that are highly correlated with political ideology will not be retained in the final version of the measure (regardless of the degree to which they include ideological content). By the same token, however, items that (1) converge with LWA and relevant external criteria and (2) are not highly correlated with political ideology will be retained in the final version of the measure, even if said items include superficially left-wing ideological content. To do otherwise would be to diminish the value of the measure. Indeed, the inclusion of left-wing content in the LWA Index may be a positive thing, assuming that the test is not highly correlated with ideology, due to the frame-of-reference effect (Lievens, DeCorte, \& Schollaert, 2008; Shaffer \& Postlewaite, 2012). 
Table 4. Principal Focal Constructs Targeted During Test Construction

\begin{tabular}{|c|c|c|}
\hline Focal Concept & Definition & Source \\
\hline $\begin{array}{l}\text { Aggression/authoritarian } \\
\text { dominance }\end{array}$ & $\begin{array}{l}\text { Damaging behaviors and/or sentiments towards threatening individuals, } \\
\text { groups, and ideologies; punitiveness towards perceived dissidents and } \\
\text { deviants. }\end{array}$ & $\begin{array}{l}\text { Adorno et al., } 1950 \\
\text { Altemeyer, } 1998 \\
\text { Stenner, } 2005 \\
\text { Ho et al., } 2015\end{array}$ \\
\hline Submission & Obsequiousness towards in-group authority. & $\begin{array}{l}\text { Adorno et al., } 1950 \\
\text { Altemeyer, } 1996\end{array}$ \\
\hline $\begin{array}{l}\text { Anti- or reverse- } \\
\text { hierarchical sentiments }\end{array}$ & $\begin{array}{l}\text { Desire to foment social, political, and/or economic revolution by force; } \\
\text { overturning or flipping the present hierarchy as a primary political aim; } \\
\text { can manifest in several strains (e.g., Leninism, Maoism, Trotskyism). }\end{array}$ & $\begin{array}{l}\text { Altemeyer, } 1996 \\
\text { LeVasseur, } 1997 \\
\text { Fromm, } 1950 \\
\text { Shils, } 1954\end{array}$ \\
\hline Conventionalism & $\begin{array}{l}\text { Rejection of the traditional and embrace of left-wing cultural and moral } \\
\text { norms; demand that members of both in- and out-group adhere to said } \\
\text { norms; rejection of rich viewpoint diversity; preference for ideological } \\
\text { uniformity/degree to which one prefers to "live in a bubble." }\end{array}$ & $\begin{array}{l}\text { Altemeyer, } 1996 \\
\text { Duckitt, } 1989 \\
\text { Stenner, } 2005\end{array}$ \\
\hline Lethal partisanship & $\begin{array}{l}\text { Rationalization of harm towards political opponents (moral } \\
\text { disengagement); lessened sympathy towards suffering of political } \\
\text { opponents (partisan schadenfreude); lessened restraint towards killing } \\
\text { political opponents (political violence). }\end{array}$ & $\begin{array}{l}\text { Kalmoe \& Mason, } \\
2018 \\
\text { Bandura, } 2016\end{array}$ \\
\hline $\begin{array}{l}\text { Prejudice towards } \\
\text { ideologically dissimilar } \\
\text { others }\end{array}$ & $\begin{array}{l}\text { Potential target groups include pro-life supporters, Evangelical Christians, } \\
\text { Wall St. executives., etc. }\end{array}$ & $\begin{array}{l}\text { Adorno et al., } 1950 \\
\text { Allport, } 1954 \\
\text { Crawford \& } \\
\text { Brandt, } 2020\end{array}$ \\
\hline Dogmatism (Rokeach) & $\begin{array}{l}\text { A relatively closed organization of beliefs and disbeliefs about reality, } \\
\text { organized around beliefs about absolute authority, which provide a } \\
\text { framework for patterns of intolerance and qualified tolerance towards } \\
\text { others. }\end{array}$ & $\begin{array}{l}\text { Rokeach, } 1960 \\
\text { Johnson, } 2009\end{array}$ \\
\hline Difference-ism & $\begin{array}{l}\text { A dispositional system of functionally related stances concerning the ideal } \\
\text { balance between group authority and uniformity, on the one hand, and } \\
\text { individual autonomy and diversity, on the other. }\end{array}$ & $\begin{array}{l}\text { Duckitt, } 1989 \\
\text { Stenner, } 2009\end{array}$ \\
\hline Moral absolutism & $\begin{array}{l}\text { Holding that some moral beliefs are objectively true, independent of one's } \\
\text { personal opinions or perspectives. }\end{array}$ & $\begin{array}{l}\text { Napier \& Jost, } \\
2008\end{array}$ \\
\hline $\begin{array}{l}\text { Susceptibility to } \\
\text { "normative" threat }\end{array}$ & $\begin{array}{l}\text { Attentiveness and responsiveness to one's preferred boundaries, norms, } \\
\text { and authorities. }\end{array}$ & $\begin{array}{l}\text { Stenner, } 2005 \\
\text { Feldman, } 2003\end{array}$ \\
\hline Tough-mindedness & $\begin{array}{l}\text { Extent to which one demonstrates low compassion and high aggression in } \\
\text { social interactions. }\end{array}$ & $\begin{array}{l}\text { Eysenck, } 1954 \\
\text { Ray \& Bozek, } \\
1981\end{array}$ \\
\hline Cognitive rigidity & $\begin{array}{l}\text { Rigid, inflexible thinking and psychological preferences for clarity and } \\
\text { certainty. }\end{array}$ & $\begin{array}{l}\text { Rokeach, } 1960 \\
\text { Jost et al., } 2003\end{array}$ \\
\hline
\end{tabular}

\section{Scale Development}

For all phases of development, item reduction analyses were conducted prior to extraction of factors and tests of dimensionality. To avoid method factors arising from item distributions, items were screened for skewness $>|2.0|$ and kurtosis $>|7.0|$ following the recommendations of Finney and DiStefano (2013). Further, items whose individual response options were endorsed by less than $5 \%$ of the sample were removed. ${ }^{8}$ In exploratory analyses, we employed both Velicer's (1976) MAP criteria and Horn's (1965) parallel analysis to determine the appropriate number of factors to retain for each version of the LWA Index. We then conducted

\footnotetext{
${ }^{8}$ This criterion was shifted to $2.5 \%$ in Samples 3 and 4, where a 7-point Likert scale was used.
} 
sets of exploratory factor analyses in each sample, using principal axis factor analysis ${ }^{9}$ with oblique (promax) rotation given our expectation of correlated factors. Potential factor solutions were evaluated based on model fit, amount of total variance explained, factor eigenvalues (i.e., with solutions containing factors that explained $<5 \%$ of variance eliminated), discriminant validity, item content, item communalities, and structure and pattern coefficients (i.e., coefficients $>.35$ were used to interpret factors). Importantly, factor solutions that manifested promising relations with external criteria were prioritized, as were solutions with high face validity, especially in the early stages of scale development.

\section{Scale Evaluation}

Tests of dimensionality. Confirmatory factor analysis (CFA) and exploratory structural equation modeling (ESEM) were employed to evaluate the dimensionality of the factors identified via EFA in previous samples. We conducted CFAs in $R$ with the lavaan package (Rosseel, 2012), using the robust weighted least squares (WLSMV) estimator given its capacity to handle categorical and non-normally distributed indicators. As recommended by Brown (2015), we placed particular emphasis on sample size-independent goodness of fit indices with good cut-off values: the Tucker-Lewis index (TLI; with values $\geq 0.95$ reflecting good fit) and the root-mean-square error of approximation (RMSEA; with values $<0.06$ reflecting good fit), but also report the chi-square test.

Nevertheless, several authors have observed that CFA is often inappropriate for multidimensional constructs for which substantial item cross-loadings are to be expected (Marsh et al., 2014). Indicators in multifactorial models are virtually never perfectly and uniquely related to a single construct and, as such, will reflect construct-relevant variance for non-target factors (Morin et al., 2016). The Independent Cluster Model, which is inherent to CFA, assumes cross-loadings of zero. Yet when cross-loadings are constrained to zero, if indicators load onto multiple substantive factors, inflated factor correlations are the only way for this to be expressed (e.g., Asparouhov \& Muthén, 2009; Marsh et al., 2014). Given that the LWA items

\footnotetext{
${ }^{9}$ Polychoric correlations were used in Samples 1 and 2.

${ }^{10}$ Allowing for cross-loadings does not obscure the meaning of latent variables. Simulation studies have shown that EFA/ESEM typically yield more precise estimates of true population values for factor correlations when even small cross-loadings are present in
}

are imbued with shared (e.g., left-wing ideological variance), the ICM's restrictive assumptions may hinder discriminant validity. Consequently, in addition to CFA, we used ESEM, a technique that incorporates strengths from both EFA and CFA into an overarching analytic framework that allows for item cross-loadings on non-target factors while also providing standard errors, traditional goodness of fit statistics, and the opportunity to model method factors and conduct invariance testing. ${ }^{10}$

ESEM analyses were conducted in MPlus (Muthén \& Muthén, 2015) using the WLSMV estimator to test models identified with EFA in previous phases. We estimated the ESEM models with correlated factors and cross-loadings freely estimated but "targeted" to be as close to zero as possible on non-target factors (i.e., using target rotation). With this approach, and following previous studies (e.g., Tóth-Király et al., 2017), ESEM was used as a confirmatory test of potential factor structures. Regarding evaluation of model fit, as ESEM models comprise many more parameters than do CFA models, we considered indicators that include a correction for parsimony (i.e., TLI and RMSEA) to be most informative (Marsh et al., 2014; Morin et al., 2016). Changes in TLI and RMSEA relative to the CFA model greater than .01 were considered meaningful (Cheung \& Rensvold, 2002; Chen, 2007). Construct reliabilities were assessed using Hancock and Mueller's (2001) $H$ value, which represents the correlation between a given factor and an optimally weighted item composite, such that $H$ values $>.80$ suggest a well-defined, replicable, latent variable (see Rodriguez et al., 2016).

Tests of validity. To evaluate the LWA Index's external validity, we adopted Westen and Rosenthal's (2003) metrics for quantifying construct validity, which provide effect size estimates (ranging from -1 to 1) for the degree to which an observed pattern of correlations between a measure of interest and relevant external criteria accord with theoretically predicted patterns of correlations (see Furr \& Heuckeroth, 2019). The first of these metrics, $r_{\text {alterting- } \mathrm{CV}}$, is the correlation between the pattern of predicted correlations between the measure of interest and external criteria (arranged as a column of data) and the pattern of $z$-transformed observed correlations (arranged as a second column of data). The second metric, $r_{\text {contrast-CV }}$, similarly increases as the

the population model (and remain unbiased when cross-loadings are not present in the population model; Marsh, Lüdtke, Nagengast, Morin, \& Von Davier, 2013; Schmitt \& Sass, 2011; see Asparouhov, Muthén, \& Morin, 2015). 
match between predicted and observed correlations increases, but also accounts for (a) sample size, (b) the median intercorrelation among the external criteria, and (c) the absolute values of each correlation. Large $r_{a l}$ terting- $\mathrm{CV}$ and $r_{\text {contrast- } \mathrm{CV}}$ values ostensibly support a test's external validity. Westen and Rosenthal do not provide formal guidelines for interpretation but take values $>$ .70 to indicate "substantial correspondence between [one's] theory of the construct and its empirical correlates" (p. 612). These analyses were conducted in $R$ using the $Q C V$ package (Furr \& Heuckeroth, 2019).

To facilitate a more granular interpretation of the LWA Index's construct validity, we calculated several versions for each Westen and Rosenthal statistic: one for which the predicted correlations were estimated on a theoretically informed, a priori basis (see Table 3 for predictions), a second where they were pegged directly to RWA's correlations with external criteria, and a third where they were pegged directly to SDO's correlations with external criteria. This ecumenical approach allowed us to document the degree to which RWA and SDO, on the one hand, and LWA, on the other, overlap in their relations with external criteria without assuming that LWA and RWA/SDO have identical nomological networks. Further, we conducted these external validity analyses using both zero-order correlations and partial correlations (controlling for political ideology). In so doing, we avoided obscuring relations between LWA, RWA, and criterion-related variables due to ideological asymmetries in authoritarianism and/or curvilinearity at the extremes of the political spectrum.

\section{Phase 1}

\section{Participants}

Details concerning Sample 1 are provided in Table 1 and in Online Supplemental Materials.

\section{Results}

Following item reduction analyses and several rounds of EFAs (see Online Supplemental Materials), Velicer's MAP suggested a 6-factor solution for the remaining 46 items, whereas parallel analysis suggested a 7-factor solution. The 6-factor solution (see Table S1) was more easily interpretable and manifested stronger relations with the expected external criteria than the 7factor solution, so we provisionally adopted the 6-factor solution $(\mathrm{RMSEA}=.082$, RMSR $=.02)$, which accounted for $52 \%$ of the total variance (with individual factors accounting for between $12 \%$ and $6 \%$ ), exhibited sum of squared loadings from 5.70 to 2.85 , and exhibited factor correlations from $|.17|$ to $|.61|$.

The first factor (11 items; $\alpha=.84$ ) was marked by items that reflect preferences for rigid enforcement from on-high of a "party line." In addition, the first factor comprised items that reflect left-wing conventionalism. Two items that seemed more consistent with other elements of authoritarianism also loaded most highly onto Factor 1 (i.e., "All people need to line up behind strong leaders who are willing to stamp out prejudice and intolerance," "Getting rid of oppression is more important than protecting our democracy"), although these items exhibited large cross-loadings with Factor 4. The second factor (11 items; $\alpha=.87$ ) was marked by items reflecting need for social uniformity, which Stenner (2009) argued lies at the core of authoritarianism. Factor 2 includes items describing willingness to discriminate against political conservatives, which dovetails with original conceptualizations of authoritarianism as imbued with prejudice (Adorno et al., 1950). Factor 3 ( 7 items; $\alpha=.79$ ) mirrored Factor 2 in the degree to which it contains content related to ideologically dissimilar others, but reflected aggression, partisan schadenfreude, and moral disengagement, rather than aversion to difference. Factor 4 comprised only three items $(\alpha=.68)$, all of which contained content concerning political violence. Although Factor 4 may have been be a method factor (due either to negative wording or item difficulty), the conceptual similarity of these violence items provisionally led us to consider Factor 4 to be substantive. Factor 5 (5-items; $\alpha=.73$ ) appeared to reflect authoritarian aggression and anti-hierarchical sentiment for economic issues. Further, the items "If a few of the worst Republican politicians were assassinated, it wouldn't be the end of the world" and "The way things are now, one should always question authority" loaded highly onto Factor 5. Finally, Factor 6 (5 items, $\alpha=.63$ ) comprised items reflecting attitudes about the suppression or outlawing of certain intolerant and racist beliefs.

Although we present the results of our construct validity analyses in Phase 4, we examined the convergent and discriminant validity of the six-factor EFA solution before moving on to Phase 2. Results are presented in Tables S2 and S3. The LWA Index (Version 1) generally showed a promising pattern of relations with relevant external criteria (e.g., LWA was related to political intolerance, dogmatism, need for closure, low openness, and low agreeableness).

\section{Phase 1 Discussion}


In this phase, we identified an interpretable and coherent factor solution for our initial pool of items. The factors appeared to reflect constellations of our focal constructs, which cohered in sometimes unexpected ways. For instance, Factors 1 and 2 both reflected heterogeneous sets of items that did not immediately lend themselves to simple interpretations. Moreover, we identified several domains in which our item pool was lacking. For instance, items concerning revolutionary, anti-establishment sentiments - potentially a core component of LWA - appeared limited to Factors 4 and 5. Overall, however, Phase 1 proved successful in providing a foundation from which to further elucidate the factor structure of LWA.

\section{Phase 2}

Building on the results of Phase 1, we sought to improve the LWA Index by both eliminating or rewriting poorly functioning items and expanding the content coverage of the item pool by generating new items. We administered Version 2 of the LWA Index to two online samples. One sample was collected via MTurk $(\mathrm{N}=$ 498 ) and the other was collected via YourMorals.org $(\mathrm{N}=4,165)$.

\section{Changes to the LWA Index}

In generating new items, we did not seek to preserve the factor structure from Phase 1. To elaborate, we did not write new items to load onto a particular factor in the six-factor solution, but instead sought to expand representation of underrepresented focal concepts. We wrote new items for the focal constructs of explicit deference to authority figures (e.g., "I would prefer a farleft leader with absolute authority over a far-right leader with limited power"), political violence (e.g., "I can imagine myself committing an act of political violence to help a left-wing revolution succeed"), anti-establishment sentiments (e.g., "The rich should be stripped of their belongings and status"), and suppression or outlawing of certain intolerant beliefs (e.g. "University authorities are right to ban hateful speech from campus").

In addition to these new items, we modified items from Phase 1 that were screened out for non-normal distributions to provide more balanced coverage of high- and low-levels of the construct. This procedure

\footnotetext{
${ }^{11}$ We next conducted an EFA of the full item pool in Sample 3 so as to further evaluate where and why model misspecification was occurring, as well as to potentially reincorporate many of the items discarded in Sample 2. Inconsistent with our EFA of Sample 2, this
}

resulted in the reduction of items that might frequently be endorsed by non-authoritarian individuals on the left as well as items so extreme as to be rarely endorsed as "Very true" (e.g., "Society would be better off if individuals with problematic views were thrown in jail"). The item pool in Study 2 comprised 89 items.

\section{Participants}

Details concerning Samples 2 and 3 are provided in Table 1 and in Online Supplemental Materials.

\section{Results}

Far fewer items were removed during item reduction analyses than in Phase 1, suggesting an improved balance of extremely easy and extremely difficult items. EFAs consistently comprised a wording direction method factor. After removing the 8 items that appeared to be driving this factor, a 6- and 8-factor solution were recommended by parallel analysis and Velicer's MAP. In the eight-factor solution, only one item loaded above .35 on Factor 8, suggesting over-factoring. In contrast, the 6 -factor model comprised only substantive factors. In the 6-factor solution, sum of squared loadings ranged from 8.18 to 3.58 and proportion of total variance explained by each factor ranged from $12 \%$ to $5 \%$. Factor correlations ranged from .23 to .67 , suggesting adequate discrimination across factors. Item content, item communalities, item complexities, factor pattern coefficients, and correlations among factors are presented in Table S4.

In Sample 3, however, a 6-factor CFA model did not demonstrate acceptable fit, $\chi^{2}=15,364.42, \mathrm{df}=978, p$ $<.001$, RMSEA $=.053[.053, .054]$, TLI $=.86$, and factor correlations were extremely high ( $r$ s from .79 to .91). The ESEM model, in contrast, demonstrated improved fit, $\chi^{2}=74,948.74, \mathrm{df}=1035, \mathrm{p}<.001$, RMSEA $=.035,90 \%$ CI $[.034, .036]$, TLI $=.95$, and discriminant validity was also much improved, with interfactor correlations ranging from .42 to .66 . Nevertheless, target loadings for Factors 4 and 5 in the 6-factor ESEM model did not exceed .50. Hence, only Factors 1-3 can be considered stable, suggesting that further exploratory evaluation of the LWA Index is merited. ${ }^{11}$

\section{Phase 2 Discussion}

EFA suggested that 3- and 4-factor solutions were plausible. Detailed results, including external validity analyses for these potential factor solutions, are presented in Tables S5 - S8. 
Given the disparities across Samples 2 and 3, we decided that further refinement of the item pool was merited. Nevertheless, Phase 2 advanced our understanding of LWA and allowed us to critically improve our item pool for subsequent Phases. For instance, we were able to identify and eliminate items that were highly correlated with political ideology or not sufficiently correlated with authoritarianism-related variables. Moreover, the combination of ESEM and EFA results from Sample 3 suggested that 3- to 4-factor models may better describe the measure than do more complex solutions, which allowed us to write additional items targeted to load onto these factors.

\section{Phase 3}

Phase 3 marks the final round of revisions to the LWA Index reported in the present investigation. Based on the measure's factor structure and criterionrelated validity in Phase 2, we modified the item pool by deleting poorly functioning items, rewording ambiguous or non-optimized items, and adding novel items to bolster underrepresented factors. Subsequently, we conducted EFAs in Sample 4 to delineate potential latent factor structures for the quasi-final version of the scale, which we then evaluated with CFA and ESEM in Sample 5. At this stage, our primary item additions were intended to fortify content coverage of potentially underrepresented areas, rather than further expand the boundaries of the LWA construct.

\section{Participants}

Details concerning Samples 2 and 3 are provided in Table 1 and in Online Supplemental Materials.

\section{Results}

Given that we anticipated this would be the final pool of items used to derive the LWA Index, we adopted a more comprehensive approach to EFAs in Sample 4. Parallel analysis suggested an 8-factor solution, so we conducted EFAs specifying 1- to 8-factor models. Solutions that included reverse-item method factors and factors with $<3$ items were discarded, resulting in our proceeding with 1-, 2-, 3-, and 7-factor solutions. We removed items with pattern factor loadings below .40 or cross-loadings above .40 (resulting in a slightly different pool of items for each model) and again computer the models. For the 7-factor solution, the three largest factors were highly similar to one another, potentially favoring a 3-factor interpretation. Moreover, the 7-factor solution was clearly over-factored, with two of its factors marked by high loadings on only 3 items. Parallel analysis of the 7-factor item pool recommended a 5-factor solution, which yielded five interpretable factors, but 3-, 2-, and 1-factor solutions were also interpretable and demonstrated adequate fit.

We then moved to a confirmatory framework in Sample 5. We estimated 1-, 2-, 3-, and 5-factor firstorder CFA models and 2-, 3-, and 5-factor first-order confirmatory ESEM models based on the results of the EFAs $^{12}$. Table 5 presents results for each of the estimated models. Model fit for the 1-factor CFA model was low, whereas, for the 2-, 3-, and 5-factor CFA models, fit was acceptable but not good (i.e., TLI $\geq .90$; RMSEA <.080). In the 2 -factor model, the factors were highly correlated $(r=.82)$. The 3 -factor CFA model demonstrated equally high factor intercorrelations $(r \mathrm{~s}$ ranged from .74 to .85), as did the 5-factor CFA model ( $r$ s ranged from 65 to .87 ). The addition of an orthogonal method factor for negatively worded items to each model improved fit negligibly and did not meaningfully change the factor correlations. As such, all four CFA models demonstrated poor discriminant validity across factors.

In contrast, the ESEM solutions provided improved representation of the data per our goodness of fit criteria (in comparing the CFA and ESEM solutions, the average $\triangle \mathrm{RMSEA}=-.015$ and $\triangle \mathrm{TLI}=.04$ across each factor model) and discriminant validity. The $90 \% \mathrm{CI}$ of the RMSEA for the best-fitting CFA solution did not overlap with the $90 \%$ CI of the RMSEA for the worst fitting ESEM solution. In the 2-factor ESEM solution, factors were correlated $r=.67$; in the 3 -factor solution, factor correlations ranged from .48 to 67; and in the 5factor solution, factor correlations ranged from .25 to .49 , with the exception of the correlation between Factor 1 and Factor $5(r=.74)$. The 5-factor ESEM solution offered a clear improvement in fit over and above the 2- and 3-factor ESEM solutions, as well as excellent fit in absolute terms, but also evinced a handful of problematic cross-loadings (i.e., instances where an item's largest loading was not on their target factor) and generally middling parameter estimates (i.e., $\lambda \mathrm{s}<.70$ ). Although the 3-factor model's fit was inferior to that of the 5 -factor model, item loadings were generally higher,

\footnotetext{
${ }^{12}$ We also estimated bifactor CFA, bifactor ESEM, and hierarchical ESEM models on an exploratory basis.
} 
Table 5. Fit Statistics for All Estimated Confirmatory Models

\begin{tabular}{lcccc}
\hline & $\chi^{2}$ & $d f$ & $R M S E A$ & $T L I$ \\
\hline 1F CFA & 6968 & 1595 & $.076[.074, .078]$ & .88 \\
2F CFA & 5308 & 1324 & $.072[.070, .074]$ & .90 \\
3F CFA & 4391 & 1172 & $.069[.066, .071]$ & .91 \\
5F CFA & 3560 & 892 & $.072[.069, .074]$ & .92 \\
2F ESEM & 3834 & 1266 & $.059[.057, .061]$ & .93 \\
3F ESEM & $\mathbf{2 9 5 2}$ & $\mathbf{1 0 7 8}$ & $\mathbf{. 0 5 5}[\mathbf{0 5 2}, .057]$ & .96 \\
5F ESEM & 1558 & 730 & $.044[.041, .047]$ & .97 \\
\hline
\end{tabular}

Note. $1 \mathrm{~F}=1$-factor model; $2 \mathrm{~F}=2$-factor model; $3 \mathrm{~F}=3$-factor model; $5 \mathrm{~F}=5$-factor model. Our final model is bolded.

and only one item loaded more highly onto a non-target than target factor. The 3-factor model was also more parsimonious and generally consistent with findings from Phase 2 (i.e., the factor content of the 3-factor ESEM generally mirrors the 3 strongest factors that consistently appeared across all manner of exploratory models in Phase 2). Ultimately, the distinction between the two solutions may be a question of depth vs. breadth, with the 3 -factor solution offering the former and the 5-factor solution offering the latter.

Hence, both the 3- and 5-factor ESEM models offer plausible interpretations of the LWA Index. To further compare the two models, we examined how each related to relevant external criteria. Beforehand, we removed items with untenable cross-loadings (i.e., higher on non-target factors) and items with poor face validity for their target factor. At this stage, the models became somewhat more similar in their goodness of fit, such that for the 3-factor model, $\chi^{2}=1735.82, d f=622, p<$ $.001 ;$ RMSEA $=.055,90 \%$ CI $[.052, .058] ; T L I=.96$, and for the 5-factor model, $\chi^{2}=918.98, d f=342, p<$ $.001 ;$ RMSEA $=.054,90 \%$ CI $[.050, .058] ; T L I=.97$. Given that the 5-factor model did not sufficiently increment the 3-factor model in terms of its relations with external criteria to justify its potentially unstable nature (see Table S10), we proceeded with the 3-factor solution. Item loadings for the 3 -factor ESEM solution are presented in Table 6 (see Table S9 for the 5-factor solution).

Factor interpretation. Factor 1 (13-items; $H=$ .91), which we termed Anti-hierarchical Aggression, reflects the belief that those currently in power should be punished, the established order should be overthrown, and that extreme actions, such as political violence, are justifiable to achieve these aims. Factor 2 (13-items; $H=.88$ ), which we termed Anti-conventionalism, reflects the rejection of traditional values, a moral absolutism concerning progressive values and concomitant dismissal of conservatives as inherently immoral, and a need for political homogeneity in one's social environment. Lastly, Factor 3 (13-items; $H=$ .91), which we termed Top-down Censorship, reflects preferences for the use of governmental and institutional authority to quash opposition and bar offensive and intolerant speech.

\section{Phase 3 Discussion}

Phase 3 yielded the final version of the LWA Index, a 39-item measure with satisfactory psychometric properties reflecting three moderately correlated, conceptually distinct dimensions. Concomitantly, Phase 3 marks the first formal articulation of our data-driven conceptualization of LWA, which mirrors the LWA Index's tripartite structure. In subsequent phases, we conduct stringent construct validational tests of the LWA Index. If the measure manifests a pattern of relations that is symmetrical with other models of authoritarianism, such a finding would provide strong evidence of LWA's existence and utility. Alternatively, if the LWA Index does not align with authoritarianism's nomological network, such a finding would require us to reevaluate the nature of LWA.

\section{Phase 4: External Validity and Implications for Left- wing Authoritarianism}

In Phase 4, we quantitatively tested the LWA Index's convergent and discriminant correlates by comparing the magnitude and directionality of its relations with external criteria to our predictions using Westen and Rosenthal's (2003) "quantifying construct validity" procedures. Below we describe measures of external criteria, detail the conceptual basis for our predicted relations, and present the results of these analyses. 
Table 6. Final LWA Index ESEM Results (Item Content and Standardized Factor Loadings)

\begin{tabular}{|c|c|c|c|}
\hline & AHA & $\mathrm{AC}$ & TDC \\
\hline The rich should be stripped of their belongings and status. & .82 & .16 & -.06 \\
\hline Rich people should be forced to give up virtually all of their wealth. & .79 & 18 & -.05 \\
\hline If I could remake society, I would put people who currently have the most privilege at the very bottom. & .77 & .15 & -.09 \\
\hline America would be much better off if all of the rich people were at the bottom of the social ladder. & .73 & .15 & -.03 \\
\hline When the tables are turned on the oppressors at the top of society, I will enjoy watching them suffer the violence that they have inflicted on so many others. & 68 & -.07 & .14 \\
\hline Most rich Wall Street executives deserve to be thrown in prison. & .70 & .17 & -.18 \\
\hline Constitutions and laws are just another way for the powerful to destroy our dignity and individuality. & .61 & -.02 & .15 \\
\hline The current system is beyond repair. & .58 & -.05 & .06 \\
\hline We need to replace the established order by any means necessary. & .56 & -.10 & .30 \\
\hline Political violence can be constructive when it serves the cause of social justice. & .50 & .02 & .15 \\
\hline Certain elements in our society must be made to pay for the violence of their ancestors. & .46 & .00 & .36 \\
\hline If a few of the worst Republican politicians were assassinated, it wouldn't be the end of the world. & .46 & .26 & -.07 \\
\hline I would prefer a far-left leader with absolute authority over a right-wing leader with limited power. & .34 & .28 & .27 \\
\hline Schools should be required by law to teach children about our country's history of racism, classism, sexism, and homophobia. & -.23 & .65 & .18 \\
\hline Anyone who opposes gay marriage must be homophobic. & -.01 & .69 & .14 \\
\hline Deep down, just about all conservatives are racist, sexist, and homophobic. & .23 & .67 & .05 \\
\hline People are truly worried about terrorism should shift their focus to the nutjobs on the far-right. & .12 & .64 & .11 \\
\hline The "old-fashioned ways" and "old-fashioned values" need to be abolished. & .10 & .65 & .05 \\
\hline Radical and progressive moral values can save our society. & -.02 & .59 & .10 \\
\hline All political conservatives are fools. & .31 & .63 & .00 \\
\hline I cannot imagine myself becoming friends with a political conservative. & .26 & .58 & .08 \\
\hline Conservatives are morally inferior to liberals. & .29 & .57 & .04 \\
\hline It is important that we destroy the West's nationalist, imperialist values. & .27 & .40 & .18 \\
\hline I try to expose myself to conservative news sources. & .16 & -.48 & -.18 \\
\hline There is nothing wrong with Bible camps. & -.13 & -.58 & .18 \\
\hline I hate being around non-progressive people. & .19 & .36 & .31 \\
\hline Classroom discussions should be safe places that protect students from disturbing ideas. & .12 & -.38 & .86 \\
\hline University authorities are right to ban hateful speech from campus. & -.23 & .23 & .82 \\
\hline I should have the right not to be exposed to offensive views. & .13 & -.20 & .66 \\
\hline To succeed, a workplace must ensure that its employees feel safe from criticism. & .18 & -.22 & .59 \\
\hline We must line up behind strong leaders who have the will to stamp out prejudice and intolerance. & -.16 & .17 & .53 \\
\hline When we spend all of our time protecting the right to "free speech" we're protecting the rights of sexists, racists, and homophobes at the cost of marginalized people. & .28 & .01 & .54 \\
\hline I am in favor of allowing the government to shut down right-wing internet sites and blogs that promote nutty, hateful positions. & -.04 & .38 & .58 \\
\hline Colleges and universities that permit speakers with intolerant views should be publicly condemned. & .11 & 24 & .56 \\
\hline Getting rid of inequality is more important than protecting the so-called "right" to free speech. & .14 & .20 & .54 \\
\hline Fox News, right-wing talk radio, and other conservative media outlets should be prohibited from broadcasting their hateful views. & .15 & .35 & .48 \\
\hline Even books that contain racism or racial language should not be censored. & -.12 & .18 & -.48 \\
\hline I don't support shutting down speakers with sexist, homophobic, or racist views. & .16 & -.21 & -.59 \\
\hline Neo-Nazis ought to have a legal right to their opinions. & .05 & -.10 & -.65 \\
\hline
\end{tabular}

Neo-Nazis ought to have a legal right to their opinions.

ote. Analyses were conducted in MPlus 8.4 using WLSMV estimation and target rotation. Factor correlations ranged from .48 to .67. Response options ranged from Strongly Disagree (1) to

Strongly Agree (7). AHA = Anti-hierarchical Aggression, AC = Anti-conventionalism; TDC = Top-down Censorship. 


\section{Measures}

Sample 1. Alongside Version 1 of the LWA Index, participants completed measures of political ideology, RWA, SDO, dogmatism, political intolerance, normal and abnormal personality, need for cognitive closure, and belief in conspiracy theories. We describe these measures below.

Political Ideology. Attitudes and beliefs about politics were assessed using the Social and Economic Conservatism Scale (SECS; Everett, 2013), a survey of favorability toward 12 political topics that are important to conservative voters, of which 6 are economic (e.g., limited government) and 6 are social (e.g., traditional values). The SECS yields two oblique dimensions ( $r=$ $.53)$, economic conservatism $(\alpha=.94)$ and social conservatism $(\alpha=.85)$. Further, participants indicated the degree to which they symbolically identified as leftwing versus right-wing using Likert-type items with seven response options.

$\boldsymbol{R} \boldsymbol{W} \boldsymbol{A}$. The 22-item Right-wing Authoritarianism Scale (RWA; Altemeyer, 1996; $\alpha=.88$ ) was administered to assess RWA.

SDO. The $\mathrm{SDO}_{7}$ (Ho et al., 2015) comprises two higher-order dimensions: Dominance ( 8 items, $\alpha=.86$ ) and Egalitarianism ( 8 items, $\alpha=.88$ ). Dominance describes a preference for group-based dominance, whereas Egalitarianism describes a dislike of groupbased inequality and hierarchy-maintaining social policies. We focus on the former construct in the present work given its direct relevance to authoritarianism (Duckitt \& Sibley, 2010).

Dogmatism. To assess dogmatism, we administered the DOG Scale (Altemeyer, 1996; $\alpha=.92$ ), a 20 -item measure of unjustified belief certainty. Given its conceptual overlap with authoritarianism, we predicted that dogmatism is positively related to LWA.

Political Intolerance. To assess political intolerance, parallel right- and left-wing versions of intolerance items were administered to participants, following procedures from previous research (e.g., Crawford \& Pilanski, 2014). The 6 items were averaged to yield a composite political intolerance score; scores were collapsed across the left and right $(\alpha=.77)$. An independent samples t-test showed that left-leaning participants did not differ significantly from right-leaning participants $\left(\mathrm{N}_{\text {Left }}=256 ; \mathrm{M}_{\text {Left }}=11.90, \mathrm{SD}_{\text {Left }}=4.38, \mathrm{~N}_{\text {Right }}=\right.$ $179 ; \mathrm{M}_{\text {Right }}=12.26, \mathrm{SD}_{\text {Right }}=4.58 ; t=0.83, p=.405, d$ $=.081)$. We predicted that political intolerance would be positively related to LWA.

Normal and Abnormal Personality. To examine the LWA Index's placement within the framework of general personality, we administered the HEXACO Personality Inventory (HEXACO; Lee \& Ashton, 2018), a 100-item measure of normal-range personality that consists of 6 factors: Honesty-Humility, Emotionality, Extraversion, Agreeableness, Conscientiousness, and Openness to Experience ( $\alpha$ s ranged from .86 to .90). Past research concerning the personality correlates of RWA and SDO informed our predictions. RWA is tied to low openness and, to a lesser extent, high conscientiousness, whereas SDO is tied to low honesty-humility, low agreeableness, and low emotionality (Ho et al., 2015; Sibley \& Duckitt, 2008; Sibley et al., 2010). Because individuals on the left are lower in conscientiousness (particularly, the orderliness facet; DeYoung et al., 2007; Jost et al., 2003) and higher in openness than individuals on the right, we expected that the personality correlates of LWA would be more similar to SDO than RWA. Specifically, we predicted that LWA would be negatively related to conscientiousness, the intellect facet of openness (i.e., perceived intelligence and intellectual engagement; DeYoung et al., 2014), honesty-humility, and agreeableness, and positively related to the openness facet of openness (i.e., engagement with perceptual and aesthetic domains; DeYoung et al., 2014).

Further, although some evidence exists that RWA buffers against certain forms of psychopathology (e.g., Van Hiel \& De Clercq, 2009), "dark" personality traits have been found to predict authoritarian dominance (e.g., Hodson et al., 2009), and one of these traits in particular, namely psychopathy, has long been theorized to predict extremist violence (Gill \& Corner, 2017). Thus, we administered the Personality Inventory for DSM 5 - Brief Form (PID-5 BF; Krueger et al., 2012), a 25-item self-report measure of the domains in the DSM-5 (American Psychiatric Association, 2013) Alternative (Section 3) Model of Personality Disorders (domain $\alpha$ s ranged from .77 to .85). We also administered the Psychopathic Personality Inventory-Revised (PPI-R; Lilienfeld \& Widows, 2005), a 154-item selfreport inventory designed to assess psychopathic traits, which yields three largely independent factors, PPI-R Fearless Dominance $(\alpha=.81)$, PPI-R Self-centered Impulsivity $(\alpha=.83)$, and PPI-R Coldheartedness $(\alpha=$ .75). We broadly predicted that LWA would be positively related to personality pathology, and, more specifically, predicted that LWA would manifest especially large relations with self-centered impulsivity and coldheartedness.

Need for Cognitive Closure. Participants completed the short version of the Need for Closure Scale-Revised (NFC; Roets \& Van Hiel, 2011), a 15-item ( $\alpha=$ 
.88) self-report measure of aversion to ambiguity and preference for concrete information, ostensible features of authoritarianism in general. Given the overlap between cognitive rigidity and authoritarianism, we expected that need for closure would be positively related to LWA.

Conspiracist Ideation. Recent literature suggests relatively complex relations between authoritarianism and belief in conspiracy theories (e.g., Grzesiak-Feldman, 2015). Nevertheless, conspiracist ideation has long been considered a component of the authoritarian personality (e.g., the F Scale includes the following item: "Most people don't realize how much our lives are controlled by plots hatched in secret places"; Adorno et al., 1950). Hence, we administered two selfreport measures of conspiratorial thinking: The $\mathrm{Ge}$ neric Conspiracist Beliefs Scale (GCBS; Brotherton et al., 2013) and Vaccine Conspiracy Theories Scale (VCBS; Shapiro et al., 2016). The GCBS is a 15-item $(\alpha=.96)$ self-report measure of beliefs in general conspiracy theories that yields a total score in addition to five factor scores. We used the GCBS total score in all analyses. The VCBS is a 7-item $(\alpha=.95)$ self-report measure of belief in vaccine-related conspiracy theories. We predicted that LWA would be positively related to conspiracist ideation.

Belief in Determinism. Scholarly recognition of potential links between deterministic beliefs and authoritarian attitudes can be traced to the origins of modern social science (Fromm, 1941), and recent evidence (Costello, Bowes, \& Lilienfeld, 2020) suggests that RWA and SDO are correlated with beliefs that actions and events are attributable to (1) "destiny" or "fate" (i.e., fatalistic determinism) and (2) material causes outside of the self (i.e., scientific determinism). Hence, we assessed philosophical beliefs in determinism using the Free Will and Determinism Plus (FAD+; Paulhus \& Carey, 2011), a 27-item self-report instrument $(1=$ totally disagree to $5=$ totally agree $)$ that measures lay beliefs in scientific $(\alpha=.69)$ and fatalistic $(\alpha=.87)$ determinism, among other dimensions of philosophical beliefs.

Sample 2. As in Sample 1, participants completed the RWA Scale $(\alpha=.92)$, the DOG Scale $(\alpha=.94)$, the revised Need for Closure Scale $(\alpha=.88)$, and the HEXACO ( $\alpha$ s ranged from .79 to .87). In addition, we administered measures of affective polarization, intellectual humility, belief certainty, general intelligence, confirmatory thinking, cognitive reflectivity, belief in conspiracy theories, and political ideology.
Political Ideology. Across three items, participants indicated the degree to which they symbolically identified as liberal or conservative in the economic domain, the social domain, and in general. Likert-type items with 7 response options were used.

Affective Polarization. Participants completed feeling thermometers for members of the opposite party (e.g., Abramowitz \& Webster, 2016) and also provided ratings for how upset, angry, and disgusted they would feel if a close family member married a member of the opposite party. The two composites were highly correlated $(r=.61)$ and were therefore combined. We expected that LWA would be positively correlated with affective polarization.

Intellectual Humility. Participants completed the Comprehensive Intellectual Humility Scale (CIHS; Krumrei-Mancuso \& Rouse, 2016), a 22-item self-report scale that measures four intercorrelated but separable dimensions of IH ( $\alpha$ s from .73 to .89) and an interpretable total score. Although consensus has yet to be reached concerning the precise definition of intellectual humility, it is often conceptualized as a meta-cognitive disposition marked by the recognition that one's beliefs may be fallible, accompanied by an appropriate attentiveness to limitations in the evidentiary basis for one's beliefs (Leary et al., 2017). We therefore expected that intellectual humility would be negatively related to authoritarianism.

Conspiracist Ideation. The Belief in Conspiracy Theories Inventory (BCTI; Swami et al., 2010) was administered, a 15-item $(\alpha=.94)$ self-report inventory of belief in specific conspiracy theories.

General Intelligence. Participants completed the International Cognitive Abilities Resource (ICAR; Condon \& Revelle, 2014), a well-validated public domain measure of general cognitive ability. Given the modest negative correlations between both RWA and SDO, on the one hand, and cognitive ability, on the other (e.g., Choma \& Hanoch, 2017), we predicted that LWA would modestly negatively predict cognitive ability.

Confirmatory Thinking. A modified version of the Confirmation Inventory (CI; Rassin, 2008), with several items added and others rewritten in simpler English, was administered to assess individual differences in confirmation bias, i.e., the tendency to prioritize information that confirms one's previously held beliefs over information that disconfirms them. We predicted that LWA would be positively correlated with confirmatory thinking.

Cognitive Reflectivity. Participants completed the revised version (CRT-2; Thomson \& Oppenheimer, 
2016) of the Cognitive Reflection Task (CRT; Frederick, 2005), which is designed to detect the extent to which individuals engage in slow, analytic processing as opposed to relying on their rapid intuitions ("gut hunches"). We predicted that LWA would be negatively related to the CRT, as RWA is related to low cognitive sophistication (Choma et al., 2019).

Sample 3. Given the nature of the YourMorals.org platform, most participants completed measures other than the LWA Index, allowing us to examine relations between the LWA Index and various external criteria (i.e., social and economic political ideology, general personality traits, disgust sensitivity, RWA, intolerance of ambiguity, and dogmatism). Nevertheless, because participants freely select which measures to complete, sample sizes varied considerably across external criteria, limiting our ability to employ Westen and Rosenthal's (2003) construct validity metrics. In light of the substantial number of external criteria already assessed in the current manuscript, methods and results for Sample 3 are presented in Tables S7 and S8.

Sample 4. As in previous samples, participants completed the HEXACO ( $\alpha$ s from .80 to .90 ), the DOG Scale $(\alpha=.85)$, and a single-item measure of left vs. right political ideology. We also assessed dogmatism via a modified version of Rokeach's (1960) Dogmatism (D) Scale. To more comprehensively assess left vs. right ideological preferences, we used interactive political compasses designed for this study. Further, participants completed measures of objectivism, social vigilantism, and belief in certain knowledge.

Political Compasses. Given the online nature of our survey administration, we sought to measure political attitudes with improved ecological validity. To that end, participants viewed two empty graphs, with the poles of each $\mathrm{x}$-axis labeled with opposing political beliefs and the poles of each y-axis labeled with a second set of opposing beliefs. Participants were instructed to place themselves within each graph by moving their mouse to the position that best represents their political ideology. We ventured that the resulting coordinate data could be decomposed (i.e., a continuous variable for placement on the y-axis and another for the $\mathrm{x}$-axis) and would be useful as a measure of differing elements of political ideology. The first political compass assessed preferences for traditionalist vs. progressive moral values (i.e., social ideology; y-axis) and preferences for high vs. low governmental involvement in the economy (i.e., economic ideology; $x$-axis). The second political compass assessed preferences for a political system with substantial centralized state control vs. one that maximizes personal and political freedom and autonomy (y-axis) and symbolic identity (x-axis), with the former variable being a proxy for authoritarianism.

Dogmatism. In addition to the DOG Scale, we constructed a semi-original measure of value-neutral dogmatism, adopting or slightly altering the wording of 8 items from Rokeach's D Scale and adding 10 original items with good face validity for Rokeach's conceptualization of dogmatism as generalized authoritarianism $(\alpha=.80$; see Table S15 for items and factor loadings). Across Samples 4 and 5, this modified D-Scale manifested large correlations with the DOG Scale $(r=.63)$, RWA $(r=.41)$, intellectual humility $(r=-.44)$, epistemic certainty $(r=.55)$, and many other relevant variables, suggesting promising convergent and discriminant validity.

Objectivism. To assess tendencies to rely on empirical information and rational considerations when making decisions, we administered the 11-item Objectivism Scale (Leary et al., 1986; $\alpha=.83$ ). Given our evaluations of LWA's relations with cognitive rigidity, we also wished to assess the degree to which LWA is associated with basing one's judgements and beliefs, however rigid, upon data and facts. We expected that LWA is negatively associated with objectivism.

Social Vigilantism. We assess social vigilantism, an individual difference variable describing the tendency to propagate one's own, ostensibly superior, beliefs onto more "ignorant" others. To do so, we administered the 14-item Social Vigilantism Scale (Saucier \& Webster, 2010; $\alpha=.86$ ). We predicted that LWA is positively correlated with social vigilantism.

Belief in Certain Knowledge. We administered the Epistemic Beliefs Inventory's Certain Knowledge subscale (5-items; $\alpha=.62$; Schraw et al., 2002), which describes one's conviction that absolute knowledge exists (vs. knowledge changing over time). We predicted that LWA would be positively correlated with belief in certain knowledge.

Sample 5. External criteria in Sample 5 were intended primarily to capture political behavior and extreme partisanship (Kalmoe \& Mason, 2018). As such, we assessed moral disengagement, political violence, free speech suppression, and partisan schadenfreude. We also administered the modified D Scale $(\alpha=.82)$, the RWA Scale $(\alpha=.96)$, the $\mathrm{SDO}_{7}(\alpha=.91)$, Leary et al.'s (2017) 6-item measure of intellectual humility ( $\alpha$ $=.88$ ), and the two political compasses. Further, we administered a modified version of Altemeyer's Belief in a Dangerous World Scale, as well as the short version of Schwartz's Values Survey (SVSS; Lindeman \& Verkasalo, 2005). 
Extreme Partisanship. Items to assess partisan moral disengagement (5-items, $\alpha=.88$ ), partisan violence (4-items, $\alpha=.88$ ), and partisan schadenfreude (3items, $\alpha=.86)$ were adapted from Kalmoe and Mason (2018); for purposes of clarity and to avoid double-barreled items, a number of the items were modified from their original wording. Differences across the left and right on these variables were not statistically significant. We predicted that all three types of extreme/lethal partisanship would be positively related to LWA.

Free Speech Suppression. To provide a situationally specific example of authoritarian behavior, we administered left- and right-wing versions of a vignette concerning government enforcement of speech limitations. Participants were provided with the following prompt: "There are always some people whose ideas are considered violent or dangerous by other people. For instance, think about [a superpatriot militia type/a communist]. If such a person wanted to make a speech in your community arguing that [we should do away with the federal government and have local civilian militia run the country/we should do away with the capitalist system and have the government run the economy], should he be banned by the government from making a speech?" Response options ranged from 1 (Definitely not) to 4 (Definitely yes); $\mathrm{M}_{\mathrm{Left}}=2.95, \mathrm{SD}=$ .86 and $\left.\mathrm{M}_{\text {Right }}=2.97, \mathrm{SD}=.97\right)$.

Belief in a Dangerous World. Altemeyer's (1988) Belief in a Dangerous World Scale was modified to remove double-barreled items and, in the case of one item, to balance potentially partisan content. We administered 13-items (e.g., $\alpha=.88$ ). As belief in a dangerous world is conceptually related to authoritarianism (see Duckitt \& Sibley, 2007), we predicted that LWA would be correlated with belief in a dangerous world.

Worldviews. The SVSS is a 10-item measure of 10 motivationally distinct values related to human needs. Of these, we judged Power (social power, authority, and wealth), reverse Self-direction (creativity, freedom, curiosity, independence, choosing one's own goals), and Conformity (obedience, honoring parents and elders, self-discipline, politeness) to be most relevant to authoritarianism. We predicted that these SVSS values would be positively related to LWA, with the caveat that Power and Conformity items may be biased by right-wing content.

\section{Construct Validity Analyses and Results}

Properties of the 3-Factor Solution in Samples 1 and 2. Given that the final pool of items was administered only to Samples 4 and 5, for Samples 1, 2, and 3, we reconstructed Version 3 of the LWA Index using the items from each factor that were available. To demonstrate that sufficient test information was provided by these quasi-short forms, we used the graded response model to fit item responses. As an additional step, we estimated confirmatory ESEM models in Samples 1,2 , and 3 to evaluate model fit in the short versions. We also used Samples 4 and 5 to calculate correlations between the items comprising the short versions and the full scales. These results are presented in Online Supplemental Materials. Factor scores of the short forms from the ESEM models were used to assess relations with external criteria in Samples 1, 2, and 3, and factor scores of the full scale ESEM models were used in Samples 4 and 5.

Political Ideology and the LWA Index. We first examined the predictive validity of the LWA Index for political ideology. LWA Index total scores were strongly positively correlated with left-wing symbolic ideology ( $r$ s ranged from .46 to .57 ), left-wing social ideology ( $r$ s from .33 to .42 ), and left-wing economic ideology ( $r$ s from .46 to .60). Across samples, correlations between Anti-hierarchical Aggression, on the one hand, and left-wing economic and social ideology, on the other, ranged from .41 to .48 and from .30 to .36 , respectively; correlations between Anti-conventionalism and left-wing economic and social ideology ranged from .55 to .60 and 50 to .59 , respectively; and correlations between Top-down Censorship and left-wing economic and social ideology ranged from .26 to .32 and .12 to .23 , respectively ${ }^{13}$.

Convergent and Discriminant Validity. Figures 1 - 6 illustrate the broad pattern of correlational results. Specifically, Figures $1-4$ illustrate LWA's relations with personality traits (Figure 1), cognitive variables (Figure 2), political variables (Figure 3), and beliefs and worldviews (Figure 4). Alongside these relations, we plot relations between an authoritarianism composite variable, on the one hand, and the same external criteria, on the other. This composite variable reflects the average of (1) RWA's correlations with external criteria, (2) SDO's correlations with external criteria,

\footnotetext{
${ }^{13}$ Party-level results are presented in Online Supplemental Materials.
} 
and (3) our hypothesized profile of correlations ${ }^{14}$. Further, Figure 5 directly compares LWA with RWA and Figure 6 directly compares LWA with SDO. Supplemental Figures S1 - S21 visualize the differences and similarities between LWA and predictions/RWA/SDO in greater detail.

Relations between the LWA Index total scores and external criteria were extremely similar to our hypothesized profile of relations both before $\left(r_{\text {alerting- } C V}\right.$ ranged from .65 to .91 , median $=.81 ; r_{\text {contrast }-C V}$ from .37 to .64 , median $=.58 ; p \mathrm{~s}<.001)$ and after $\left(r_{\text {alerting- } C V}\right.$ ranged from .83 to .96 , median $=.91 ; r_{\text {contrast }-C V}$ from .61 to .75 , median $=.69 ; p \mathrm{~s}<.001)$ controlling for left vs. right political identification. Moreover, results were similar after controlling for social ideology $\left(r_{\text {alerting- } \mathrm{CV}}\right.$ ranged from .78 to $.95 ; r_{\text {contrast }-C V}$ from .61 to $\left..72, p \mathrm{~s}<.001\right)$ and economic ideology $\left(r_{\text {alerting- } C V}\right.$ ranged from .86 to .93; $r_{\text {contrast }-C V}$ from .54 to $\left..69, p \mathrm{~s}<.001\right)$.

Results when either RWA's relations with external criteria were used in place of the predicted values $\left(r_{\text {alert }}\right.$ ${ }_{\text {ing-CV }}$ from .08 to .26 , median $=.13 ; r_{\text {contrast }-C V}$ from .07 to .19 , median $=.07, p s$ from .06 to $<.01$ ) or SDO's relations with external criteria were used in place of the predicted values (Sample 1: $r_{\text {alerting- } C V}=.45, r_{\text {contrast }-C V}=$ $.33, p<.001$; Sample 5: $r_{\text {alerting- } C V}=.18, r_{\text {contrast }-C V}=.15$, $p<.001)$ were more mixed before controlling for political ideology. After controlling for left-right symbolic ideology, an extremely similar pattern of correlations was again obtained for both RWA ( $r_{\text {alerting- } C V}$ from .79 to .81 , median $=.79 ; r_{\text {contrast }-C V}$ from .57 to .65 , median $=.63, p s<.001)$ and SDO (Sample 1: $r_{\text {alerting }-C V}=.65$, $r_{\text {contrast }-C V}=.54, p<.001$; Sample 5: $r_{\text {alerting- } C V}=.84, r_{\text {con- }}$ $\left.{ }_{\text {trast }-C V}=.68, p<.001\right)$, with these results proving robust across social ideology $\left(r_{\text {alerting- } C V}\right.$ from .52 to $.77 ; r_{\text {contrast- }}$ ${ }_{C V}$ from .44 to $\left..58, p \mathrm{~s}<.001\right)$ and economic ideology ( $r_{\text {alerting-CV }}$ from .66 to $.81 ; r_{\text {contrast }-\mathrm{CV}}$ from .45 to $.62, p \mathrm{~s}$ $<.001)$.

LWA and RWA (see Figure S3 and Figure 5) demonstrated virtually identical relations with numerous variables, especially after controlling for political ideology (e.g., partial $r$ s within .10 for belief in a dangerous world, extraversion, need for closure, coldheartedness, cognitive reflectivity, fatalistic determinism, conspiracy beliefs, power motives, honesty-humility, affective polarization, agreeableness, conscientiousness, fearless dominance, disinhibition, cognitive ability, and antagonism) but differed markedly in their re-

\footnotetext{
${ }^{14}$ We note that the average correlation between RWA's pattern of relations and SDO's pattern of relations was $r_{\text {alerting- } C V}=.84$, the average correlation for RWA and our hypothesized point estimates was $r_{\text {alerting- } C V}=.77$, and the average correlation for SDO and our
}

lations with other variables (e.g., belief in science, valuing conformity, openness, confirmatory thinking, free speech suppression, scientific determinism). Similarly, LWA and SDO (see Figure S4 and Figure 6) were highly similar (i.e., partial $r$ s within .10) in their relations with detachment, conspiracy beliefs, intellectual humility, conformity motives, extraversion, dogmatism, power motives, openness, agreeableness, self-direction motives, disinhibition, psychoticism, and partisan violence, but differed in their relations with belief in science, state control preferences, political intolerance, need for closure, belief in a dangerous world, opposition to free speech, conformity motives, emotionality, and openness. Thus, with several notable exceptions, RWA and SDO's nomological networks provided an accurate portrayal of the LWA Index's obtained nomological network.

Factor 1: Anti-hierarchical Aggression. As shown in Table 7 and Tables S11 to S14, Anti-hierarchical Aggression demonstrated considerable similarity to prediction in its pattern of relations with external criteria both before and after controlling for political ideology. Anti-hierarchical Aggression's nomological network tended to be more similar to SDO's nomological network than it was to RWA's nomological network, suggesting that the factor preferentially captures authoritarian dominance.

In the personality domain, Anti-hierarchical Aggression was marked by low agreeableness, low honesty-humility, and low conscientiousness. Further, concerning cognitive styles, Anti-hierarchical Aggression was most strongly associated with dogmatism and low intellectual humility. Concerning beliefs/worldviews, Anti-hierarchical Aggression was moderately correlated with conspiracist ideation, support for state control, and belief in a dangerous world. After controlling for ideology, Anti-hierarchical Aggression's profile of relations became more pronounced. For instance, $r \mathrm{~s}>$ .30 for Moral Disengagement, Partisan Violence, Partisan Schadenfreude, the D Scale, the DOG Scale, Political Intolerance, low Intellectual Humility, Social Vigilantism, Affective Polarization, Free Speech Suppression, and Self-centered Impulsivity.

Factor 2: Anti-conventionalism. Construct validity analyses were somewhat different for LWA Anticonventionalism (see Table 7 and Tables S11 to S14), especially before controlling for political ideology, such that Anti-conventionalism's nomological net

hypothesized point estimates was $r_{\text {alerting- } C V}=.75$. Nevertheless, the composite was not employed in any of our analyses and is used in Figures $1-4$ for illustrative purposes. 


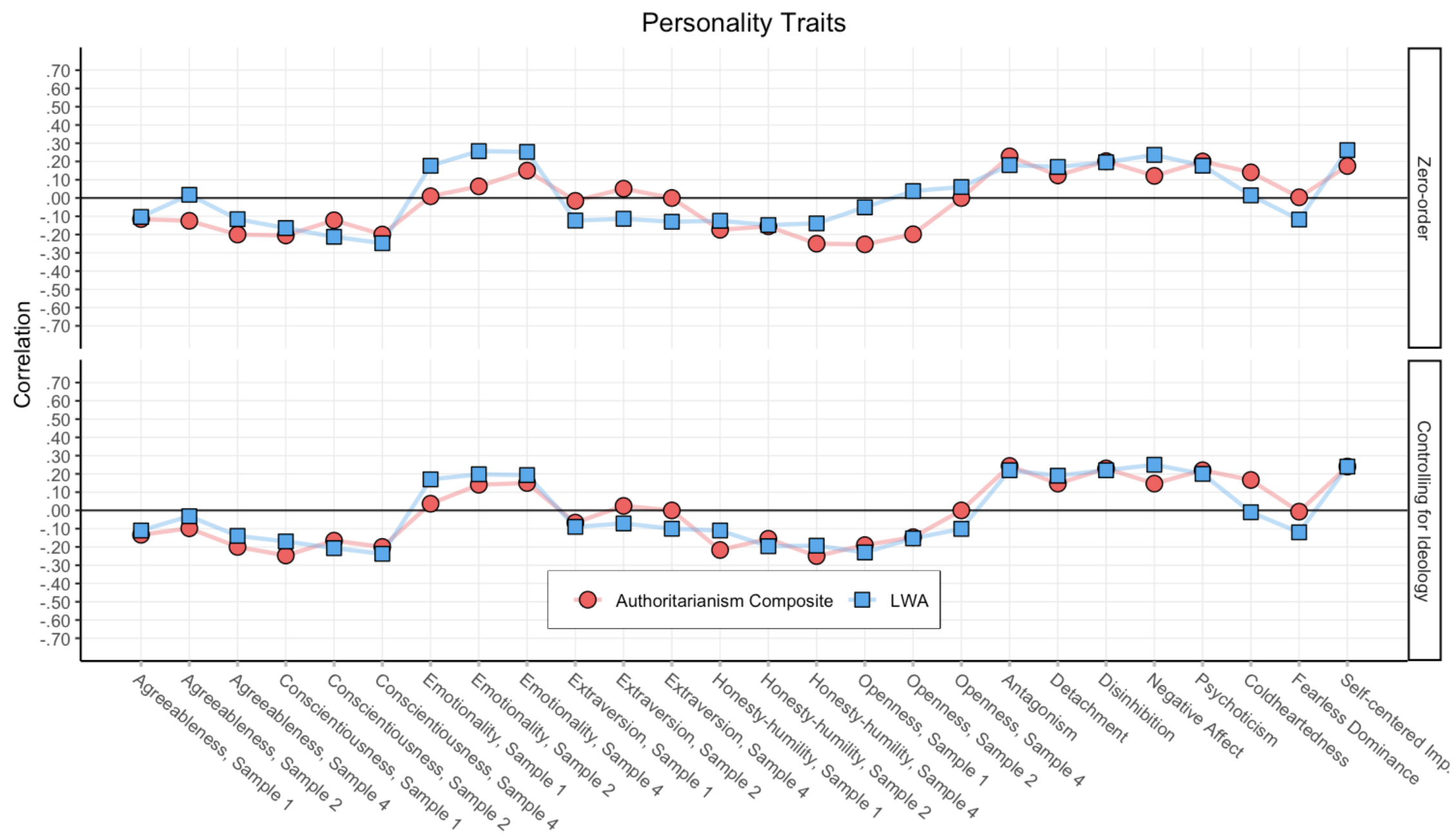

Figure 1. Point estimates of the LWA Index's relations with personality traits across samples 1-5, compared with authoritarianism's projected nomological network (i.e., operationalized as the average of RWA's relations with external criteria, SDO's relations with external criteria, and our predictions). 


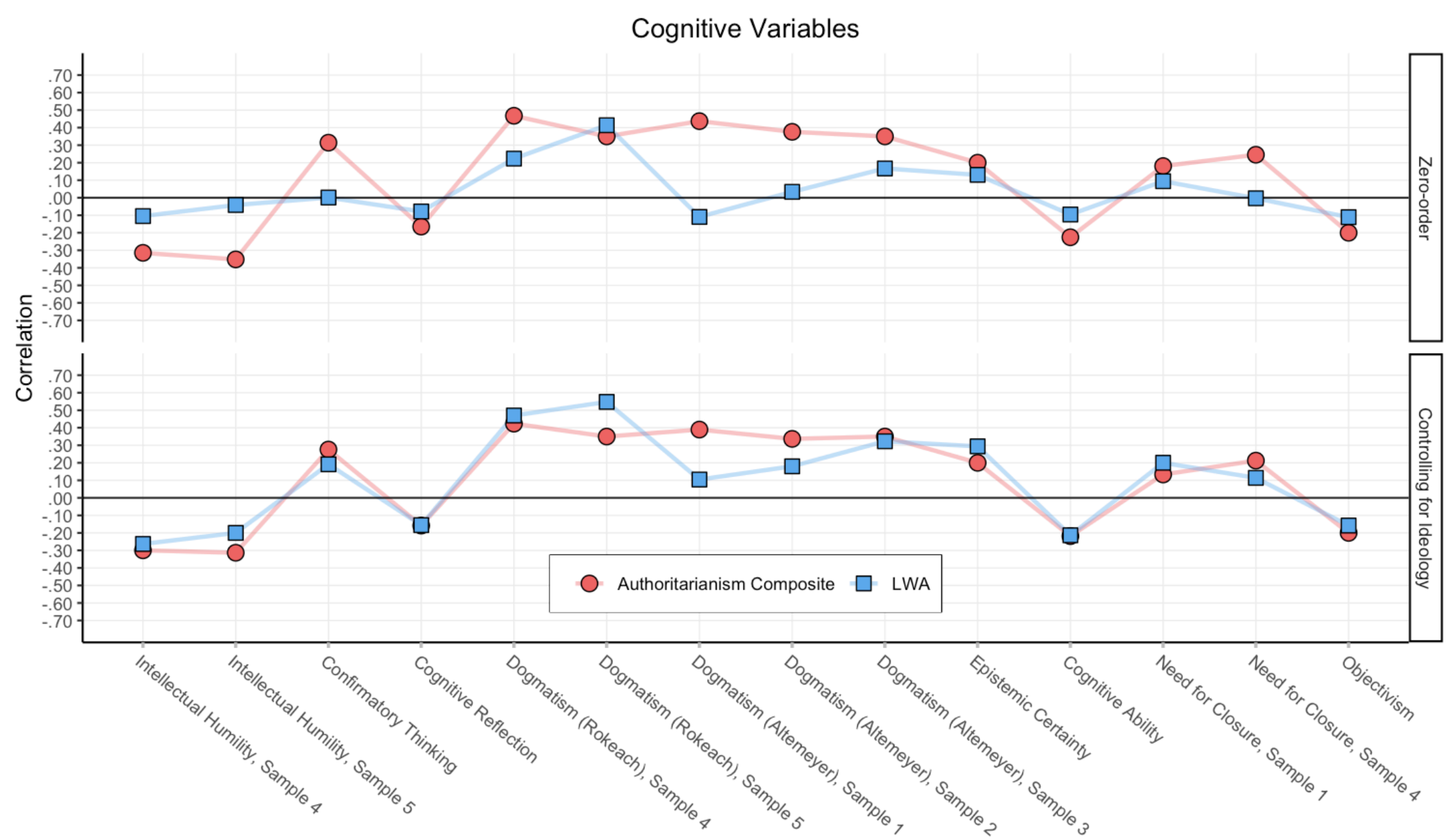

Figure 2. Point estimates of the LWA Index's relations with cognitive variables across samples 1-5, compared with authoritarianism's projected nomological network (i.e., operationalized as the average of RWA's relations with external criteria, SDO's relations with external criteria, and our predictions). 


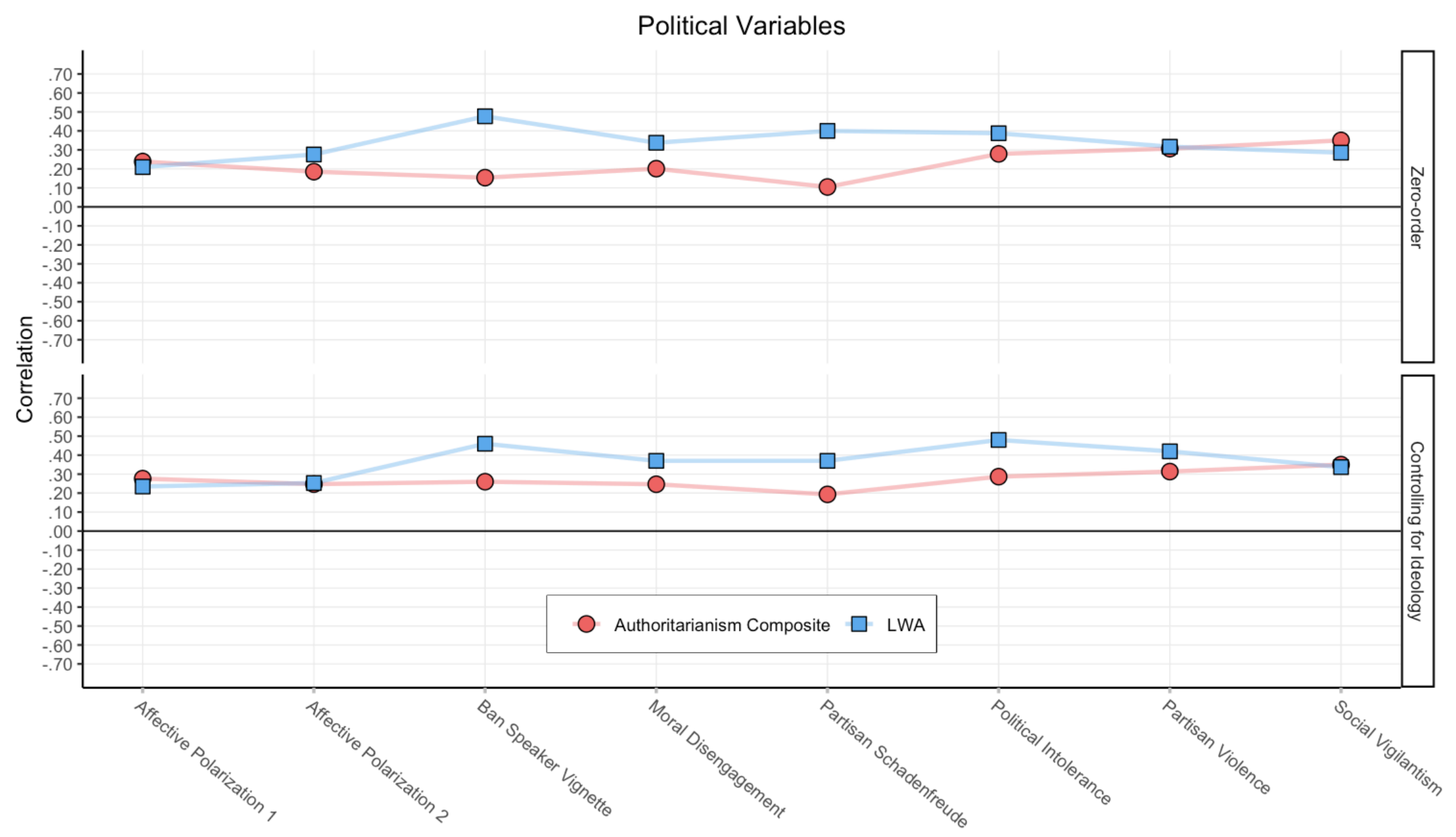

Figure 3. Point estimates of the LWA Index's relations with political variables across samples 1-5, compared with authoritarianism's projected nomological network (i.e., operationalized as the average of RWA's relations with external criteria, SDO's relations with external criteria, and our predictions). 


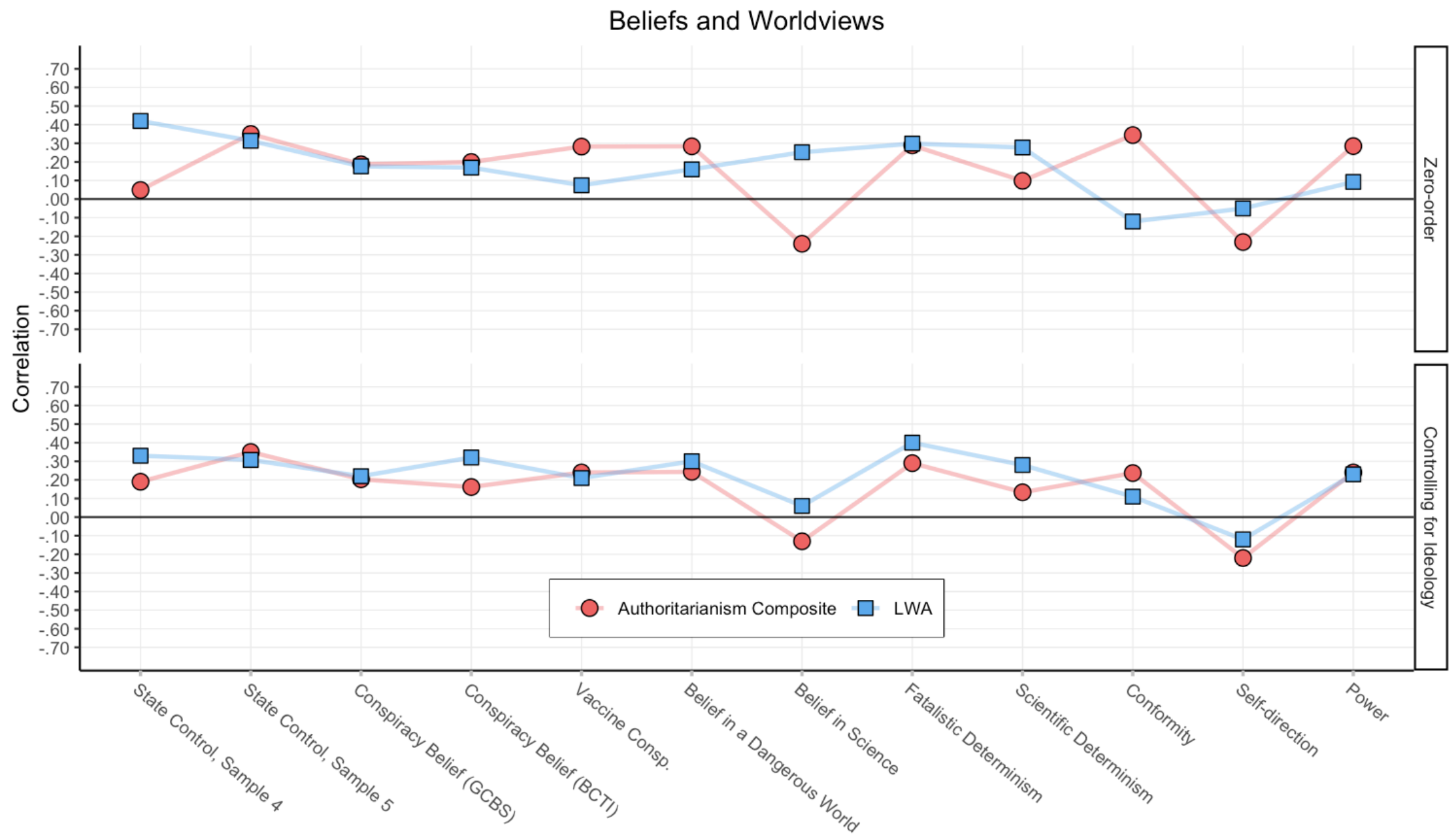

Figure 4. Point estimates of the LWA Index's relations with beliefs and worldviews across samples 1-5, compared with authoritarianism's projected nomological network (i.e., operationalized as the average of RWA's relations with external criteria, SDO's relations with external criteria, and our predictions). 


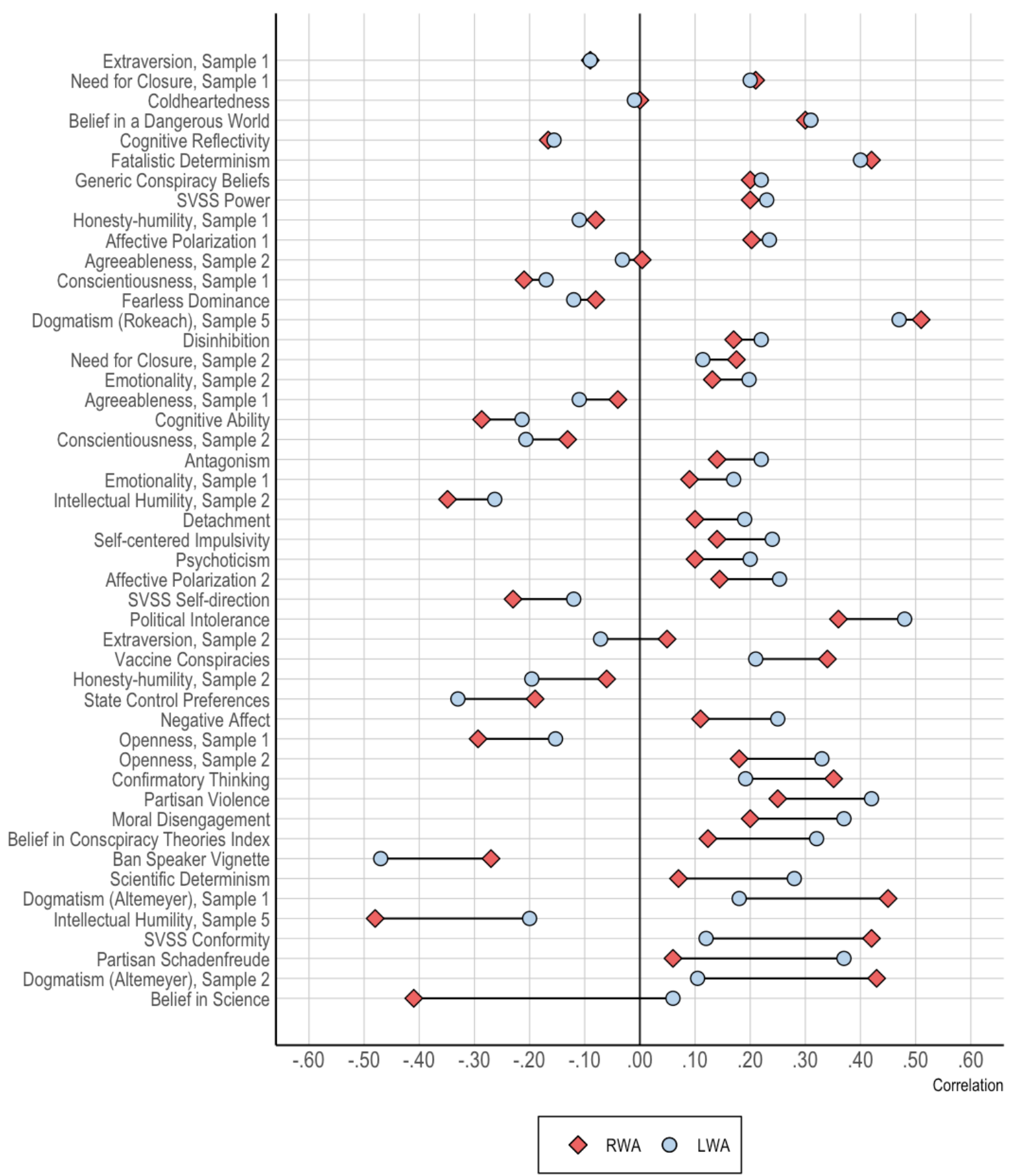

Figure 5. Point estimates of the LWA Index's partial correlations (controlling for symbolic ideology) with external criteria across Samples 1-5, compared with RWA's partial correlations across Samples 15. 


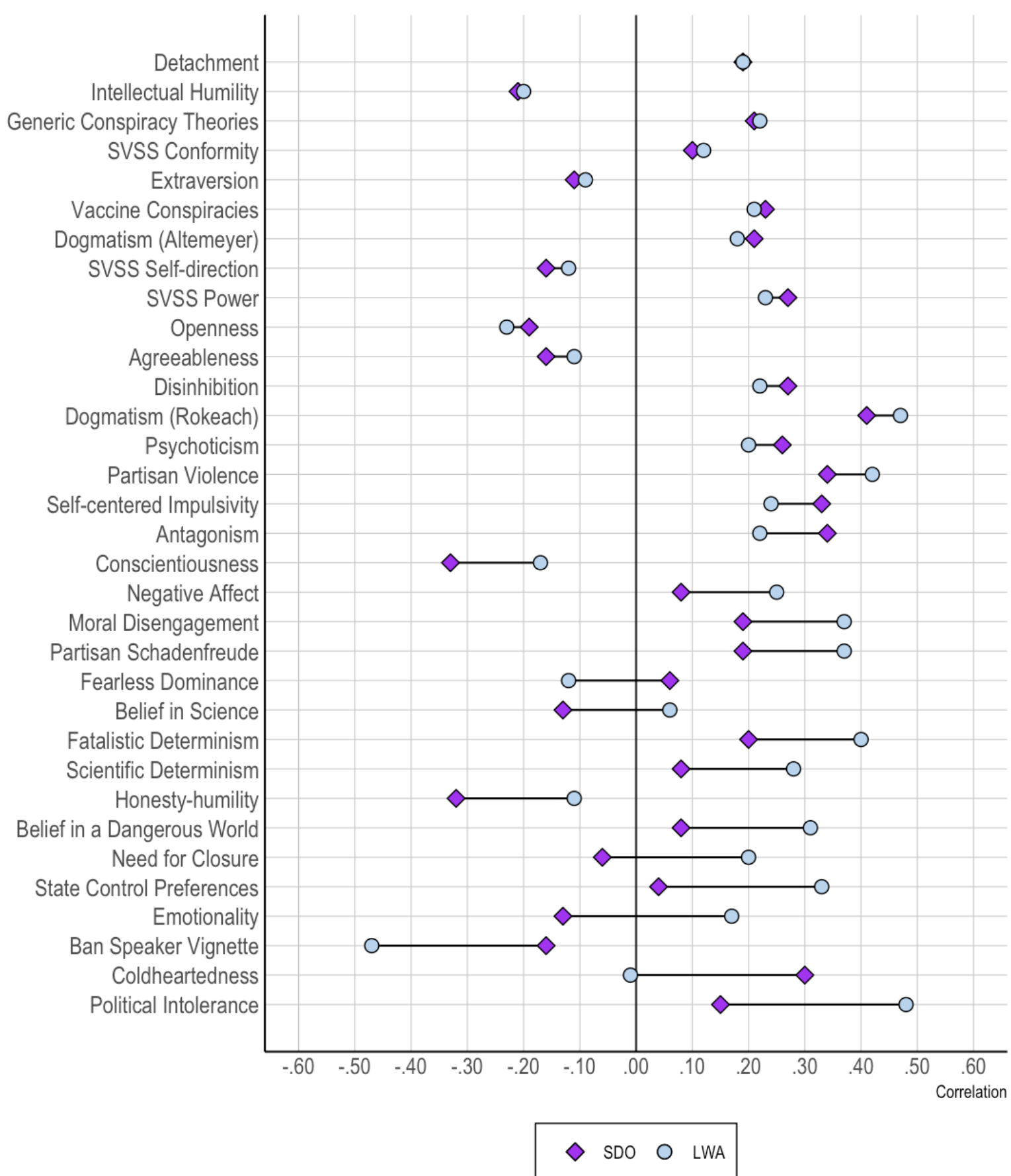

Figure 6. Point estimates of the LWA Index's partial correlations with external criteria (controlling for symbolic ideology) across Samples 1-5, compared with SDO's partial correlations across Samples 1-5. 
was frequently negatively correlated with RWA's nomological net. Still, after controlling for political ideology, Anti-conventionalism demonstrated a high degree of similarity to both the predicted nomological nets and RWA's and SDO's nomological nets, suggesting that Anti-conventionalism is a marker of authoritarianism.

Personality correlates of Anti-conventionalism varied from sample to sample, but for the final version of the LWA Index they were emotionality, low extraversion, and openness. Anti-conventionalism did not appear to be associated with rigid cognitive style before controlling for ideology, after which Anti-conventionalism manifested large positive correlations with dogmatism and other rigidity indicators. Anti-conventionalism was a strong predictor of political behavior/extreme partisanship, demonstrating associations with Moral Disengagement, Partisan Violence, Free Speech Suppression, Partisan Schadenfreude, Social Vigilantism, and Political Intolerance, with these relations being especially pronounced after controlling for ideology.

Factor 3: Top-down Censorship. LWA Top-down Censorship was quite similar to the predicted nomological net and, to a slightly lesser extent, also similar to RWA's and SDO's nomological nets. Further, after controlling for political ideology, clear similarity with RWA was demonstrated, suggesting that individuals high in either Top-down Censorship or RWA evince much the same profile of psychological differences relative to the norms for their political affiliation. In contrast to Anti-hierarchical Aggression, Top-down Censorship was more similar to RWA than SDO in this regard, suggesting that Top-down Censorship preferentially reflects authoritarian submission.

Personality markers of Top-down Censorship were Emotionality, low Conscientiousness, and low Openness. Concerning cognitive style, Top-down Censorship manifested significant relations with the DOG Scale, Epistemic Certainty, Confirmatory Thinking, Need for Closure, and low Cognitive Reflectivity. Topdown Censorship was also a strong predictor of political behavior/lethal partisanship, manifesting relations with Moral Disengagement, Partisan Violence, Free Speech Suppression, Partisan Schadenfreude, and Social Vigilantism. With the exception of Free Speech Suppression, however, these relations were generally smaller than those for Anti-hierarchical Aggression and Anti-conventionalism. On the belief/worldview front, Top-down Censorship was associated with Belief in a Dangerous World and Belief in Conspiracy Theories. After controlling for ideology, Top-down Censorship predicted Free Speech Suppression, Political Intolerance, Moral Disengagement, the D Scale, the DOG Scale, State Control Preferences, Belief in a Dangerous World, HEXACO Emotionality, and Need for Closure with $r \mathrm{~s}>.30$.

\section{Phase 4 Discussion}

Our systematic test of the LWA Index's nomological validity provided clear support for both LWA's existence and its utility as a psychological construct. Our construct validational analyses revealed stark symmetries between both RWA and SDO, on the one hand, and LWA, on the other. These results were robust across samples and psychological domains, spanning personality traits, cognitive variables, political variables, and beliefs and worldviews. Moreover, the LWA Index's three dimensions manifested divergent patterns of results with external criteria, suggesting promising discrimination across dimensions. By the same token, several clear differences between left- and right-wing authoritarianism also emerged, highlighting promising avenues for future research.

Nevertheless, to this point, our findings do not extend beyond self-report measures. When the same measurement methods are used across measures, irrelevant variance is often introduced, which can lead to an overestimation of relations among constructs (Campbell \& Fiske, 1959). Moreover, none of our samples could be said to closely approximate the population we intend to explain (i.e., the United States). In subsequent phases, we extend our tests of validity to a behavioral paradigm (Phase 5) and nationally representative sample (Phase 6), seeking to address these important limitations.

\section{Phase 5: Behavioral Aggression}

In Phase 5, we sought to evaluate relations between LWA Index, the RWA Scale, and the $\mathrm{SDO}_{7}$, on the one hand, and a behavioral measure of out-group aggression, on the other. Given the centrality of punitiveness and threat sensitivity in most conceptualizations of authoritarianism, behavioral aggression towards threatening members of the opposite party were expected to be closely tied to authoritarianism, even above and beyond political affiliation (e.g., Stenner, 2005). 
Table 7. Quantifying the Construct Validity of the LWA Index.

\begin{tabular}{|c|c|c|c|c|c|c|c|c|c|c|c|c|}
\hline & \multicolumn{3}{|c|}{ Sample 1 (Scale Version 1) } & \multicolumn{3}{|c|}{ Sample 2 (Scale Version 2) } & \multicolumn{3}{|c|}{ Sample 4 (Scale Version 3) } & \multicolumn{3}{|c|}{ Sample 5 (Scale Version 3) } \\
\hline & $\mathrm{AHA}$ & $\mathrm{AC}$ & TDC & AHA & $\mathrm{AC}$ & TDC & AHA & $\mathrm{AC}$ & $\mathrm{TDC}$ & AHA & $\mathrm{AC}$ & TDC \\
\hline & $\begin{array}{c}r_{\text {alerting }} / \\
r_{\text {contrast }}\end{array}$ & $\begin{array}{c}r_{\text {alerting }} / \\
r_{\text {contrast }}\end{array}$ & $\begin{array}{c}r_{\text {alerting }} / \\
r_{\text {contrast }}\end{array}$ & $\begin{array}{c}r_{\text {alerting }} / \\
r_{\text {contrast }}\end{array}$ & $\begin{array}{c}r_{\text {alerting }} / \\
r_{\text {contrast }}\end{array}$ & $\begin{array}{c}r_{\text {alerting }} / \\
r_{\text {contrast }}\end{array}$ & $\begin{array}{c}r_{\text {alerting }} / \\
r_{\text {contrast }}\end{array}$ & $\begin{array}{c}r_{\text {alerting }} / \\
r_{\text {contrast }}\end{array}$ & $\begin{array}{c}r_{\text {alerting }} / \\
r_{\text {contrast }}\end{array}$ & $\begin{array}{c}r_{\text {alerting }} / \\
r_{\text {contrast }}\end{array}$ & $\begin{array}{c}r_{\text {alerting }} / \\
r_{\text {contrast }}\end{array}$ & $\begin{array}{c}r_{\text {alerting }} \\
r_{\text {contrast }}\end{array}$ \\
\hline & \multicolumn{12}{|c|}{$\underline{\text { Zero-order Correlations }}$} \\
\hline Predictions & $.79 / .56$ & $.71 / .47$ & $.49 / .37$ & $.80 / .52$ & $.06 / .03$ & $.65 / .37$ & $.90 / .68$ & $.64 / .33$ & $.89 / .51$ & $.88 / .72$ & $.55 / .44$ & $.81 / .53$ \\
\hline RWA Scale & $.17 / .13$ & $-.15 /-.11$ & $.58 / .44$ & $.35 / .25$ & $-.61 /-.34$ & $.51 / .29$ & - & - & - & $.26 / .25$ & $-.30 /-.25$ & $.27 / .19$ \\
\hline SDO Dominance & \multicolumn{12}{|c|}{$\underline{\text { Controlling for Left vs. Right Symbolic Ideology }}$} \\
\hline Predictions & $.85 / .64$ & $.91 / .60$ & $.48 / .40$ & $.89 / .66$ & $.79 / .34$ & $.72 / .48$ & $.91 / .79$ & $.89 / .50$ & $.88 / .55$ & $.93 / .78$ & $.87 / .61$ & $.88 / .58$ \\
\hline RWA Scale & $.70 / .55$ & $.61 / .42$ & $.73 / .57$ & $.77 / .59$ & $.45 / .20$ & $.85 / .55$ & - & - & - & $.78 / .70$ & $.57 / .43$ & $.84 / .56$ \\
\hline SDO Dominance & $.86 / .65$ & $.79 / .53$ & $.17 / .15$ & - & ${ }^{-}$Cont & Controlling for Social Political Ideology & $\begin{array}{c}- \\
\text { al Political }\end{array}$ & $\begin{array}{c}- \\
\text { eology }\end{array}$ & - & $.90 / .77$ & $.77 / .55$ & $.65 / .45$ \\
\hline Predictions & $.82 / .64$ & $.87 / .57$ & $.50 / .38$ & - & - & - & $.91 / .77$ & $.86 / .46$ & $.89 / .53$ & $.94 / .77$ & $.86 / .61$ & $.86 / .55$ \\
\hline RWA Scale & $.81 / .64$ & $.68 / .46$ & $.48 / .37$ & - & - & - & - & - & - & $.75 / .68$ & $.50 / .39$ & $.67 / .45$ \\
\hline SDO Dominance & $.76 / .60$ & $.63 / .43$ & $.09 / .07$ & - & - & - & - & - & - & $.79 / .70$ & $.56 / .43$ & $.46 / .32$ \\
\hline & \multicolumn{12}{|c|}{ Controlling for Economic Political Ideology } \\
\hline Predictions & $.83 / .62$ & $.85 / .54$ & $.48 / .39$ & - & - & - & $.89 / .77$ & $.83 / .43$ & $.86 / .55$ & $.91 / .75$ & $.71 / .47$ & $.86 / .52$ \\
\hline RWA Scale & $.48 / .39$ & $.23 / .16$ & $.78 / .60$ & - & - & - & - & - & - & $.70 / .63$ & $.24 / .17$ & $.77 / .49$ \\
\hline SDO Dominance & $.90 / .66$ & $.76 / .49$ & $.36 / .30$ & - & - & - & - & - & - & $.87 / .74$ & $.53 / .36$ & $.68 / .44$ \\
\hline
\end{tabular}

Note. Bolded correlations indicate $p<.05$. AHA $=$ Anti-hierarchical Aggression, AC = Anti-conventionalism; TDC = Top-down Censorship. RWA $=$ Right-wing Authoritarianism. SDO = Social Dominance Orientation. Analyses were conducted in $R$ using the $Q C V$ package (Furr \& Heuckeroth, 2019). 


\section{Behavioral Aggression Task}

We adapted the Tangram Help/Hurt Task (Saleem et al., 2015) to assess behavioral aggression. In the original version of the Tangram Task, participants are asked to assign 11 tangram puzzles to another participant and told the other participant will win a prize if they complete 10 of these puzzles within 10 minutes. The first participant is then provided with a pool of 30 puzzles - 10 labeled easy, 10 labeled medium, and 10 labeled hard - and asked to choose 11 of the 30, with more difficult puzzles indicating greater aggression. The task has been successfully administered both online and in-person in numerous studies (e.g., Barlett \& Anderson, 2011; Gentile et al., 2009; Van Damme et al., 2017). Meta-analytic evidence suggests that the Tangram Help/Hurt Task is correlated with trait aggression and (reversed) prosociality, and experimental evidence indicates that situational primes influence task scores (e.g., Saleem et al., 2015; Saleem et al., 2017).

We used the following procedures in our modification of the Help/Hurt task. Participants first watched a video clip that familiarized them with tangrams. Participants were informed that they would be assigning 11 tangram puzzles to a second participant who had the opportunity to win $\$ 35$ for completing all 11 tangrams in the allotted time $(10 \mathrm{~min})$. Participants were also informed that the second participant would receive no compensation for participating in the study if they failed to solve the puzzles, increasing the harm associated with choosing more difficult puzzles. Prior to choosing the puzzles, participants were randomly assigned to view 1 of 6 mocked-up political Facebook posts ( 3 pro-left-wing and 3 pro-right-wing) for $10 \mathrm{sec}-$ onds. Participants were told this post belonged to the second participant. Half were shown posts that matched their own political views and half were shown posts that conflicted with their political views. Immediately after viewing the posts, participants viewed 30 tangram puzzles of varying difficulty and were instructed to select 11 puzzles for the person behind the Facebook profile to complete. These instructions also stated that (a) on average, easy puzzles take 20 seconds to solve, medium puzzles take 60 seconds to solve, and hard puzzles take 120 seconds to solve and (b) the second participant would have 10 minutes, or 600 seconds, to complete all 11 puzzles. As a manipulation check, after choosing the puzzles, participants completed a small battery of questions assessing their motivations when assigning the puzzles, their feelings toward the second participant, and whether and to what extent they felt threatened by the values espoused in the second participant's post.
Construction and selection of the Facebook posts. Politically active Facebook groups were monitored over a period of several months as a means of curating images and content. Candidate profile images $(\mathrm{N}=10)$ were then generated using photo editing software; parallel left and right versions of each image were created (see Online Supplemental Materials), with only the political content varying across them. We recruited a sample of 830 MTurkers to evaluate the candidate images, with the aim of arriving at balanced, realistic stimuli that evoked the desired response, namely, a sense of antagonism and normative threat (Stenner, 2009). After viewing the images, these 830 participants completed (1) the Discrete Emotions Questionnaire, (2) a feeling thermometer towards the person behind the Facebook page, (3) a 4-question scale designed to assess normative threat, and (4) a 1-item assessment of whether or not participants believed the Facebook image to be real. Results are presented in Online Supplemental Materials. Three image pairs were chosen based on the degree of normative threat, fear, anxiety, and low warmth ratings they evoked in ideology-incongruent respondents, as well as on the basis of their respondent-assessed realism (which was consistently high).

\section{Analyses and Results}

Manipulation checks. In Sample 5, all three checks indicated that our manipulation was successful. For affective warmth $\left(\mathrm{M}_{\text {Ally Profile }}=53.23, \mathrm{SD}_{\text {Ally Profile }}=27.41\right.$; Mopponent Profile $=29.72$, SD $\left._{\text {Opponent Profile }}=26.95\right)$, motivation to help (low scores) vs. harm (high scores) $\left(\mathrm{M}_{\text {Ally }}\right.$ Profile $=3.32, \mathrm{SD}_{\text {Ally Profile }}=1.02 ; \mathrm{M}_{\text {Opponent Profile }}=4.10$, $\left.\mathrm{SD}_{\text {Opponent Profile }}=1.34\right)$, and normative threat $\left(\mathrm{M}_{\text {Ally Pro- }}\right.$ file. $=2.13, \mathrm{SD}_{\text {Ally Profile }}=.85 ; \mathrm{M}_{\text {Opponent Profile }}=2.82, \mathrm{SD}_{\text {Op- }}$ ponent Profile $=.75)$, effects were significant and in the expected direction ( $t \mathrm{~s}$ ranged from 7.31 to $9.70, p \mathrm{~s}<.001$, $d$ s from 0.66 to 0.87 ).

Tangram assignments. In the spirit of using easily interpretable units of measurement in psychological research (Wilkinson \& APA Task Force on Statistical Inference, 1999), we used the expected length of time that the 11 chosen puzzles required to solve (i.e., per the information we provided to participants) as a dependent variable. This score was calculated by multiplying the number of easy, medium, and hard puzzles chosen by each participant by their respective time estimates and summing the results. The lowest possible score was 260 $\mathrm{s}(4.33 \mathrm{~min})$ and the highest was $1260 \mathrm{~s}(21 \mathrm{~min})$. Across conditions, the mean score was $11.50 \mathrm{~min}$ (SD $=5.88 \mathrm{~min}$ ). As predicted, the manipulation influenced behavior as a function of whether the profiles matched 
with participants' political ideology. Participants who were shown a profile that matched their own political views selected puzzles that were significantly easier than those who were shown a profile that was incongruent with their political views $\left(\mathrm{M}_{\text {Ally Profile }}=9.66 \mathrm{~min}\right.$, $\mathrm{SD}=5.15 \mathrm{~min} ; \mathrm{M}_{\text {Opponent Profile }}=13.70 \mathrm{~min}, \mathrm{SD}=5.84$ $\min ; t=8.26, \mathrm{p}<.001, d=0.74)$.

LWA, RWA, SDO, and Behavioral Aggression. We next compared the ability of the LWA Index, the RWA Scale, and the $\mathrm{SDO}_{7}$ to account for variance in harming vs. helping behaviors towards political opponents vs. allies. More specifically, we examined the ex-

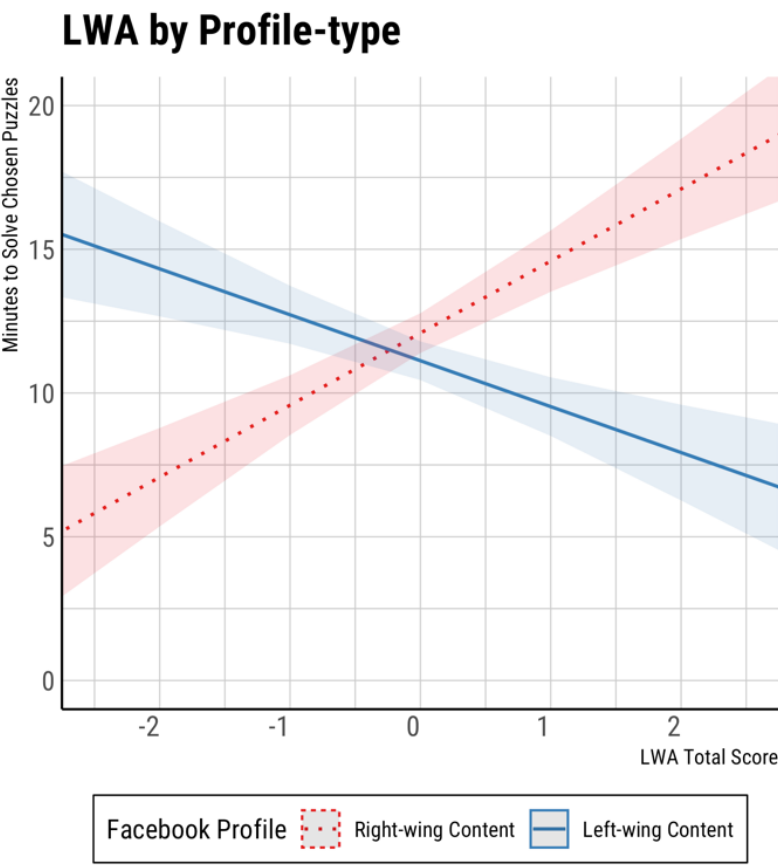

tent to which LWA, RWA, and SDO scores were associated with increased aggression in the Opponent Profile condition and increased helping in the Ally Profile condition by way of each measure's statistical interaction with a dummy coded Profile-type variable in hierarchical multiple regression analyses. LWA, RWA, and SDO were examined in separate models. Moderation analyses were conducted by entering the mean centered multiplicative interaction term into the models following main effects. Confidence intervals (95\%) were generated using 5,000 bootstrapped samples. To mitigate Type I error, only total scores on the LWA Index were used.

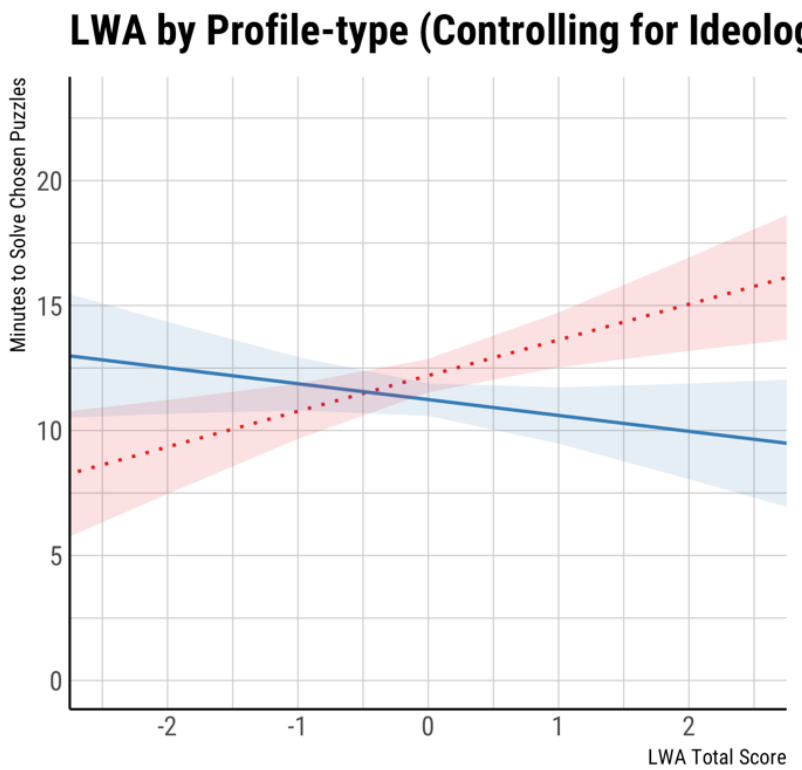

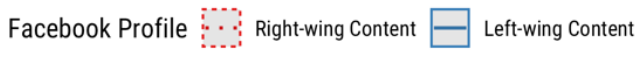

Figure 7. Predicted values for the interaction between LWA Total Scores (x axis) and Profile-content for difficulty of assigned puzzles (y axis).

As depicted in Figure 7, LWA significantly interacted with profile-type in a disordinal manner, $F(1$, $504)=57.17, \Delta \mathrm{R}^{2}=.096, p<.001$, such that individuals shown right-wing profiles who were high on LWA assigned considerably more difficult puzzles and individuals who were shown left-wing profiles who were high on LWA assigned considerably less difficult puzzles. Similarly, RWA significantly interacted with profile-type in a disordinal manner, $F(1,503)=50.50, \Delta \mathrm{R}^{2}$ $=.086, p<.001$, such that individuals shown left-wing profiles who were high on RWA assigned considerably more difficult puzzles and individuals shown right- wing profiles who were high on RWA assigned considerably less difficult puzzles. The same interaction effect was present for SDO, $F(1,504)=59.66, \Delta \mathrm{R}^{2}=$ $.108, p<.001$.

It was not clear, however, whether these effects were due to political ideology variance in the LWA Index, RWA Scale, and $\mathrm{SDO}_{7}$. Thus, we added a political ideology covariate to the model (both the main effect of political ideology and an ideology by profile-type interaction term). The interaction between profile-type and LWA incremented variance explained by these political ideology covariate terms, including for symbolic 
ideology $\left(F[1,502]=11.27, \Delta \mathrm{R}^{2}=.018, p<.001\right)$, social ideology $\left(F[1,489]=21.14, \Delta \mathrm{R}^{2}=.038, p<.001\right)$, and economic ideology $\left(F[1,489]=10.20, \Delta \mathrm{R}^{2}=.021\right.$, $p<.001)$. Similarly, SDO's interaction with profiletype incremented variance explained by symbolic ide$\operatorname{ology}\left(F[1,502]=12.68, \Delta \mathrm{R}^{2}=.025, p<.001\right)$, social ideology $\left(F[1,489]=21.13, \Delta \mathrm{R}^{2}=.043, p<.001\right)$, and economic ideology $\left(F[1,489]=20.79, \Delta \mathrm{R}^{2}=.040, p<\right.$ $.001)$. The interaction between profile-type and RWA, however, was not statistically significant after controlling for both symbolic ideology and social ideology $\left(\Delta \mathrm{R}^{2}=.002\right.$ and $.007, p s=.368$ and .071$)$. In contrast, controlling for economic ideology did not account for RWA's interaction effect entirely, such that $F(1,500)$ $=8.03, \Delta \mathrm{R}^{2}=.015, p=.005$.

\section{Phase 5 Discussion}

Given the conceptual fuzziness surrounding authoritarianism, behavioral outcomes serve as an important signpost for evaluating measures and conceptualizations of this construct. Punishment of norm-violators and deviants has historically been one of the few means of assessing authoritarian behavior in liberal democracies (e.g., McAbee \& Cafferty, 1982; Stenner, 2005), where unequivocally fascistic and anti-democratic behaviors are, for the most part, scarce. In Phase 5, we modified a well-validated aggression paradigm to assess aggression towards combative, motivated, and prejudiced members of the opposite political party. LWA, RWA, and SDO predicted aggression in response to these politically valanced normative threats and helping behaviors towards members of one's political in-group with large effect sizes (i.e., roughly $10 \%$ of the total variance). Moreover, both LWA and SDO (but not RWA) predicted behavioral aggression vs. helping over and above political ideology, providing strong evidence for a shared pattern of aggressive behavior across LWA and SDO, as well as for the construct validity of both the LWA Index and the $\mathrm{SDO}_{7}$.

We can envision several plausible, mutually compatible reasons for our finding that RWA was significant on the tangram help/hurt task only before political orientation was controlled. First, this effect may not be specific to RWA but to conservatism in general (Hodson \& Dhont, 2015; cf. Crawford \& Brandt, 2020) ${ }^{15}$. Second, our findings arguably accord with Duckitt's (2001) dual-process model, which posits that SDO primarily captures authoritarian aggression, whereas

\footnotetext{
${ }^{15} \mathrm{We}$ thank a reviewer for suggesting this possibility.

${ }^{16}$ We aired on the side of caution, such that participants who failed any one of our three attention checks were screened out. We
}

RWA primarily captures submission. Third, the RWA Scale is more highly correlated with political ideology than is either the LWA Index or the $\mathrm{SDO}_{7}$. Given these various possibilities, additional research on this topic is needed.

\section{Phase 6: Preregistered Replication and Extension in a Nationally Representative Sample}

In our sixth and final phase, we address several limitations of the previous studies. Namely, to this point, none of our samples could be said to closely approximate the United States population, which we seek to explain in the present investigation. Thus, we sought to cross-validate and replicate results from the previous five phase in a nationally representative sample of the United States. We also extend our findings to several important and timely outcomes of relevance to LWA, including participation in political violence during the widespread protests for racial justice that erupted across the U.S. in May of 2020. We preregistered our predictions (e.g., the magnitude and directionality of LWA's relations with all external criteria) to more clearly distinguish exploratory and confirmatory results (https://osf.io/cseyx).

\section{Participants}

A sample reflecting the demographic distribution of the U.S. population was recruited using Prolific, an online participant recruitment service. Specifically, our sample was cross-stratified across age (five 9-year brackets), sex (male and female categories), and ethnicity (five categories), resulting in 50 subgroups: one for each combination of categories. Members of these subgroups were then recruited such that our sample was consistent with 2015 population estimates from the U.S. Census Bureau. Our intended sample size was N $=1000$, which is Prolific's maximum deliverable representative sample. Following data cleaning on the basis of failed attention checks ${ }^{16}, 834$ participants remained. As described in Table S16, our sample modestly underrepresented individuals with household incomes greater than $\$ 150,000$ and was not representative of individuals older than 80 and those without a high school degree. Concerning political identification, $49.0 \%$ of participants identified with the Democratic party, $24.0 \%$ identified with Republicans, $13.6 \%$ did not identify with a political party, $5.5 \%$ identified with

adopted this strict approach to mitigate the possibility that our analysis of low base-rate outcomes, such as participation in political violence, were not distorted due to errant responding. 
a party not listed in the survey, 3.4\% identified with the Socialist party, $2.6 \%$ identified with the Libertarian party, and $1.6 \%$ identified with the Green party. Participants were paid $\$ 4.00$ for an average of 30 minutes work.

\section{Measures}

In addition to the LWA Index $(\alpha=.95)$, Altemeyer's RWA Scale $(\alpha=.96)$, the Comprehensive Intellectual Humility Scale $(\alpha=.89)$, Rokeach's (Modified) Dogmatism Scale $(\alpha=.82)$, and the previously described measures of partisan schadenfreude $(\alpha=.82)$, partisan moral disengagement $(\alpha=.88)$, and partisan violence $(\alpha=.86)$, participants completed measures of (1) autocratic/anti-democratic orientation, (2) past use of force or violence for a political cause, (3) desire to use force or violence for a political cause, (4) politically-motivated social media use, (4) willingness to sign petitions endorsing authoritarian political policies, (5) support for violent collective action during protests in the summer of 2020, and (6) participation in violence during said protests.

Autocratic/Anti-democratic orientation. We administered the Autocratic Orientation Scale (Bartusevičius et al., 2020), a three-item measure of preferences for autocratic versus democratic forms of governance. Participants with left-wing political views were administered left-wing versions of the items, whereas individuals with right-wing political views were administered right-wing versions. The items were as follows: "Only [leftists/conservatives] are allowed to stand for election and hold office," "[Armed revolutionaries/the army] come[s] in to govern the country," and "Elections and Congress are abolished so that a [leftist/conservative] president can decide everything." Response options ranged from (1) Strongly disapprove to (7) Strongly approve. We computed each participant's total score over the three items (higher values indicate a more autocratic orientation), $\mathrm{M}=4.74, \mathrm{SD}=2.75$. Internal consistency was satisfactory for both left-wing participants $(\alpha=.78)$ and right-wing participants $(\alpha=$ .78).

Political social media. Intolerance of difference is a fundamental component of authoritarianism (e.g., Stenner, 2009). As such, highly authoritarian individuals should tend to prefer ideologically homogeneous social media environments. To test this hypothesis, we assessed the frequency with which participants had blocked, unfriended or hidden someone on social media for (1) posting too much political content, (2) posting political content that participants disagreed with,
(3) posting political content that participants found offensive, (4) arguing about political issues with participants or someone participants know, (5) disagreeing with political content that participants posted, and (6) posting political content that participants worried would offend their friends or people who follow them. Participants responded on a scale ranging from [0] "Never" to [3] "Very Often." The six items $(\alpha=.88)$ were averaged to yield a total score $(\mathrm{M}=.64, \mathrm{SD}=$ $0.68)$.

Petitions in support of authoritarian policies. Mocked-up left- and right-wing versions of petitions in support of anti-democratic values (i.e., opposition to personal autonomy, individual rights, and freedom of expression and belief) were administered to participants. Participants were asked to sign two left-wing anti-democratic petitions and two right-wing anti-democratic petitions. Response options ranged from [1] "Definitely would not sign" to [5] "Definitely would sign." The left-wing petitions were highly correlated ( $r$ $=.60)$, as were the right-wing petitions $(r=.53)$, so we summed them to yield a left-wing petition score $(\mathrm{M}=$ $3.98, \mathrm{SD}=2.03)$ and a right-wing petition score $(\mathrm{M}=$ $4.73, \mathrm{SD}=2.60)$.

Violent protests. In May 2020, sweeping protests emerged across more than 2,000 cities and towns in the U.S. in response to the killings of George Floyd and other unarmed black Americans by police officers and civilians. The protests included mostly peaceful behavior, but they also included some violent protest behavior, such as burning police stations and cars, destroying property, and throwing projectiles at police officers and political opponents. Given that RWA and SDO predict pro-state violence, LWA should predict anti-state violence (Webber et al., 2020). Hence, the protests afforded an opportunity for a unique test of LWA's explanatory power for real-world behavior.

Attitudes. We constructed a 9-item measure of support for violent aspects of the protests, with items ranging in severity from "Damaging property" to "Getting into physical fights with political opponents." Response options ranged from (1) Completely oppose to (7) Completely support. Parallel analysis favored a 1factor solution, which fit the data well, accounting for $81.1 \%$ of the total variance. The 9 items were a highly internally consistent $(\alpha=.95)$ and were summed to yield a total score $(\mathrm{M}=1.46, \mathrm{SD}=0.19)$. Notably, most participants $(88 \%)$ did not endorse any support for violence (operationalized as scores above the scale's midpoint), resulting in a highly positively skewed distribution (skew $=3.06$, kurtosis $=10.00$ ). Accordingly, we calculated a binary variable for violent protest support 
(i.e., does not support violence [0] vs. supports violence [1]).

Behaviors. We modified the protest scale to assess behavior (9-items; $\alpha=.98$ ). Participants were asked whether they had participated in a range of behaviors in response to the recent deaths of unarmed Black citizens. Response options were (1) "No," (2) "Once or twice." (3) "Two to three times," (4) "Four to six times," and (5) "Seven-plus times." Further, participants were asked whether they had participated in "Nonviolent protests in support of police reform" in the past year, using the same set of response options. This allowed us to establish the percentage of our sample who had participated in the protests non-violently $(15.2 \%)$. This estimate is broadly consistent with polling data that suggests approximately $6-10 \%$ of adults in the United States participated in demonstrations as of June 2020 (Buchanan et al., 2020). In contrast, the vast majority of participants $(97.7 \%)$ in this nationally representative sample had not participated in violence during the protests. Accordingly, we again calculated a binary variable for violent protest behavior (i.e., did not engage in violence [0] vs. engaged in violence [1]).

Use of force or violence for political cause. Participation in political violence was also measured with a single-item self-report measure of "use of force for a political cause." This measure was adapted from prior research on political violence (Afrobarometer, 2015) and has shown promising construct validity (Bartusevičius et al., 2020). Response options ranged from (1) "No" to (4) "Very Often" ( $\mathrm{M}=1.09, \mathrm{SD}=0.43)$. Once again, the vast majority of participants $(99.2 \%)$ did not report having used force for a political cause, so we calculated a binary variable (i.e., did not engage in violence [0] vs. did engage in violence [1]). Participants also indicated whether they would have used force for a political cause if given the chance. A majority of participants $(91.13 \%)$ indicated that they would not, so this variable was again dichotomized.

\section{Results}

Model fit of the LWA Index was slightly diminished in this sample, relative to the results for MTurk samples, but remained broadly acceptable, such that for the

\footnotetext{
${ }^{17}$ One item (item 13) loaded more highly onto a non-target (TDC) than target (AHA) factor. As the content of this item reflects the use of absolute authority, this cross-loading is broadly consistent with our conceptualization of AHA and TDC.

${ }^{18} \mathrm{We}$ deviated from the preregistration plan in several places. First, we did not administer the HEXACO, SVS, and political donation tasks for reasons of cost, as they would have lengthened the survey considerably. Second, the six social cohesion items demon-
}

3-factor confirmatory ESEM model, $\chi^{2}=3738.46, d f=$ $627, p<.001 ;$ RMSEA $=.077,90 \%$ CI $[.075, .080] ;$ TLI $=.93$. Factor correlations ranged from $r=.37$ to .61 , suggesting appropriate discrimination across factors. Item loadings and construct replicabilities were equivalent to, or higher than, those from previous samples (see Table S18 for details; factor $\alpha$ s from .88 to .93; factor $H$ s from .90 to .95$)^{17}$.

LWA's and RWA's distributional properties, demographic correlates, and ideological correlates. As shown in Table S16, LWA and RWA tended to be relatively stable across gender, race, and income. As might be expected, however, LWA was negatively correlated with age $(r=-.36, p<.001)$ whereas RWA was positively correlated with age $(r=.17, p=.001)$. Further, LWA was positively correlated with left-wing social $(r=.50)$ and economic $(r=.57)$ political ideology and RWA was positively correlated with right-wing social $(r=.75)$ and economic $(r=.56)$ political ideology $(p \mathrm{~s}<.001)$.

Construct Validity. We preregistered our hypotheses for LWA's relations with external criteria prior to data collection ${ }^{18}$. LWA's profile of relations with external criteria (see Figure 8) was extremely similar to our hypothesized profile $\left(r_{\text {alerting- } C V}=.83, p<.001 ; r_{\text {con- }}\right.$ trast $-C V=.59, p<.001)$. Controlling for political ideology yielded comparable results across symbolic ideology $\left(r_{\text {alerting- } C V}=.83, p<.001 ; r_{\text {contrast }-C V}=.62 p<.001\right)$, social ideology $\left(r_{\text {alerting- } C V}=.81, p<.001 ; r_{\text {contrast }-C V}=.61\right.$ $p<.001)$, and economic ideology $\left(r_{\text {alerting-CV }}=.81, p<\right.$ $\left..001 ; r_{\text {contrast }-C V}=.60, p<.001\right)$. Further, LWA's profile of relations corresponded to RWA's profile of relations ( $\left.r_{\text {alerting- } C V}=.63, p<.001 ; r_{\text {contrast- } C V}=.47, p<.001\right)$, with their similarities increasing after controlling for symbolic ideology $\left(r_{\text {alerting- } C V}=.88, p<.001 ; r_{\text {contrast- } C V}\right.$ $=.65, p<.001)$, social ideology $\left(r_{\text {alerting- } C V}=.89, p<\right.$ $\left..001 ; r_{\text {contrast }-C V}=.66 p<.001\right)$, and economic ideology $\left(r_{\text {alerting- } C V}=.81, p<.001 ; r_{\text {contrast }-C V}=.60, p<.001\right)$.

As shown in Figure 8, LWA manifested large positive correlations (i.e., $r \mathrm{~s}>.40$ ) with autocratic orientation, dogmatism, partisan moral disengagement, partisan schadenfreude, partisan violence, as well as willingness to sign petitions advocating for (a) "scaling back" the rights of the capitalist ruling class and (b) violently overthrowing capitalism, as well as support for

strated poor internal consistency $(\alpha=.36)$ and could not be interpreted as a total score. As such, although we advanced predictions for these variables, they were not included in our Westen \& Rosenthal (2003) analyses. Third, as variables reflecting participation in political violence were highly zero-inflated, we analyzed them separately using two-part regression models, as reported below. Nevertheless, including these violence-related variables in our correlational analyses did not meaningfully change the results. 

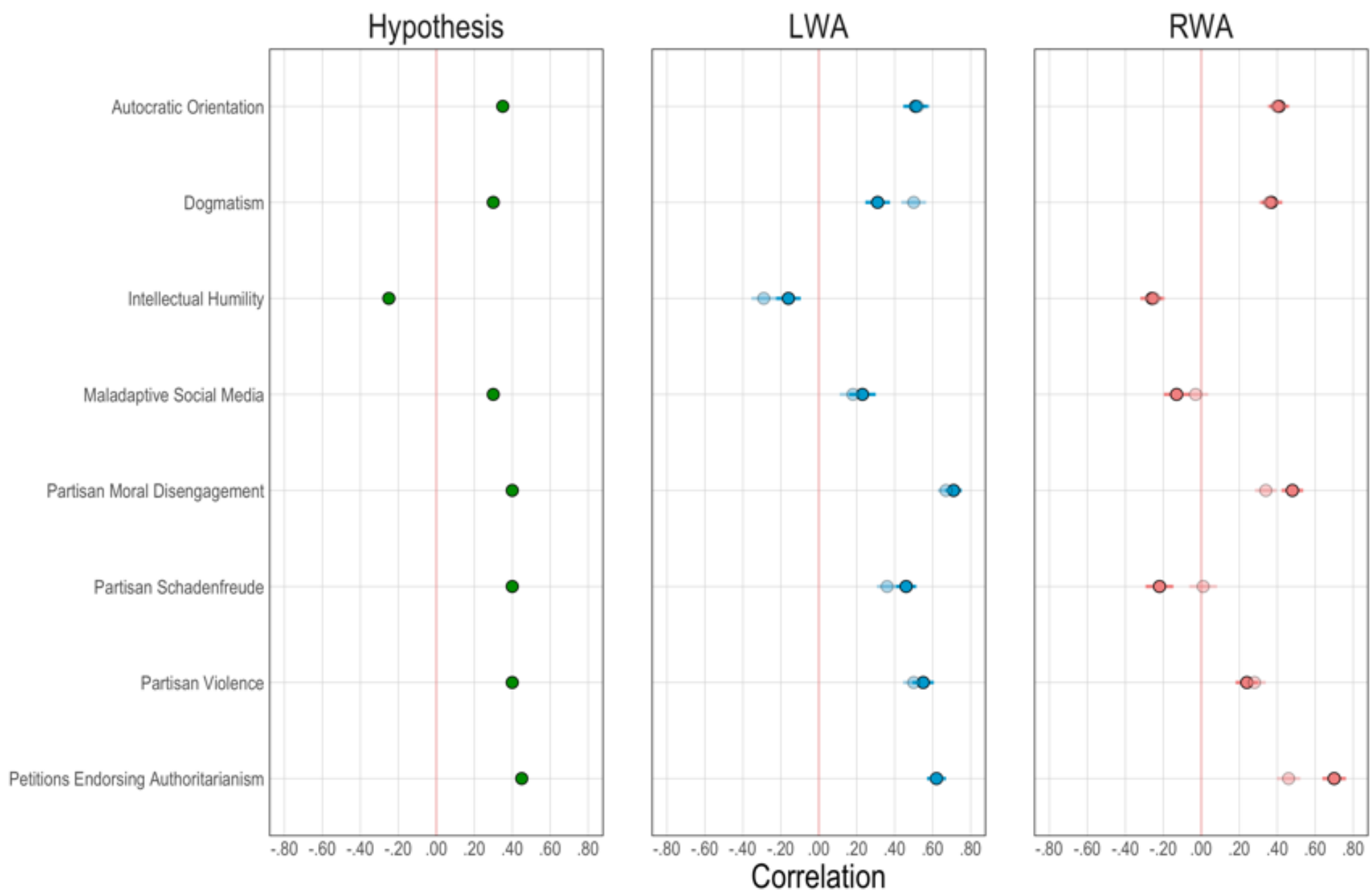

US. Nationally Representative Sample, $N=834$

Figure 8. Comparing our preregistered predictions with LWA's and RWA's observed results in Sample 6. Results after controlling for political ideology are plotted in a lighter shade for $L W A$ and $R W A$. 
violent collective action during protests against police brutality against Black Americans in the summer of 2020. Similarly, RWA manifested large correlations with autocratic orientation, dogmatism, partisan moral disengagement, willingness to sign petitions advocating for (a) federal prosecution of left-wing journalists and (b) the government to recognize far-left activist groups, such as ANTIFA, as terrorist organizations. Detailed results are presented in Table 8.
Political violence. We used two-part regression to estimate the relation between LWA and outcomes involving political violence, which were highly zero-inflated (e.g., Belotti et al., 2015). The two-part model first consists of fitting a binary logistic regression to model the probability of a low base-rate, binary outcome, given predictors of interest (i.e., LWA and RWA). Then, conditional on a positive outcome, an appropriate regression model is fit for the positive out-

Table 8. LWA, RWA, and Outcomes for Sample 6.

\begin{tabular}{|c|c|c|c|c|c|}
\hline & LWA AHA & LWA AC & LWA TDC & LWA Total & RWA \\
\hline & \multicolumn{5}{|c|}{ Zero-order Correlations } \\
\hline Social conservatism & -.36 & -.65 & -.12 & -.50 & .75 \\
\hline Economic conservatism & -.42 & -.64 & -.31 & -.57 & .56 \\
\hline Autocratic orientation & .52 & .39 & .31 & .51 & .41 \\
\hline Partisan schadenfreude & .48 & .47 & .05 & .46 & -.22 \\
\hline Partisan violence & .55 & .51 & 16 & .55 & .24 \\
\hline Moral disengagement & .65 & .69 & .29 & .71 & .48 \\
\hline LWA petitions & .62 & .46 & 49 & .62 & -.05 \\
\hline RWA petitions & -.25 & -.52 & .00 & -.36 & .70 \\
\hline Dogmatism & .42 & .12 & .21 & .31 & .37 \\
\hline Intellectual humility & -.23 & -.06 & -.10 & -.16 & -.26 \\
\hline \multirow[t]{2}{*}{ Political social media } & .19 & .24 & .12 & .23 & -.13 \\
\hline & \multicolumn{5}{|c|}{ Controlling for Symbolic Ideology } \\
\hline Autocratic orientation & .50 & .38 & .28 & .52 & .40 \\
\hline Partisan schadenfreude & .41 & .37 & -.03 & .36 & .01 \\
\hline Partisan violence & .49 & .47 & .10 & .50 & .28 \\
\hline Moral disengagement & .59 & .68 & .23 & .67 & .34 \\
\hline LWA petitions & .60 & .45 & .46 & .62 & .16 \\
\hline RWA petitions & .01 & -.12 & .20 & .01 & .46 \\
\hline Dogmatism & .54 & .35 & .26 & .50 & .36 \\
\hline Intellectual humility & -.31 & -.22 & -.14 & -.29 & -.25 \\
\hline \multirow[t]{2}{*}{ Political social media } & .14 & .19 & .09 & .18 & -.03 \\
\hline & \multicolumn{5}{|c|}{ Controlling for Social Ideology } \\
\hline Autocratic orientation & .54 & .46 & .30 & .57 & .35 \\
\hline Partisan schadenfreude & .41 & .35 & .01 & .36 & .06 \\
\hline Partisan violence & .50 & .47 & .13 & .51 & .30 \\
\hline Moral disengagement & .61 & .71 & .27 & .69 & .50 \\
\hline LWA petitions & .61 & .46 & .48 & .62 & .15 \\
\hline RWA petitions & -.06 & -.25 & .09 & -.11 & .50 \\
\hline Dogmatism & .51 & .29 & .23 & .44 & .41 \\
\hline Intellectual humility & -.30 & -.19 & -.12 & -.26 & -.26 \\
\hline \multirow{2}{*}{ Political social media } & .14 & .17 & .10 & .16 & .02 \\
\hline & \multicolumn{5}{|c|}{ Controlling for Economic Ideology } \\
\hline Autocratic orientation & .54 & .44 & .30 & .58 & .57 \\
\hline Partisan schadenfreude & .41 & .39 & -.04 & .38 & .06 \\
\hline Partisan violence & .51 & .49 & .10 & .53 & .30 \\
\hline Moral disengagement & .61 & .70 & .23 & .70 & .45 \\
\hline LWA petitions & .58 & .38 & .44 & .58 & .15 \\
\hline RWA petitions & -.05 & -.31 & .19 & -.11 & .50 \\
\hline Dogmatism & .52 & .26 & .26 & .45 & .41 \\
\hline Intellectual humility & -.29 & -.15 & -.14 & -.25 & -.26 \\
\hline Political social media & .17 & .24 & .09 & .22 & .02 \\
\hline
\end{tabular}

Bolded indicates $p<.001$; italicized indicates $p<.01$. AHA $=$ Anti-hierarchical Aggression; AC $=$ Anti-conventionalism; TDC $=$ Top-down Censorship. 
come using continuous or ordinal data (e.g., correlations between the predictors of interest and a non-dichotomized outcome variable among the subset of participants who scored positively on the dichotomized outcome variable).

Violent protest attitudes. The odds of supporting violent collective action during the summer of 2020 increased by a factor of 6.55 for each SD increase in LWA $(\mathrm{OR}=6.55,95 \%$ CI $[4.48,9.58], p<.001)$. Controlling for left vs. right political identification did not meaningfully attenuate this relation, $\mathrm{OR}=5.52,95 \%$ CI $[3.72,8.51], p<.001)$, which was also the case for social ideology $(\mathrm{OR}=6.15,95 \%$ CI $[4.13,9.54], p<$ $.001)$ and economic ideology $(\mathrm{OR}=5.68,95 \% \mathrm{CI}$ $[3.88,8.64], p<.001)$. Among participants who expressed support for violence $(\mathrm{N}=67)$, LWA was positively correlated with their degree of support $(r=.26$, $95 \%$ CI $[.02, .47], p=.035)^{19}$. Accordingly, LWA predicted (a) whether participants supported violence during protests and (b) the extremity of said support. In contrast, the odds of support decreased significantly for each unit increase in RWA, OR $=0.40,95 \%$ CI $(0.28$, $0.60), p<.001$, but this relation became non-significant after controlling for symbolic ideology $(\mathrm{OR}=1.01$, $95 \%$ CI $[0.65,1.55], p=.980)$, social ideology (OR = $0.88,95 \%$ CI $[0.52,1.42], p=.624)$, and economic ide$\operatorname{ology}(\mathrm{OR}=0.73,95 \% \mathrm{CI}[0.47,1.07], p=.125)$.

Violent protest behaviors. Participants' odds of having taken part in violence during protests in the summer of 2020 increased by a factor of 2.19 for each SD increase in LWA $(\mathrm{OR}=2.19,95 \%$ CI $[1.40,3.44]$, $p<.001)$. This relation was moderately increased after controlling for symbolic ideology $(\mathrm{OR}=2.96,95 \% \mathrm{CI}$ $[1.72,5.09], p<.001)$, social ideology $(\mathrm{OR}=3.09,95 \%$ CI $[1.81,5.40], p<.001)$, and economic ideology (OR $=2.29,95 \% \mathrm{CI}[1.36,3.86], p=.002)$. Among participants who engaged in violent protests during the summer of $2020(\mathrm{~N}=19)$, LWA was non-significantly correlated with frequency of violence $(r=.19,95 \%$ CI [.$.29, .59], p=.432$ ). RWA was not a significant predictor of participation in violence, $\mathrm{OR}=1.10,95 \% \mathrm{CI}$ $(0.68,1.71), p=.681$, a finding that held true after controlling for symbolic, social, and economic ideology (ORs ranged from 1.18 to 1.49 , $p$ s from .638 to .124).

Use of force for a political cause. Participants were over three times as likely to report desiring to have engaged in political violence in the last five years (i.e., had they been provided with the opportunity) for each SD increase in LWA $(\mathrm{OR}=3.14,95 \%$ CI $[2.40,4.19]$,

\footnotetext{
${ }^{19}$ In the full sample, this correlation was $r=.54,95 \%$ CI (.49, $.58), p<.001$.
}

$p<.001)$. Results were modestly diminished after controlling for symbolic ideology $(\mathrm{OR}=2.58,95 \% \mathrm{CI}$ $[1.88,3.57], p<.001)$, social ideology $(\mathrm{OR}=2.57,95 \%$ CI $[1.90,3.51], p<.001)$, and economic ideology (OR $=2.62,95 \%$ CI $[1.93,3.59], p<.001)$. For each unit increase in RWA, however, the likelihood decreased $(\mathrm{OR}=0.47,95 \%$ CI $[0.34,0.67], p<.001)$. After controlling for political ideology, RWA's relation became non-significant (ORs ranged from 0.77 to $1.03, p$ s from .888 to .155 , across symbolic, social, and economic ideology). Among participants who expressed a desire to have engaged in violence $(\mathrm{N}=73)$, both LWA $(r=.17$, $95 \%$ CI $[-.07, .39])$ and RWA $(r=.39,95 \%$ CI $[.17$, $.57]$ ) were positively correlated with desired frequency of violence, but only the latter relation was significant $(p=.155 \text { and } p<.001 \text {, respectively })^{20}$.

Only five participants reported having used force for a political cause in the last five years. Still, the odds of political violence increased significantly for each SD increase in LWA (OR $=2.73,95 \%$ CI $[1.17,6.74]), p$ $=.021)$. After controlling for political ideology, this relation was substantially, albeit not significantly, larger, with these results holding across symbolic ideology $(\mathrm{OR}=5.89,95 \% \mathrm{CI}[2.10,19.08], p=.001)$, social ideology $(\mathrm{OR}=5.36,95 \% \mathrm{CI}[1.89,17.27], p=.002)$, and economic ideology $(\mathrm{OR}=3.30,95 \%$ CI $[1.24,8.97], p$ $=.016)$. RWA was slightly less predictive, both before $(\mathrm{OR}=1.83,95 \% \mathrm{CI}[0.82,4.10], p=.140)$ and after controlling for symbolic and social ideology (ORs = 2.05 and 2.44, $p \mathrm{~s}=.127$ and .177). Nevertheless, RWA became a significant predictor after controlling for economic ideology, $\mathrm{OR}=2.58,95 \%$ CI $(1.04,6.16], p=$ $.031)$. We did not conduct correlational analyses in the subset of participants who engaged in political violence due to the exceedingly small sample size.

\section{General Discussion}

LWA numbers among the most infamous constructs in political psychology. Several authors have mounted widely cited arguments that the evidence for LWA's existence is less than persuasive and that the search for LWA should be abandoned. In the service of clarifying LWA's nature and structure, we used exploratory test construction (Loevinger, 1957; Tellegen \& Waller, 2008; Westen \& Rosenthal, 2003) to develop and preliminarily validate a multidimensional measure of LWA. Our results suggest that LWA both exists and

\footnotetext{
${ }^{20}$ In the full sample, these correlations were $r=.30,95 \%$ CI $(.24$, $.36), p<.001$, for LWA and $r=-.08,95 \%$ CI $(-.15,-.02), p=.015$, for RWA.
} 
predicts key psychological and behavioral outcomes, including participation in political violence. In the following sections, we unpack our results, compare differences and similarities across LWA and RWA, discuss the role of political ideology in LWA and RWA, highlight limitations of the present research, and outline several promising directions for future research. We conclude with a discussion of LWA's implications for (a) general authoritarianism and (b) psychological science.

\section{The Structure, Correlates, and Nature of LWA}

Authoritarianism among rightists has generally been understood to involve two broad dimensions: RWA and SDO, which reflect authoritarian submission and dominance, respectively (Duckitt \& Sibley, 2017). RWA describes support for coercive social control, obsequiousness to established authorities, and conformity to traditional norms, whereas SDO describes support for hierarchy and the dominance of powerful groups over weaker groups. Other scholars have conceptualized authoritarianism as intolerance of difference and/or need for social uniformity (e.g., Feldman \& Stenner, 1997). At the outset of this investigation, we did not have reason to suspect that LWA would necessarily mirror these conceptualizations due to their being tailored to right-wing populations. At the same time, we expected that LWA would dovetail with some core elements of previous conceptualizations, and in so doing, provide conceptual clarity concerning the nature of authoritarianism writ large.

Our results point to the fruitfulness of a tripartite conceptualization of LWA comprising three correlated dimensions - anti-hierarchical aggression, top-down censorship, and anti-conventionalism - that broadly and inexactly reflect authoritarian dominance (e.g., SDO), authoritarian submission (e.g., RWA), and morally absolutist and intolerant desires for coercive forms of social organization, respectively. Anti-hierarchical aggression reflects motivations to forcefully overthrow the established hierarchy and punish those in power, perhaps mirroring SDO's definitional core. Moreover, anti-hierarchical aggression's nomological network was extremely similar to SDO's nomological network, especially in the personality domain (i.e., low agreeableness, low honesty-humility, low conscientiousness, and psychopathic disinhibition and meanness), further

\footnotetext{
${ }^{21}$ As described in Table S17, for Sample 6 (the nationally representative sample), 19 of 22 potential interactions we examined were statistically significant at $p<.01\left(\right.$ median $\left.\Delta R^{2}=.024\right)$.
}

suggesting that both constructs reflect authoritarianism's power- and dominance-related features (Altemeyer, 1998), even as they differ in their orientation towards the established social hierarchy (i.e., challenging vs. upholding).

Similarly, top-down censorship reflects motivations to wield group authority (e.g., governmental limitations on speech) as a means of regulating characteristically right-wing beliefs and behaviors, mirroring RWA's definitional core. Fittingly, top-down censorship's nomological network was more similar to RWA's nomological network (i.e., low openness, cognitive rigidity, political intolerance, and dangerous worldview) than it was SDO's. Thus, despite their manifest ideological differences, top-down censorship and RWA may similarly reflect authoritarian submission. Nevertheless, the parallels between anti-hierarchical aggression and SDO and top-down censorship and RWA are far from perfect. In Sample 5, for instance, anti-hierarchical aggression demonstrated greater similarity to both RWA and SDO than did top-down censorship, raising the possibility that anti-hierarchical aggression is simply a more direct analogue of rightist forms of authoritarianism than is top-down censorship.

Anti-conventionalism, the final LWA dimension, reflects a moral absolutism concerning progressive values and concomitant dismissal of conservatives as inherently immoral, an intolerant desire for coercively imposing left-wing beliefs and values on others, and a need for social and ideological homogeneity in one's environment. As such, anti-conventionalism does not clearly map onto authoritarian dominance or submission, yet still reflects openly authoritarian sentiments and can be subsumed by the LWA construct. Consistent with this interpretation, before controlling for ideology, anti-conventionalism manifested a pattern of correlations with external criteria that was not consistent with SDO or RWA, notwithstanding anti-conventionalism's large positive relations with free-speech suppression, social vigilantism, and lethal partisanship. Nevertheless, anti-conventionalism's pattern of relations was more consistent with RWA and SDO after controlling for political ideology. Moreover, in exploratory interaction analyses, anti-conventionalism often potentiated the relation between anti-hierarchical aggression or top-down censorship, on the one hand, and outcome variables, on the other, with large effect sizes 21 . These findings raise the possibility of multiplicative relations 
among LWA dimensions, such that LWA Index total scores are more than the sum of their parts.

Thus, recognizable analogs of authoritarian dominance and submission were present in the LWA Index, situating LWA in parallel to longstanding accounts of authoritarianism on the right. By the same token, our investigation also revealed substantive differences between LWA and rightist forms of authoritarianismmost consistently found in the anti-conventionalism factor-underscoring the need for a more expansive conception of authoritarianism (see Duckitt, 2020). Exploring the similarities and differences between LWA and RWA/SDO may offer a great deal of conceptual clarity in this regard.

\section{LWA and RWA/SDO: Similarities and Differences}

By and large, LWA and RWA/SDO seem to reflect a shared constellation of traits that might be considered the "heart" of authoritarianism. These traits include preference for social uniformity, prejudice towards different others, willingness to wield group authority to coerce behavior, cognitive rigidity, aggression and punitiveness towards perceived enemies, outsized concern for hierarchy, and moral absolutism. Nevertheless, several notable differences between LWA and RWA/SDO also emerged. These differences can be broadly characterized as personological (i.e., variables reflecting a stable pattern of affect, cognition, and desires/motives that manifest in behavior), ideological (i.e., beliefs, attitudes, worldviews), and both personological and ideological (e.g., partisan violence).

On the personological front, the most pronounced differences between LWA and RWA were negative affect (larger for LWA), confirmatory thinking (larger for RWA), and the DOG Scale (larger for RWA) 22. Further, RWA was more strongly related to cognitive rigidity and low openness than was LWA prior to controlling for political ideology. This finding is consistent with the possibility that cognitive rigidity is functionally related to social conservatism in WEIRD samples (Van Hiel et al., 2016). Personological differences for LWA and SDO included coldheartedness (positive for SDO, null for LWA) and need for closure (positive for

\footnotetext{
${ }^{22}$ Several of these differences can likely be attributed to method variance. For instance, our operationalization of conformity and power, the short form of Schwartz's Values Survey, describes them to participants in a manner that arguably disposes right-wing individuals to answer affirmatively. "Conformity" is translated as "obedience, honoring parents and elders, self-discipline, politeness," and as such probably preferentially captures conformity towards traditional, patriarchal norms. "Power" is translated as "social
}

LWA, negative for SDO). Moreover, although authoritarianism has long been understood to centrally involve dispositional needs for control, certainty, and reduction of threats (either to the social order or status threats; e.g., Adorno et al., 1950; Jost, 2017; Wilson, 1973), critics have observed that neither RWA nor SDO is associated with neuroticism, a personality trait characterized by the perception that the world is a dangerous place, along with the tendency to experience intense negative emotions and a sense of uncontrollability in response to stress (Feldman \& Huddy, 2014; Barlow et al., 2014). LWA, in contrast, consistently predicted neuroticism in our data. This finding preliminarily suggests that left-wing authoritarians may be more sensitive to certain facets of threat and uncertainty than are right-wing authoritarians. By and large, though, LWA and RWA/SDO demonstrated far more personological similarities than differences. For instance, after controlling for political ideology, personological point estimates for LWA and RWA were within $r=.05$ for psychopathic meanness, cognitive reflectivity, the Dogmatism Scale, conscientiousness, need for closure, disinhibition, and psychopathic boldness. For SDO, point estimates were within $\mathrm{r}=.05$ for antagonism, the DOG Scale, openness, extraversion, disinhibition, and psychoticism.

On the ideological front, LWA's and RWA's most pronounced differences were belief in science (null for LWA and negative for RWA), SVSS Conformity (negative for LWA and positive for RWA), and SVSS Selfdirection (both negative, larger for RWA). For SDO, ideological differences were state control preferences (positive for LWA, null for SDO), determinism beliefs (larger for LWA), belief in science (null for LWA, negative for SDO), and belief in a dangerous world (larger for LWA). Point estimates for LWA and RWA were within $r=.05$ for fatalistic determinism beliefs, belief in conspiracy theories, and belief in a dangerous world. For LWA and SDO, these similarities were belief in conspiracy theories, SVSS Power, and SVSS Conformity.

We also assessed several variables that capture both personological and ideological features, such as affective polarization and political intolerance. LWA and RWA were most dissimilar for partisan schadenfreude

power, authority, and wealth," which may bias individuals who would endorse LWA items such as "Most rich Wall Street executives deserve to be thrown in prison" against answering affirmatively. Further, as there were more left-wing than right-wing participants in our samples, it makes sense that partisan schadenfreude would be more strongly related to LWA even after controlling for political ideology due to collider bias. 
(positive for LWA, null for RWA), political social media use (positive for LWA, null for RWA), willingness to ban opposing views (larger for LWA), partisan violence (larger for LWA), and moral disengagement (larger for LWA). For SDO, the most pronounced differences were political intolerance (larger for LWA), willingness to opposing views (larger for LWA), partisan schadenfreude (positive for LWA, null for RWA), and moral disengagement (larger for LWA). LWA's seemingly superior performance in this domain can likely be explained, at least in part, by the partisan skew of our samples (i.e., there were more leftists than rightists). If our samples had included more rightists than leftists, RWA and SDO would likely have been better predictors than LWA prior to controlling for ideology.

What is more, political violence, a key component of folk and historical theories of authoritarianism (Wintrobe, 2006), is well-represented in the LWA Index and RWA Scale. Political violence can be directed either against the system (e.g., violent protests, terrorism) or to support the system (e.g., police brutality, support for war, state sanctioned torture of prisoners). LWA emphasizes anti-state violence, whereas RWA/SDO emphasize pro-state violence (Webber et al., 2020). Consistent with this possibility, LWA uniquely predicted participation in use of force for a political cause within the last five years, as well as support for, and participation in, anti-state violence during the summer of 2020. The fact that anti-state political violence has heretofore been largely excluded from the authoritarianism construct exemplifies the shortcomings of an exclusively right-wing account of authoritarianism.

\section{Authoritarianism and Political Ideology}

Having raised the possibility that a shared psychological core underlies different manifestation of authoritarianism, it is important to note that what authoritarianism fundamentally is, in psychological terms, remains a matter of ongoing debate (see Duckitt, 2020). Indeed, the chimerical construct has variously been conceptualized as a personality trait or disposition (e.g., Ludeke \& Krueger, 2013), a rigid and absolutist style of thinking (e.g., Rokeach, 1960), an ideological attitude that satisfies discrete cognitive-motivational goals (e.g., Duckitt, 2001), and an index of political conservatism driven by needs to reduce and manage threat and uncertainty (e.g., Jost et al., 2003). These (at times) radically different conceptualizations complicate attempts

\footnotetext{
23 Seeking to synthesize the core elements of these definition, Gerring (1997) suggests that "Ideology, at the very least, refers to a
}

to understand and discriminate between authoritarianism's antecedents, authoritarianism's consequents, and authoritarianism itself. Given these complexities, understanding the role that political ideology plays in measuring and conceptualizing authoritarianism represents an important avenue for future work.

To understand whether and how authoritarianism and political ideology are related to one another, it should be acknowledged that various definitions of ideology have been advanced in the literature, and these are even more divergent and contradictory than those of authoritarianism (e.g., Gerring, 1997)23. Nevertheless, when psychologists have investigated political ideology, they have typically sought to understand why people are drawn to specific ideological beliefs (e.g., free-market capitalism), emphasizing the content of ideological claims (Zmigrod, 2020). Yet how someone holds their beliefs may be of equal or greater psychological relevance to authoritarianism than specific ideological content (Rokeach, 1960, pp. 14-15). Far-left and far-right ideologies (e.g., communism and fascism) are similarly authoritarian in their structure - both exert powerful pressures to maintain discipline among members, advocate aggressive and censorious means of stifling opposition, believe in top-down, absolutist leadership, and so on. The content of communism, however, is arguably humanitarian and anti-authoritarian (e.g., the ideological aim is to remove economic inequities and take care of individuals per the doctrine, "from each according to their abilities, to each according to their needs"). In contrast, the content of fascism is wholly authoritarian. If this is so, individuals may initially be drawn to far-left and far-right authoritarianism for different reasons (e.g., with the hopes of eliminating injustices vs. exacerbating them), even if they ultimately act in similarly authoritarian manners (Rokeach, 1960; see also Conway et al., 2020).

Following this point, if authoritarianism is, indeed, a personality trait or disposition, it remains plausible that authoritarianism can be measured in a "Platonic" form independent of one's ideology. Hence, future research should attempt to tease apart LWA and RWA's structure and content. Nevertheless, if authoritarianism is fundamentally or partially motivational, as others have argued, then measures of authoritarianism that are ideologically neutral may be of limited utility and/or not yield a coherent score. Moreover, even if LWA and RWA share many or most of their psychological substrates, left-wing ideology and right-wing ideology

set of idea-elements that are bound together, that belong to one another in a non-random fashion" (p. 980) 
may interact with authoritarianism in different ways, rendering LWA and RWA both (a) more than the sum of their parts and (b) relatively unique "flavors" of authoritarianism. Were this the case, attempting to measure authoritarianism in an ideologically neutral manner would obscure not only the unique contours of LWA and RWA but also their areas of substantive overlap.

Until these competing possibilities can be resolved, it is necessary to measure and conceptualize LWA and RWA separately. For this reason, we chose to retain items in the LWA Index with left-wing content (but which were not highly correlated with ideology). In so doing, we ensured that our instrument measures authoritarianism in service of fundamentally left-wing motives and outcomes, thereby preserving future researchers' ability to compare and contrast LWA and RWA. Still, we were also quite careful to avoid creating a measure of left-wing ideology. Factors 1 and 3 of the LWA Index (as well as the measure's total score) were consistently correlated $<.45$ with left-wing ideology and accounted for variance over and above ideology across dozens of criterion-related outcomes. LWA Factor 2, Anti-conventionalism, tended to manifest larger correlations with ideology, but also accounted for variance in numerous criterion-related outcomes following statistical control for political ideology24. The magnitude of these correlations is comparable to those commonly found among complementary but conceptually and empirically distinct pairs of psychological constructs, such as self-esteem and narcissism (Orth et al., 2016), shame and guilt (Paulhus et al., 2004), and affective empathy and cognitive empathy (Murphy et al., 2018). Moreover, the ACT Scale (i.e., an RWA measure with little explicit left vs. right political content; Duckitt et al., 2010), manifests correlations with political conservatism of a similar or larger magnitude than does the LWA Index (e.g., rs .60; Dunwoody \& Plane, 2019). Thus, despite the presence of political content in some LWA items, the LWA Index successfully discriminates between political ideology and authoritarianism.

\section{Limitations and Future Directions}

To our knowledge, the present studies represent the most comprehensive investigation of LWA to-date. Nevertheless, we wish to delineate what can and cannot be concluded from our results. For instance, our results cannot directly speak to whether and to what extent the

\footnotetext{
${ }^{24}$ Insofar as this dimension is intended to reflect attitudes concerning imposing left-wing ideological conventions on others, this finding is unsurprising. Nevertheless, researchers who desire a
}

political right is more authoritarian than the political left, or vice versa, in part because it is unlikely that scores on the LWA Index and RWA Scale can be used and interpreted interchangeably in left- and right-wing samples. IRT scaling/equating procedures may be useful in addressing this problem (i.e., by placing IRT parameter estimates from different test forms and populations on a common scale; Lee \& Lee, 2018), although whether LWA and RWA can be distilled into a unidimensional, value-neutral authoritarianism construct remains an open empirical question.

Further, the LWA Index comprises many more positively-keyed items than it does negatively-keyed items. This was done intentionally, as reverse-coded items frequently produce an artifactual "keying factor" that obscures the dimensionality of a latent construct (e.g., Netemeyer et al., 2003). Nevertheless, our nomological network analyses involving measures that also favor positively-keyed items, such as the Personality Inventory for DSM-5 (Krueger et al., 2012), may have been distorted due at least in part to shared method variance (e.g., due to respondents who tend to respond positively to positively-keyed items, regardless of item content). Developing a relatively balanced pool of protrait and con-trait LWA items would be a worthy aim for future research. Granting this limitation, the LWA Index displayed dramatically different relations with a range of external criteria, including behavioral aggression, suggesting at least some substantive variance rising above method-covariance.

An additional limitation concerns "jingle-jangle" fallacies (Block, 1995). Jingle fallacies entail the erroneous assumption that two measures with the same or similar names (e.g., Rokeach's Dogmatism Scale and Altemeyer's DOG Scale) reflect the same construct. In contrast, jangle fallacies entail the erroneous assumption that two measures with different names reflect different constructs. It could be argued that "authoritarianism" may not be an appropriate term for describing the shared core of LWA and RWA/SDO, at least insofar as authoritarianism is understood to entail deference to established authority (but see Conway et al., 2020). Future research could evaluate the psychological appropriateness of the term authoritarianism by using a version of Meehl et al.'s (1971) recaptured item technique, whereby one group of raters independently generates candidate factor names, based on a subset of items, and then a second group of raters attempts to "recapture" items by assigning them to their appropriate

measure of LWA that is less imbued with left-wing content may wish to emphasize Factors 1 and 3. 
factor name, using a second subset of items. Combining measures of LWA, RWA, and SDO into a single item pool and drawing on this approach may be especially informative. Relatedly, recent evidence suggests that both left- and right-wing individuals report knowing many left-wing authoritarians (as well as right-wing authoritarians) in their everyday lives, and that this effect holds when the definition of authoritarianism is left open-ended (Conway et al., 2020). Similarly, future work drawing on lexical approaches, which have been extensively used to clarify the structure and nature of personality traits and have even been adapted to the study of values (e.g., De Raad et al., 2016), may be a useful means of better understanding authoritarianism.

Nevertheless, describing LWA and RWA using the same terminology without also clearly addressing the core ways they differ arguably risks blurring potentially important distinctions between them. As we have noted, communism and socialism, unlike fascism, propose humanitarian, egalitarian solutions to social injustices, which may attract individuals who hope to alleviate these injustices (Rokeach, 1960). Accordingly, left-wing authoritarians may come to believe that authoritarianism is "a necessary evil," rather than an end unto itself. Some individuals who score highly on the LWA Index may be well-intentioned idealists seeking to build a better and a more equitable society by tearing down the establishment. Thus, any psychological similarities across LWA and RWA notwithstanding, we endorse no claims of motivational or moral equivalence (or a lack thereof) across the two constructs at present.

Left-wing authoritarian ideologies may also appeal to individuals with greater cognitive complexity, because endorsing both authoritarianism and egalitarianism arguably involves reconciling two (seemingly) mutually contradictory beliefs. Indeed, embrace of contradiction is a key element of Marxist dialects (i.e., the ideological foundation of the Soviet Union and other left-wing authoritarian regimes; Hanson, 1997). Future research designed to find and clarify any differences between LWA and RWA is sorely needed to provide a more well-rounded view of the two constructs.

\section{Towards a More Comprehensive Science of Authoritarianism}

We have argued that a movement away from the conceptualization and measurement of exclusively rightist forms of authoritarianism may be required to

\footnotetext{
${ }^{25}$ As Hannah Arendt (1970) wrote, "the most radical revolutionary will become a conservative the day after the revolution".
}

crystalize authoritarianism's definitional core. Having documented LWA, we now outline several additional new directions for future research in service of advancing the science of authoritarianism.

One natural next step may be to construct a measure and conceptualization of authoritarianism that reflect the general properties held in common by left- and right-wing authoritarianism, drawing from the psychological commonalities revealed in the present investigation. Any such conceptualization would, in theory, apply to all positions on the ideological spectrum. Although past attempts to capture general authoritarianism have not succeeded (e.g., Rokeach, 1960), modern methods of scale development, such as those used in the present studies, may be cause for optimism. Further, the LWA Index and RWA Scale offer clear benchmarks for criterion-related validity that were not available to previous researchers. Success in this domain would offer enormous theoretical and practical advantages. For instance, a general measure could be fruitfully applied to new or yet-unstudied forms of authoritarianism, including authoritarianism in nations with politics that aren't easily classified along the traditional left-right spectrum or authoritarianism in nonpolitical domains.

Another natural progression of the present research involves exploring questions that might be more easily addressed by measuring authoritarianism in both leftist and rightist individuals. One such question concerns authoritarianism's psychological and environmental antecedents. If the etiologies of RWA and LWA are highly similar, such a finding would support the hypothesis that a "general" authoritarianism underlies both constructs. In contrast, if LWA and RWA appear to stem from separate processes, such a finding would indicate that they are analogous but distinct phenomena, akin to organisms of separate species that develop functionally similar features via convergent evolution.

Despite LWA's and RWA's marked similarities, it remains to be seen whether left-wing authoritarians who successfully overthrow the establishment tend to turn around and defend the new status-quo, thereby mirroring the right-wing authoritarians who came before them ${ }^{25}$. Individuals high in LWA may instead tend to push back against any current power structure, even those born of revolutionary action, in which case there may be important psychological differences between 
LWA and RWA. Longitudinal research would be informative in this respect as it might hold the potential to arbitrate between these competing possibilities.

Further, given that a third of the global population live in nations with autocratic or authoritarian governments (Freedom House, 2020), yet another avenue for future research concerns exploring the diversity and complexity of the authoritarian phenomenon, which straddles sociopolitics, culture, and personality psychology, in non-WEIRD cultures, and especially in nations with authoritarian governments. Clarifying the psychology of authoritarianism among individuals who have first-hand knowledge of such systems of government, using measures explicitly tailored to their circumstances, would better allow researchers to triangulate the general properties held in common by all forms of authoritarianism. Even if LWA and RWA cannot ultimately be distilled into "general authoritarianism," creating nuanced psychological portraits of individuals who exhibit authoritarian traits in diverse ideological and cultural contexts should provide substantial heuristic and functional value to the scientific research community and to public knowledge.

\section{Conclusion}

The dominant view of RWA as the "gold standard" of authoritarianism writ large is not merely an influential theoretical framework or a historical quirk-it limits the questions we ask as scientists, the methods we employ to answer those questions, and the types of theories we use to interpret our results. As such, the nearly universal exclusion of left-wing features from conceptualizations of authoritarianism, with little consideration of LWA's and RWA's psychological commonalities, has limited the kinds of knowledge we can produce as psychological scientists. Our intention in the present study was to advance a new means of conceptualizing authoritarianism. Specifically, we have demonstrated the utility of conceptualizing and measuring leftist forms of authoritarianism, challenging longstanding portrayals of LWA as the "Loch Ness Monster" of political psychology. In light of authoritarianism's enduring relevance to global politics and human behavior, we anticipate and hope that our work will allow researchers to better understand authoritarianism in all of its forms.

\section{References}

Abramowitz, A. I., \& Webster, S. (2016). The rise of negative partisanship and the nationalization of US elections in the 21 st century. Electoral Studies, 41, 12-22.

Adorno, T. W., Frenkel-Brunswik, E., Levinson, D. J., \& Sanford, R. N. (1950). The authoritarian personality. New York: Harper.

Afrobarometer (2015). Merged round 5 data (34 countries) (20112013) [Data set]. Retrieved from http://afrobarometer.org/data/merged-round-5-data-34-countries-2011-2013-lastupdate-july-2015.

Allport, G. W. (1954). The nature of prejudice. Reading: AddisonWesley Pub. Co.

Altemeyer, B. (1981). Right Wing Authoritarianism. Winnipeg: University of Manitoba Press.

Altemeyer, B. (2007). The authoritarians. Winnipeg: University of Manitoba Press.

Altemeyer, B. (1988). Enemies of freedom: Understanding rightwing authoritarianism. San Francisco: Jossey-Bass.

Altemeyer, B. (1996). The authoritarian specter. Cambridge: Harvard University Press.

Altemeyer, B. (1998). The other 'authoritarian personality'. In M. Zanna (Ed.) Advances in Experimental Social Psychology, 30 (pp. 47-92). San Diego: Academic Press.

American Psychiatric Association. (2013). Diagnostic and statistical manual of mental disorders (DSM-5). American Psychiatric Pub.

Asparouhov, T., \& Muthén, B. (2009). Exploratory structural equation modeling. Structural Equation Modeling: A Multidisciplinary Journal, 16, 397-438.

Asparouhov, T., Muthén, B., \& Morin, A. J. S. (2015). Bayesian structural equation modeling with cross-loadings and residual covariances: Comments on Stromeyer et al. Journal of Management, 41, 1561-1577.

Bandura, A. (2016). Moral disengagement: How people do harm and live with themselves. Worth Publishers.

Barker, E. N. (1963). Authoritarianism of the political right, center, and left. Journal of Social Issues, 19, 63-74.

Barlett, C. P., \& Anderson, C. A. (2011). Reappraising the situation and its impact on aggressive behavior. Personality and Social Psychology Bulletin, 37, 1564-1573.

Baron, J., \& Jost, J. T. (2019). False equivalence: Are liberals and conservatives in the United States equally biased?. Perspectives on Psychological Science, 14, 292-303.

Bartusevicius, H., van Leeuwen, F., \& Petersen, M. B. (2020). Dominance-driven autocratic political orientations predict political violence in western, educated, industrialized, rich, and democratic (weird) and non-weird samples. Psychological Science. Advance online publication.

Belotti, F., Deb, P., Manning, W. G., \& Norton, E. C. (2015). twopm: Two-part models. The Stata Journal, 15, 3-20.

Berger, D. (2006). Outlaws of America: The weather underground and the politics of solidarity. Oakland: AK Press.

Billig, O. (1985). The lawyer terrorist and his comrades. Political Psychology, 6, 29-46.

Block, J. (1995). A contrarian view of the five-factor approach to personality description. Psychological Bulletin, 117, 187-215.

Brandt, M. J. \& Crawford, J. T. (2020). Worldview conflict and prejudice. In B. Gawronski (Ed.) Advances in Experimental Social Psychology.

Brotherton, R., French, C. C., \& Pickering, A. D. (2013). Measuring belief in conspiracy theories: The generic conspiracist beliefs scale. Frontiers in Psychology, 4; 279. 
Brown, T. A. (2015). Confirmatory factor analysis for applied research. New York: Guilford Publications.

Buchanan, Bui, \& Patel (2020, July 3). Black Lives Matter may be the largest movement in U.S. history. New York Times. https://www.nytimes.com/interactive/2020/07/03/us/georgefloyd-protests-crowd-size.html.

Campbell, D. T., \& Fiske, D. W. (1959). Convergent and discriminant validation by the multitrait-multimethod matrix. Psychological Bulletin, 56, 81-105.

Chen, F. F. (2007). Sensitivity of goodness of fit indexes to lack of measurement invariance. Structural Equation Modeling: A Multidisciplinary Journal, 14, 464-504.

Cheung, G. W., \& Rensvold, R. B. (2002). Evaluating goodness-offit indexes for testing measurement invariance. Structural Equation Modeling, 9, 233-255.

Chirumbolo, A. (2002). The relationship between need for cognitive closure and political orientation: the mediating role of authoritarianism. Personality and Individual Differences, 32, 603610.

Choma, B. L., \& Hanoch, Y. (2017). Cognitive ability and authoritarianism: Understanding support for Trump and Clinton. Personality and Individual Differences, 106, 287-291.

Choma, B. L., Sumantry, D., \& Hanoch, Y. (2019). Right-wing ideology and numeracy: A perception of greater ability, but poorer performance. Judgment \& Decision Making, 14, 412-422.

Christie, R. (1991). Authoritarianism and related constructs. In J. P. Robinson \& P. R. Shaver (Eds.), Measures of personality and social psychological attitudes (pp. 501-571). San Diego: Academic Press.

Condon, D. M., \& Revelle, W. (2014). The International Cognitive Ability Resource: Development and initial validation of a public-domain measure. Intelligence, 43, 52-64.

Conway III, L. G., Houck, S. C., Gornick, L. J., \& Repke, M. A. (2018). Finding the Loch Ness monster: Left-wing authoritarianism in the United States. Political Psychology, 39, 1049-1067.

Conway, L.G., McFarland, J.D., Costello, T.H., Lilienfeld, S.O. (Under review). The curious case of left-wing authoritarianism: When authoritarian persons meet anti-authoritarian norms.

Costello, T.H. (In press). The Conundrum of Measuring Authoritarianism. In W. O’Donohue \& C. Frisby (Eds.), Political bias in psychology. New York, NY: Springer.

Crawford, J. T., \& Brandt, M. J. (2020). Ideological (a) symmetries in prejudice and intergroup bias. Current Opinion in Behavioral Sciences, 34, 40-45.

Crawford, J. T., \& Pilanski, J. M. (2014). Political intolerance, right and left. Political Psychology, 35, 841-851.

Crowson, H. M., Thoma, S. J., \& Hestevold, N. (2005). Is political conservatism synonymous with authoritarianism? The Journal of Social Psychology, 145, 571-592.

De Raad, B., Morales-Vives, F., Barelds, D. P., Van Oudenhoven, J. P., Renner, W., \& Timmerman, M. E. (2016). Values in a cross-cultural triangle: A comparison of value taxonomies in the Netherlands, Austria, and Spain. Journal of Cross-Cultural Psychology, 47, 1053-1075.

De Regt, S., Mortelmans, D., \& Smits, T. (2011). Left-wing authoritarianism is not a myth, but a worrisome reality. Evidence from 13 Eastern European countries. Communist and Post-Communist Studies, 44, 299-308.

DeYoung, C. G., Quilty, L. C., Peterson, J. B., \& Gray, J. R. (2014). Openness to experience, intellect, and cognitive ability. Journal of Personality Assessment, 96, 46-52.
DeYoung, C. G., Quilty, L. C., \& Peterson, J. B. (2007). Between facets and domains: 10 aspects of the Big Five. Journal of Personality and Social Psychology, 93, 880-896.

DiRenzo, G. J. (1967). Professional politicians and personality structures. American Journal of Sociology, 73, 217-225.

Ditto, P. H., Liu, B. S., Clark, C. J., Wojcik, S. P., Chen, E. E., Grady, R. H., ... \& Zinger, J. F. (2019). At least bias is bipartisan: A meta-analytic comparison of partisan bias in liberals and conservatives. Perspectives on Psychological Science, 14, 273-291.

Duckitt, J. (2020). Authoritarianism: Conceptualization, research, and new developments. Forthcoming in: G.G. Sibley \& D. Osborne (Eds). The Cambridge Handbook of Political Psychology. Cambridge, UK: Cambridge University Press.

Duckitt, J. (1989). Authoritarianism and group identification: A new view of an old construct. Political Psychology, 10, 63-84.

Duckitt, J. (2009). Authoritarianism and dogmatism. In M. Leary \& R. Hoyle (Eds.), Handbook of individual differences in social behavior (pp. 298-317). New York: Guilford Press.

Duckitt, J. (2001). A dual-process cognitive-motivational theory of ideology and prejudice. Advances in Experimental Social Psychology, 33, 41-113.

Duckitt, J., \& Sibley, C. G. (2010). Personality, ideology, prejudice, and politics: A dual-process motivational model. Journal of Personality, 78, 1861-1894.

Duckitt, J., Bizumic, B., Krauss, S. W., \& Heled, E. (2010). A tripartite approach to right-wing authoritarianism: The authoritarianism-conservatism-traditionalism model. Political Psychology, 31, 685-715.

Duckitt, J., \& Sibley, C. G. (2007). Right wing authoritarianism, social dominance orientation and the dimensions of generalized prejudice. European Journal of Personality, 21, 113-130.

Economist Intelligence Unit. (2019). Democracy index 2019: Me too? Political participation, protest, and democracy. London, England: Economist Intelligence Unit.

Eckstein, A. M. (2016). Bad Moon Rising: How the Weather Underground Beat the FBI and Lost the Revolution. Yale University Press.

Everett, J. A. (2013). The 12 item Social and Economic Conservatism Scale (SECS). PLoS ONE, 8, e82131.

Eysenck, H. J. (1954). The science of personality: Nomothetic. Psychological Review, 61, 339-342.

Ezrow, N. M., \& Frantz, E. (2011). Dictators and dictatorships: Understanding authoritarian regimes and their leaders. New York: Bloomsbury Publishing.

Feldman, S. (2003). Enforcing social conformity: A theory of authoritarianism. Political Psychology, 24, 41-74.

Feldman, S., \& Stenner, K. (1997). Perceived threat and authoritarianism. Political Psychology, 18, 741-770.

Finney, S., \& DiStefano, C. (2013). Non-normal and categorical data in structural equation modeling. In G.R. Hancock \& R.O. Mueller (Eds.), Structural equation modeling: A second course (pp. 269-314). Greenwich: Information Age.

Fowler, F. J. (1995). Improving survey questions: Design and evaluation. Thousand Oaks, CA: Sage Publications.

Frederick, S. (2005). Cognitive reflection and decision making. Journal of Economic Perspectives, 19, 25-42.

Fromm, E. (1941). Escape from freedom. New York: Holt, Rinehart, \& Winston.

Fromm, E. (1950). Psychoanalysis and religion. New Haven: Yale University Press.

Furr, R. M., \& Heuckeroth, S. (2019). The "Quantifying Construct Validity" procedure: Its role, value, interpretations, and computation. Assessment, 26, 555-566. 
Gentile, D. A., Anderson, C. A., Yukawa, S., Ihori, N., Saleem, M., Ming, L. K., ... \& Rowell Huesmann, L. (2009). The effects of prosocial video games on prosocial behaviors: International evidence from correlational, longitudinal, and experimental studies. Personality and Social Psychology Bulletin, 35, 752-763.

Gerring, J. (1997). Ideology: A definitional analysis. Political Research Quarterly, 50, 957-994.

Green, S., \& Siegal, S. (Directors) (2004). The Weather Underground [Film]. The Free History Project.

Gignac, G. E., \& Szodorai, E. T. (2016). Effect size guidelines for individual differences researchers. Personality and Individual Differences, 102, 74-78.

Gill, P., \& Corner, E. (2017). There and back again: The study of mental disorder and terrorist involvement. American Psychologist, 72, 231.

Grzesiak-Feldman, M. (2015). Are the high authoritarians more prone to adopt conspiracy theories? In M. Bilewicz, A. Cichocka, \& W. Soral (Eds.), The Psychology of Conspiracy (pp. 99117). New York, NY: Routledge.

Gurven, M. D. (2018). Broadening horizons: Sample diversity and socioecological theory are essential to the future of psychological science. Proceedings of the National Academy of Sciences, 115, 11420-11427.

Hancock, G. R., \& Mueller, R. (2001). Rethinking construct reliability within latent variable systems. Structural Equation Modeling: Present and Future--Festschrift in honor of Karl Jöreskog, 195-216.

Hanson, D. J. (1968). Dogmatism and authoritarianism. Journal of Social Psychology, 76, 89-95.

Hanson, S. E. (1997). Time and revolution: Marxism and the design of Soviet institutions. University of North Carolina Press.

Henrich, J., Heine, S. J., \& Norenzayan, A. (2010). Most people are not WEIRD. Nature, 466, 29-29.

Ho, A. K., Sidanius, J., Kteily, N., Sheehy-Skeffington, J., Pratto, F., Henkel, K. E., . . . Stewart, A. L. (2015). The nature of social dominance orientation: Theorizing and measuring preferences for intergroup inequality using the new $\mathrm{SDO}_{7}$ scale. Journal of Personality and Social Psychology, 109, 1003-1028.

Hodson, G., \& Dhont, K. (2015). The person-based nature of prejudice: Individual difference predictors of intergroup negativity. European Review of Social Psychology, 26, 1-42.

Hodson, G., Hogg, S. M., \& MacInnis, C. C. (2009). The role of "dark personalities" (narcissism, Machiavellianism, psychopathy), Big Five personality factors, and ideology in explaining prejudice. Journal of Research in Personality, 43, 686-690.

Horn, J. L. (1965). A rationale and test for the number of factors in factor analysis. Psychometrika, 30, 179-185.

Jenemann, D. (2020). "Nothing is True Except the Exaggerations". In A Companion to Adorno (eds P.E. Gordon, E. Hammer and M. Pensky). Wiley.

Johnson, J. J. (2009). What's so wrong with being absolutely right: The dangerous nature of dogmatic belief. Prometheus Books.

Jost, J. T. (2017). Ideological asymmetries and the essence of political psychology. Political Psychology, 38, 167-208.

Jost, J. T., Federico, C. M., \& Napier, J. L. (2013). Political ideologies and their social psychological functions. In M. Freeden (Ed.), Oxford handbook of political ideologies (pp. 232-250). New York, NY: Oxford University Press.

Jost, J. T., Glaser, J., Kruglanski, A. W., \& Sulloway, F. J. (2003). Political conservatism as motivated social cognition. Psychological Bulletin, 129, 339-375.
Jost, J. T., \& Kende, A. (2020). Setting the record straight: System justification and rigidity-of-the-right in contemporary Hungarian politics. International Journal of Psychology. Advance online publication.

Kalmoe, N., \& Mason, L. (2018). Lethal mass partisanship: Prevalence, correlates, and electoral contingencies. Paper presented at the 2018 American Political Science Association's Annual Meeting, Boston, MA, Aug. 30-Sept. 2.

Krueger, R. F., Derringer, J., Markon, K. E., Watson, D., \& Skodol, A. E. (2012). Initial construction of a maladaptive personality trait model and inventory for DSM-5. Psychological Medicine, 42, 1879-1890.

Krumrei-Mancuso, E. J., \& Rouse, S. V. (2016). The development and validation of the comprehensive intellectual humility scale. Journal of Personality Assessment, 98, 209-221.

Leary, M. R., Diebels, K. J., Davisson, E. K., Jongman-Sereno, K. P., Isherwood, J. C., Raimi, K. T., ... \& Hoyle, R. H. (2017). Cognitive and interpersonal features of intellectual humility. Personality and Social Psychology Bulletin, 43, 793-813.

Leary, M. R., Shepperd, J. A., McNeil, M. S., Jenkins, T. B., \& Barnes, B. D. (1986). Objectivism in information utilization: Theory and measurement. Journal of Personality Assessment, 50, 32-43.

Lee, K., \& Ashton, M. C. (2018). Psychometric Properties of the HEXACO-100. Assessment, 25, 543-556.

Lee, W. C., \& Lee, G. (2018). IRT linking and equating. The Wiley Handbook of Psychometric Testing: A Multidisciplinary Reference on Survey, Scale and Test Development, 639-673.

Lerner, J. (2002, February 24). I was a terrorist. Washington Post. https://www.washingtonpost.com/archive/lifestyle/magazine/2002/02/24/i-was-a-terrorist/5a37fc9f-9c10-410a-b47b3e98ffe9a3a1/.

LeVasseur, J. B. (1997). Authoritarianism and political orientation: Validation of a left-wing authoritarianism scale (Doctoral Dissertation, University of Maine).

Li, L., Lin, X., Hinshaw, S. P., Du, H., Qin, S., \& Fang, X. (2018). Longitudinal associations between oppositional defiant symptoms and interpersonal relationships among Chinese children. Journal of Abnormal Child Psychology, 46, 1267-1281.

Lilienfeld, S., \& Widows, M. (2005). Professional manual for the psychopathic personality inventory-revised (PPI-R). Lutz, FL: Psychological Assessment Resources.

Lindeman, M., \& Verkasalo, M. (2005). Measuring values with the Short Schwartz's Value Survey. Journal of Personality Assessment, 85, 170-178.

Loevinger, J. (1957). Objective tests as instruments of psychological theory. Psychological Reports, 3, 635-694.

Ludeke, S. (2016). Authoritarianism: Positives and negatives. In V. Zeigler-Hill \& D. K. Marcus (Eds.), The dark side of personality: Science and practice in social, personality, and clinical psychology (p. 231-250). American Psychological Association.

Ludeke, S. G., \& Krueger, R. F. (2013). Authoritarianism as a personality trait: Evidence from a longitudinal behavior genetic study. Personality and Individual Differences, 55, 480-484.

Marsh, H. W., Lüdtke, O., Nagengast, B., Morin, A. J., \& Von Davier, M. (2013). Why item parcels are (almost) never appropriate: Two wrongs do not make a right —Camouflaging misspecification with item parcels in CFA models. Psychological Methods, 18, 257.

Marsh, H. W., Morin, A. J., Parker, P. D., \& Kaur, G. (2014). Exploratory structural equation modeling: An integration of the best features of exploratory and confirmatory factor analysis. Annual Review of Clinical Psychology, 10, 85-110. 
Martin, J. L. (2001). The authoritarian personality, 50 years later: What questions are there for political psychology? Political Psychology, 22, 1-26.

McAbee, T. A., \& Cafferty, T. P. (1982). Degree of prescribed punishment as a function of subjects' authoritarianism and offenders' race and social status. Psychological Reports, 50, 651-654.

Meehl, P. E., Lykken, D. T., Schofield, W., \& Tellegen, A. (1971). Recaptured-Item Technique (RIT): A method for reducing somewhat the subjective element in factor naming. Journal of Experimental Research in Personality, 5, 171-190.

Mondak, J. J., \& Halperin, K. D. (2008). A framework for the study of personality and political behaviour. British Journal of Political Science, 38, 335-362.

Morin, A. J., Arens, A. K., \& Marsh, H. W. (2016). A bifactor exploratory structural equation modeling framework for the identification of distinct sources of construct-relevant psychometric multidimensionality. Structural Equation Modeling: A Multidisciplinary Journal, 23, 116-139.

Murphy, B. A., Costello, T. H., Watts, A. L., Cheong, Y. F., Berg, J. M., \& Lilienfeld, S. O. (2020). Strengths and weaknesses of two empathy measures: A comparison of the measurement precision, construct validity, and incremental validity of two multidimensional indices. Assessment, 27, 246-260.

Muthén, L., \& Muthén, B. (2015). MPlus for windows 7.31. Los Angeles: Muthén \& Muthén.

Napier, J. L., \& Jost, J. T. (2008). Why are conservatives happier than liberals? Psychological Science, 19, 565-572.

Netemeyer, R. G., Bearden, W. O., \& Sharma, S. (2003). Scaling procedures: Issues and applications. Sage Publications.

Nilsson, A., \& Jost, J. T. (2020). The authoritarian-conservatism nexus. Current Opinion in Behavioral Sciences, 34, 148-154.

Orth, U., Robins, R. W., Meier, L. L., Conger, R. D. (2016). Refining the vulnerability model of low self-esteem and depression: Disentangling the effects of genuine self-esteem and narcissism. Journal of Personality and Social Psychology, 110, 133-149.

Paulhus, D. L., Robins, R. W., Trzesniewski, K. H., Tracy, J. L. (2004). Two replicable suppressor situations in personality research. Multivariate Behavioral Research, 39, 303-328.

Rassin, E. (2008). Individual differences in the susceptibility to confirmation bias. Netherlands Journal of Psychology, 64, 8793.

Ray, J. J. (1983). Half of all authoritarians are left wing: A reply to Eysenck and Stone. Political Psychology, 4, 139-143.

Ray, J. J., \& Bozek, R. S. (1981). Authoritarianism and Eysenck's P scale. The Journal of Social Psychology, 113, 231-234.

Reich, W. (1933). The mass psychology of fascism. New York: Orgone Institute Press.

Reifen Tagar, M., Federico, C. M., Lyons, K. E., Ludeke, S., \& Koenig, M. A. (2014). Heralding the authoritarian? Orientation toward authority in early childhood. Psychological Science, 25, 883-892.

Rodriguez, A., Reise, S. P., \& Haviland, M. G. (2016). Evaluating bifactor models: calculating and interpreting statistical indices. Psychological Methods, 21, 137-150.

Roets, A., \& Van Hiel, A. (2011). Item selection and validation of a brief, 15-item version of the Need for Closure Scale. Personality and Individual Differences, 50, 90-94.

Rokeach, M. (1960). The open and closed mind: investigations into the nature of belief systems and personality systems. Basic Books.

Rollwage, M., Dolan, R. J., \& Fleming, S. M. (2018). Metacognitive failure as a feature of those holding radical beliefs. Current Biology, 28, 4014-4021.
Rosseel, Y. (2012). Lavaan: An R package for structural equation modeling and more. Version 0.5-12 (BETA). Journal of Statistical Software, 48, 1-36.

Saleem, M., Anderson, C. A., \& Barlett, C. P. (2015). Assessing helping and hurting behaviors through the Tangram help/hurt task. Personality and Social Psychology Bulletin, 41, 13451362.

Saleem, M., Barlett, C. P., Anderson, C. A., \& Hawkins, I. (2017). Helping and hurting others: person and situation effects on aggressive and prosocial behavior as assessed by the Tangram task. Aggressive Behavior, 43, 133-146.

Saucier, D. A., \& Webster, R. J. (2010). Social vigilantism: measuring individual differences in belief superiority and resistance to persuasion. Personality and Social Psychology Bulletin, 36, 19-32.

Saunders, B. A., Badaan, V., Hoffarth, M., \& Jost, J. T. (2020). Spotting the loch ness monster, or smiling for the surgeon's photograph? A critique of conway and colleagues' (2018) research on left-wing authoritarianism. In Lucian Gideon Conway, III (Chair), Is left-wing authoritarianism real? Evidence on both sides of the debate. Symposium conducted at the 21st Annual Meeting of the Society for Personality and Social Psychologists, New Orleans, LA.

Schinka, J. A. (2012). Further issues in determining the readability of self-report items: Comment on McHugh and Behar (2009). Journal of Consulting and Clinical Psychology, 80(5), 952-955.

Schmitt, T. A., \& Sass, D. A. (2011). Rotation criteria and hypothesis testing for exploratory factor analysis: Implications for factor pattern loadings and interfactor correlations. Educational and Psychological Measurement, 71, 95-113.

Schraw, G., Bendixen, L. D., \& Dunkle, M. E. (2002). Development and validation of the Epistemic Belief Inventory (EBI). In B. K. Hofer \& P. R. Pintrich (Eds.), Personal epistemology: The psychology of beliefs about knowledge and knowing (p. 261-275). Lawrence Erlbaum Associates Publishers.

Shapiro, G. K., Holding, A., Perez, S., Amsel, R., \& Rosberger, Z. (2016). Validation of the vaccine conspiracy beliefs scale. Papillomavirus Research, 2, 167-172.

Shils, E. (1954). Authoritarianism "right" and "left". Glencoe, IL: Free Press.

Sibley, C. G., \& Duckitt, J. (2008). Personality and prejudice: a meta-analysis and theoretical review. Personality and Social Psychology Review, 12, 248-279.

Sibley, C. G., Harding, J. F., Perry, R., Asbrock, F., \& Duckitt, J. (2010). Personality and prejudice: Extension to the HEXACO personality model. European Journal of Personality, 24, 515534.

Sidanius, J., \& Pratto, F. (2001). Social dominance: An intergroup theory of social hierarchy and oppression. Cambridge University Press.

Simms, L. J., Zelazny, K., Williams, T. F., \& Bernstein, L. (2019). Does the number of response options matter? Psychometric perspectives using personality questionnaire data. Psychological Assessment, 31, 557-566.

Smith, J. D., Dishion, T. J., Shaw, D. S., Wilson, M. N., Winter, C. C., \& Patterson, G. R. (2014). Coercive family process and earlyonset conduct problems from age 2 to school entry. Development and Psychopathology, 26, 917-932.

Smithers, A. G., \& Lobley, D. M. (1978). Dogmatism, social attitudes and personality. British Journal of Social and Clinical Psychology, 17, 135-142. 
Sønderskov, K. M., \& Dinesen, P. T. (2015). Trusting the state, trusting each other? The effect of institutional trust on social trust. Political Behavior, 38, 179-202.

Stenner, K. (2005). The authoritarian dynamic. Cambridge University Press.

Stenner, K. (2009). Three kinds of "conservatism". Psychological Inquiry, 20, 142-159.

Stone, W. F. (1980). The myth of left-wing authoritarianism. Political Psychology, 2, 3-19.

Sturgis, P., \& Smith, P. (2010). Assessing the validity of generalized trust questions: What kind of trust are we measuring? International Journal of Public Opinion Research, 22, 74-92.

Swami, V., Chamorro-Premuzic, T., \& Furnham, A. (2010). Unanswered questions: A preliminary investigation of personality and individual difference predictors of 9/11 conspiracist beliefs. Applied Cognitive Psychology, 24(6), 749-761.

Tellegen, A., \& Waller, N. G. (2008). Exploring personality through test construction: Development of the Multidimensional Personality Questionnaire. In G. J. Boyle, G. Mathews \& D. H. Saklofske (Eds.), Handbook of personality theory and testing: Vol II. Personality measurement and testing. London, UK: Sage.

Thomson, K. S., \& Oppenheimer, D. M. (2016). Investigating an alternate form of the cognitive reflection test. Judgment and Decision Making, 11, 99-113.

Toth-Kiraly, I., Bothe, B., Rigo, A., \& Orosz, G. (2017). An Illustration of the Exploratory Structural Equation Modeling (ESEM) Framework on the Passion Scale. Frontiers in Psychology, $8: 1968$.

Tung, I., \& Lee, S. S. (2014). Negative parenting behavior and childhood oppositional defiant disorder: differential moderation by positive and negative peer regard. Aggressive Behavior, 40, 79-90.

Van Damme, C., Deschrijver, E., Van Geert, E., \& Hoorens, V. (2017). When praising yourself insults others: Self-superiority claims provoke aggression. Personality and Social Psychology Bulletin, 43, 1008-1019.
Van Hiel, A., \& De Clercq, B. (2009). Authoritarianism is good for you: Right-wing authoritarianism as a buffering factor for mental distress. European Journal of Personality, 23, 33-50.

Van Hiel, A., Duriez, B., \& Kossowska, M. (2006). The presence of left-wing authoritarianism in Western Europe and its relationship with conservative ideology. Political Psychology, 27, 769793.

Van Hiel, A., Onraet, E., Crowson, H. M., \& Roets, A. (2016). The relationship between right-wing attitudes and cognitive style: A comparison of self-report and behavioural measures of rigidity and intolerance of ambiguity. European Journal of Personality, 30, 523-531.

Velicer, W. F. (1976). Determining the number of components from the matrix of partial correlations. Psychometrika, 41, 321-327.

Wilkinson, L., \& APA Task Force on Statistical Inference (1999). Statistical methods in psychology journals: Guidelines and explanations. American Psychologist, 54, 594-604

Webber, D., Kruglanski, A., Molinario, E., \& Jasko, K. (2020). Ideologies that justify political violence. Current Opinion in Behavioral Sciences, 34, 107-111.

Westen, D., \& Rosenthal, R. (2003). Quantifying construct validity: two simple measures. Journal of Personality and Social Psychology, 84, 608-618.

Wilson, G. D. (1973). A dynamic theory of conservatism. In G. D. Wilson, The psychology of conservatism. Academic Press.

Wintrobe, R. (2006). Rational extremism: the political economy of radicalism. Cambridge University Press.

Yagoda M. (2013). ADHD is different for women. The Atlantic. https://www.theatlantic.com/health/archive/2013/04/adhd-isdifferent-forwomen/381158/.

Zmigrod, L., Rentfrow, P. J., \& Robbins, T. W. (2020). The partisan mind: Is extreme political partisanship related to cognitive inflexibility? Journal of Experimental Psychology: General, 149, 407-418. 